Florida International University

FIU Digital Commons

3-17-2020

\title{
Organizational and Practitioner Characteristics that Impact Implementation Fidelity of Trauma Focused-Cognitive Behavioral Therapy
}

Kimberly Ann Purinton

kpuri001@fiu.edu

Follow this and additional works at: https://digitalcommons.fiu.edu/etd

Part of the Social Psychology Commons, and the Social Work Commons

\section{Recommended Citation}

Purinton, Kimberly Ann, "Organizational and Practitioner Characteristics that Impact Implementation Fidelity of Trauma Focused-Cognitive Behavioral Therapy" (2020). FIU Electronic Theses and Dissertations. 4432.

https://digitalcommons.fiu.edu/etd/4432

This work is brought to you for free and open access by the University Graduate School at FIU Digital Commons. It has been accepted for inclusion in FIU Electronic Theses and Dissertations by an authorized administrator of FIU Digital Commons. For more information, please contact dcc@fiu.edu. 


\title{
FLORIDA INTERNATIONAL UNIVERSITY
}

Miami, Florida

\section{ORGANIZATIONAL AND PRACTITIONER CHARACTERISTICS THAT IMPACT IMPLEMENTATION FIDELITY OF TRAUMA-FOCUSED CONGITIVE BEHAVIORAL THERAPY}

\author{
A dissertation submitted in partial fulfillment of the \\ requirements for the degree of \\ DOCTOR OF PHILOSOPHY \\ in \\ SOCIAL WELFARE \\ by
}

Kimberly A. Purinton 


\section{To: Dean Tómas Guilarte}

Robert Stempel College of Public Health and Social Work

This dissertation, written by Kimberly A. Purinton, and entitled Organizational and Practitioner Characteristics that Impact Implementation Fidelity of Trauma-Focused Cognitive Behavioral Therapy, having been approved in respect to style and intellectual content, is referred to you for judgment.

We have read this dissertation and recommend that it be approved.

$\begin{array}{r}\text { Staci Morris } \\ \hline \text { Melissa Howard } \\ \hline \text { Michelle Hospital } \\ \hline\end{array}$

Eric F. Wagner, Major Professor

Date of Defense: March 17, 2020

The dissertation of Kimberly A. Purinton is approved.

Dean Tómas Guilarte Robert Stempel College of Public Health and Social Work

Andrés G. Gil

Vice President for Research and Economic Development and Dean of the University Graduate School

Florida International University, 2020 
(C) Copyright 2020 by Kimberly A. Purinton

All rights reserved. 


\section{DEDICATION}

I dedicate this dissertation to the unwavering support of my incredible family and friends. To my husband, David, kids; Brent \& Kara (and now Manny \& Taylor), Mom and Dad, my sister and bro-in-law, Kelly and Matt, thank you for feigning interest as I would rattle on about the trials and tribulations of research, my topic and page numbering stress: thank you for not always understanding but loving me through this. The friends who have hung in there with me when I don't return calls or texts, yet still send me support, love and prayers. You have inspired and encouraged me to complete this endeavor. Ultimately, I would like to thank God Almighty for giving me the strength, knowledge, ability and opportunity to undertake this research study and to persevere and complete it satisfactorily. Without His blessing, this achievement would not have been possible.

${ }^{20}$ Now to him who is able to do far more abundantly than all that we ask or think, according to the power at work within us, ${ }^{21}$ to him be glory in Christ Jesus throughout all generations, forever and ever. Amen.

Ephesians 3:20-21 


\section{ACKNOWLEDGMENTS}

I must begin with the humble and grateful acknowledgment of my major

professor and trail guide, Dr. Eric Wagner. Your mentorship and guidance throughout the process have been invaluable. I so often felt like a fish out of water that did not belong, yet your encouragement and reminders of how far I had already come was essential, inspiring and energizing. Thank you for understanding me and the approach I needed for this process. Thank you for your open door willingness to problem solve on short notice and making the complex understandable.

Next, to my three committee members: Dr. Michelle Hospital, Dr. Melissa Howard, and Dr. Staci Morris. Dr. Hospital, a simple thank you does not seem sufficient to cover the amount of gratitude in my heart for the way you have supported me. As my 4th grade math class trauma triggers were running high, you expertly made complex processes understandable, always willing to meet and explain. You reassured me that you were committed to supporting me and that I did not have to go it alone, and I will be eternally grateful for you. Dr. Morris, like Dr. Hospital and Dr. Wagner, you consistently encouraged and reminded me of the knowledge base I had, and that I was adequate for this challenge. Your gracious expertise and mentorship in the area implementation research were like a match made in heaven, and I am so thankful you joined me on this journey! Dr. Howard, like Dr. Morris, I was thrilled to work with you, a kindred spirit, who feels strongly about how to get good interventions into the hand of practitioners in order impact the lives of those served by them. Thank you for always taking the time to share your knowledge, passion and kindness. 
Additionally, I want to acknowledge and thank Dr. Hui Huang for her support and guidance early on, helping to clarify the complex so graciously and expertly. Your kindness and encouragement have been true blessings to me! Dr. Rachel Clarke and Dr. Sophi Fernandez, please know how thankful I am for your willingness to jump in to support my journey as well. You are brilliant and an amazing educators!

To the school of Social Work, with heartfelt thanks especially to Dr. Richard Beaulearier, I express my thanks and appreciation for your warm support in navigating the at time complex processes throughout these last years.

I have often referred to my committee as my Dream Team and it is so very true. The realization of my dream of attaining a Ph.D. has come to pass because of your support! You all have been a lifegiving blessing to me, precious gifts each of you and I can only aspire to pay it forward in the same fashion.

Lastly, I am exceedingly blessed by my friends and family who have loved and supported me during this season. My husband, David...this is a win for both of us! My sweet children and their spouses now (Brent \& Taylor; Kara \& Manny), thank you for keeping it real and reminding me to enjoy the simple gifts that each day offers. My parents and my sister \& brother in law, your encouragement and understanding have been lifegiving to me. I am truly blessed.

${ }^{3}$ I thank my God every time I think of you!

Philippians 1:3-5 


\section{ABSTRACT OF THE DISSERTATION \\ ORGANIZATIONAL AND PRACTITIONER CHARACTERISTICS THAT IMPACT \\ IMPLEMENTATION FIDELITY OF TRAUMA-FOCUSED CONGITIVE \\ BEHAVIORAL THERAPY \\ by}

Kimberly A. Purinton

Florida International University, 2020

Miami, Florida

Professor Eric F. Wagner, Major Professor

In the field of child welfare, previous research has largely focused on assessing the efficacy and effectiveness of interventions rather than the implementation of the intervention. The primary aim of this dissertation was to expand understanding of implementation fidelity of an evidence-based practice (EBP) among community setting practitioners working with trauma exposed youth impacted by the child welfare system. The goal was to document specific practitioner and organizational characteristics that may influence implementation fidelity.

This dissertation is a secondary analysis of implementation fidelity of a volunteer practitioner group $(\mathrm{N}=201)$ that participated in TF-CBT training. To identify organizational and practitioner predictors of implementation fidelity, binary and multivariate logistical regression analyses were conducted. The following predictor variables were examined: practitioner belief in the value of EBPs; practitioner belief in personal skillset; practitioner endorsement of supervisory requirements; and, practitioner 
age and clinical experience. Possible moderating organizational variables, organizational readiness and management support also were explored.

Analyses revealed a significant positive association between practitioner belief in their skillset and implementation fidelity. Additionally, practitioner years of experience were inversely related to implementation fidelity; the odds of implementing TF-CBT with fidelity were lower for more senior practitioners. Findings suggest the importance of including skill set enhancement components in practitioner training; such components may be particular critical for ensuring treatment fidelity among more experienced clinicians. It is well known that treatment is most effective when implemented with fidelity. Thus, ensuring treatment fidelity is incumbent upon federal, state, and private agencies charged with providing treatment. Through this lens, the applied and scholarly implications of the study's findings are explored. 


\section{TABLE OF CONTENTS}

\section{CHAPTER}

PAGE

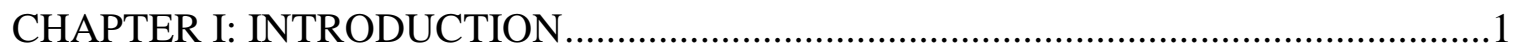

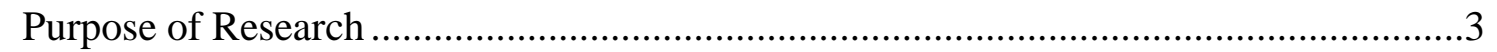

Research Aims ...........................................................................................

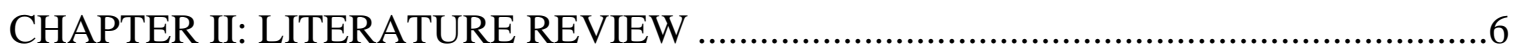

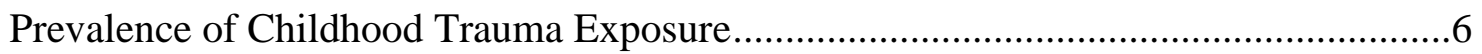

Childhood Trauma Characteristics .................................................................................9

Impact of Childhood Trauma..............................................................................

Trauma Exposed Youth in the Child Welfare System...............................................16

Child Welfare System: Mental Health and Trauma Exposed Youth...........................19

Intervention Fidelity and Trauma Exposed Youth ...................................................22

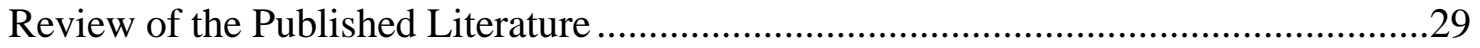

Practitioner Characteristics Measured ....................................................................

Organizational Characteristics Measured ………………........................................32

Measuring Implementation Fidelity ........................................................................33

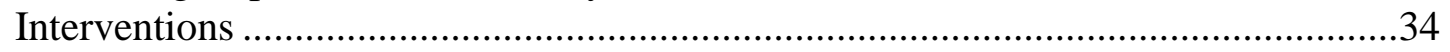

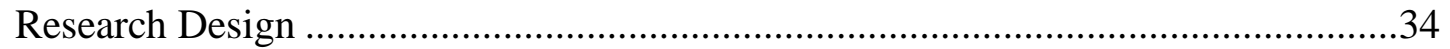

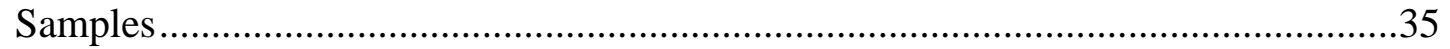

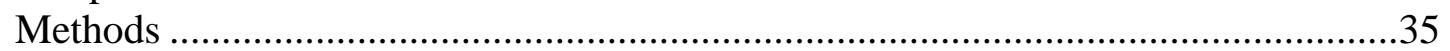

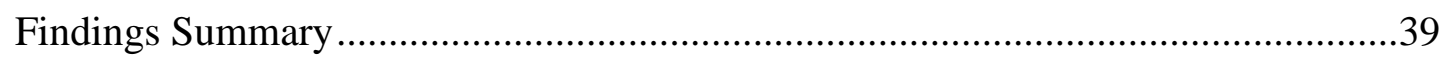

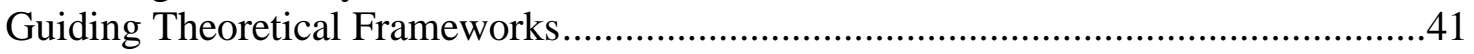

Diffusion of Innovations ................................................................................

Active Implementation Frameworks ...................................................................45

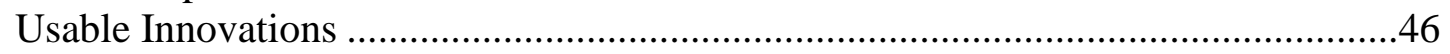

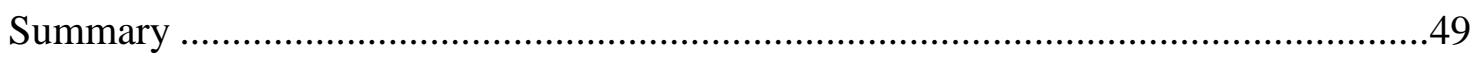

CHAPTER III. RESEARCH DESIGN AND METHODOLOGY ……….......................50

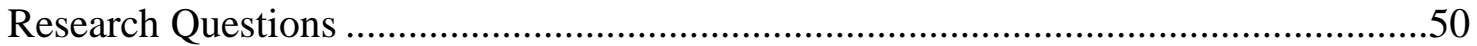

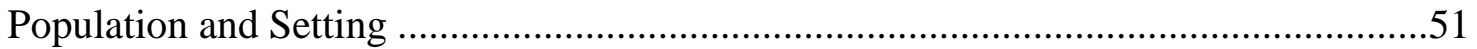

Recruitment and Inclusion Criteria for Participation in TF-CBT Training ................52

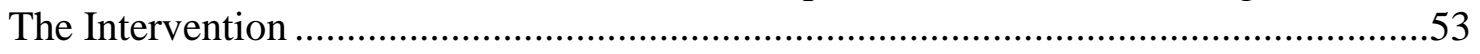

TF-CBT Training Components..........................................................................54

Overview of Design and Procedures ……………..............................................55

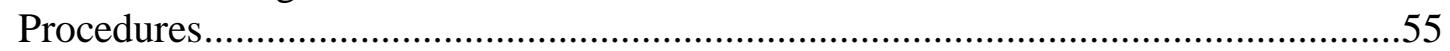

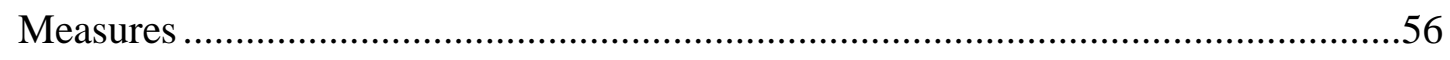

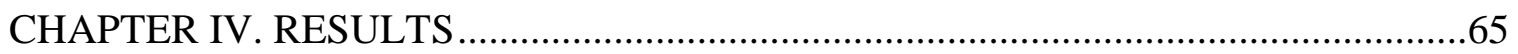

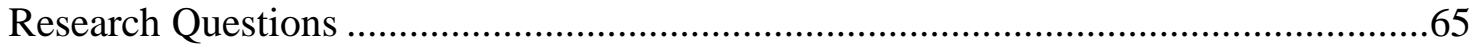

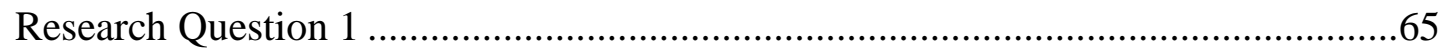

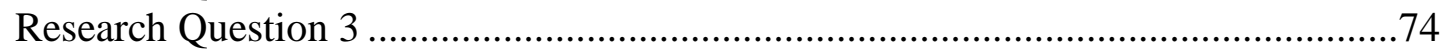

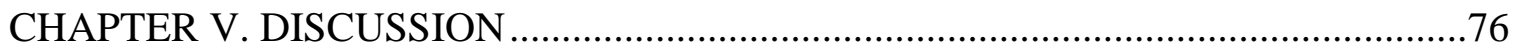




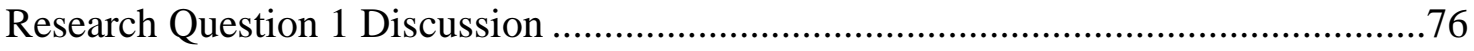

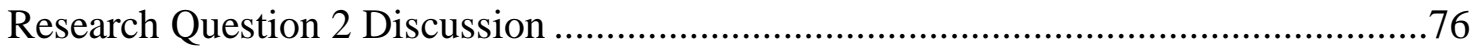

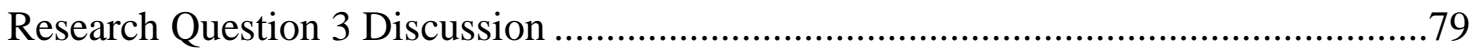

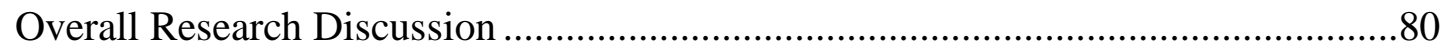

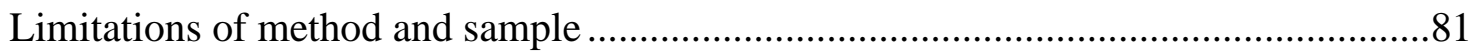

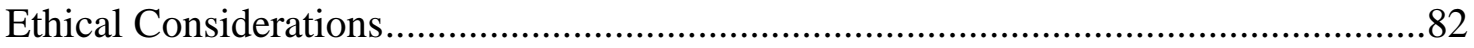

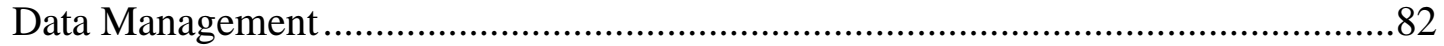

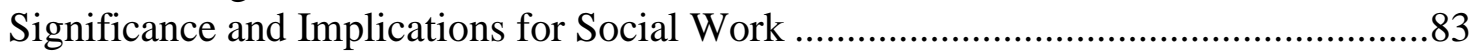

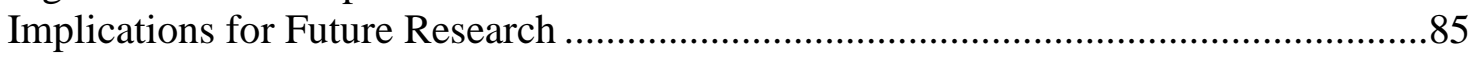

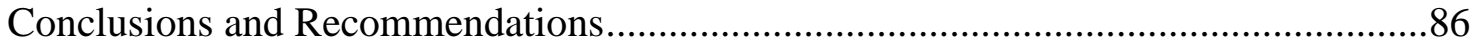

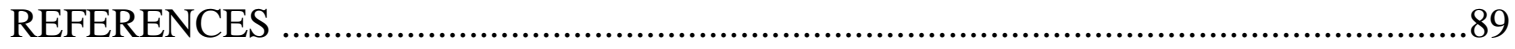

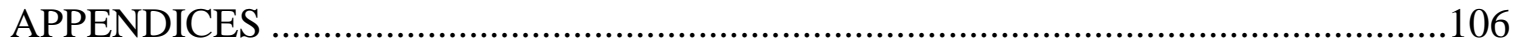

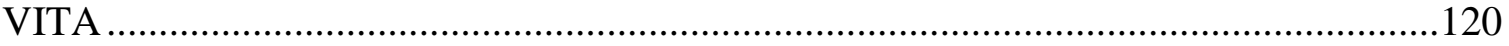




\section{LIST OF TABLES}

TABLE

PAGE

1. Demographic and Professional Background Characteristics

2. Binary Logistic Regression of Fidelity on Practitioner Belief in the Value (PBV) of EBP

3. Binary Logistic Regression of Fidelity on Practitioner Belief in Their Skillsets (PBPS)

4. Binary Logistic Regression of fidelity on Practitioner Endorsement of Supervisory Requirements (PBES).

5. Binary Logistic Regression of Fidelity on Practitioner Endorsement of Supervisory Requirements (PBES)

6. Binary Logistic Regression of Fidelity on Practitioner Age ...................................70

7. Multivariate Logistic Regression of Fidelity on PBV, PBPS and PBES and Practitioner Age

8. Binary Logistic Regression of Fidelity on Clinical Experience

9. Multivariate Logistic Regression of Fidelity on PBV, PBPS and PBES and Experience. 


\section{LIST OF FIGURES}

FIGURE

PAGE

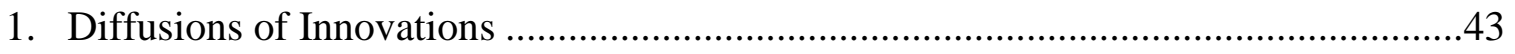

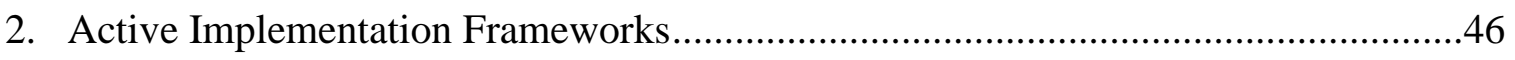

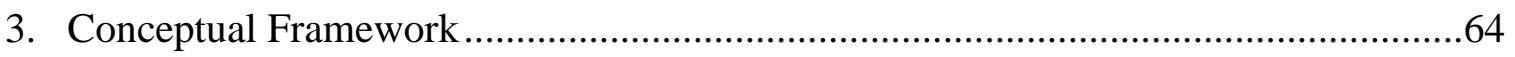




\section{CHAPTER I: INTRODUCTION}

Implementation research is defined as the study of factors that guarantee uptake of scientific knowledge into routine practice (Bhattacharyya et al., 2009). The goal of implementation research is to examine and explore solutions to reducing the knowledge to practice "gap" (Bhattacharyya et al., 2009), which often is caused by dependence on information diffusion (e.g., trainings, manuals) to distribute knowledge (Armstrong et al., 2007; Lavis et al., 2003). Alternatively, implementation research emphasizes two overarching constructs: the active process of intervention dissemination (Kerner \& Hall, 2009 ) and the extent of practitioner fidelity adherence to program activities (Dane \& Schneider, 2008; Durlak, 1998; Dusenbury et al., 2003; Institute of Medicine, 2001) as training alone does not ensure effective implementation (Fixsen et al., 2009).

Previous research in many disciplines, including those related to the child welfare field, has focused largely on assessing intervention efficacy and effectiveness to ensure accountability on behalf of children and families receiving services (Cash \& Berry, 2003; Fraser et al., 1991; Schuerman et al., 1994), rather than focusing on the implementation of the intervention (Cash \& Berry, 2003; Stern et al., 2008), when both are needed. Standardization among implementation fidelity assessment approaches have challenged the focus on intervention implementation; however, the field is rapidly evolving, showing increased promise for robust research that includes both intervention and implementation examination (Fixsen et al., 2015).

As stated, traditionally an assumption is made that traditional and formal education (i.e., higher education, certificate programs, in-service training, certificate program) is a satisfactory method of ensuring the transfer of information into practice 
(Armstrong et al., 2007; Lavis et al., 2003; Lilienfeld, 2012). This assumption is contrary to the Diffusion of Innovations theory, discussed further on as a theoretical framework of the study at hand, which considers the uptake of interventions, including evidence-based practices (EBPs), as a deliberate act partly influenced by practitioners' beliefs, attitudes, and values and their likeness with those of the intervention being implemented (Rogers, 2003). Subsequently, implementation research further challenges this supposition by elucidating the factors that influence practitioners' use of EBPs in their own practice settings (Meyers et al., 2012; Proctor \& Rosen, 2008).

In implementation research, implementation fidelity is referred to as "the degree to which ... programs are implemented... as intended by the program developers" (Dusenbury et al., 2003). Often, this concept is labeled "integrity" (Dane \& Schneider, 2008; Dusenbury et al., 2003). Implementation fidelity may act as a possible moderator of the relationship between interventions and their intended outcomes. Simply, it is a factor that could impact the relationship between these two variables, such as how much outcomes are affected by the intervention. This is one of the primary reasons why implementation fidelity needs to be measured, as the literature suggests that the fidelity with which an intervention is implemented affects how well it succeeds (Dusenbury et al., 2003; Fixsen et al., 2015; Mihalic, 2002). It is only by ensuring proper evaluation of the fidelity of an interventions implementation that a viable assessment can be made of its contribution to outcomes.

As EBP implementation research evolves, it is increasingly clear that examination of interventions and their subsequent outcomes should involve an evaluation of implementation fidelity if the true effect of an EBP intervention is to be discerned. 
Furthermore, practitioners utilizing EBPs must also be able to comprehend and quantify the fidelity of the intervention they are implementing. Inherent in evidence-based practice is the assumption that an intervention is being implemented in full accordance and compliance as prescribed by its developers. This is vital due to the increased potential for implementation inconsistencies in "real world" rather than experimental conditions.

The study of how best to ensure implementation fidelity of interventions will guide social work practice and augment its core knowledge base (Tucker \& Blythe, 2008) as understanding implementation fidelity is foundationally vital for any field of practice to advance (Dane \& Schneider, 2008). As aforementioned, implementation fidelity includes the key components of competence and treatment adherence (Tucker \& Blythe, 2008). According to Tucker and Blythe (2008), adherence is defined as the degree to which practitioners utilize prescribed approaches and techniques outlined in each intervention while competence is referred to as the skill level at which the intervention is delivered by the practitioner. Measuring fidelity informs social work practice, supporting successful implementation of the intervention's core principles, which promotes comparable outcomes as in previous studies (Bond et al., 2009). Thus, continued research will provide a critical assessment of specific organizational and practitioner characteristics that impact implementation fidelity.

\section{Purpose of Research}

The research at hand highlights the vital nature of studying both moderating and direct effects of organizational and practitioner characteristics on implementation fidelity. As outlined previously, more favorable attitudes toward change and scientific information distinguish early adopters from late adopters of interventions (Aarons, 2004; 
Rogers, 2003). Furthermore, practitioner attitudes toward EBPs are associated with provider characteristics, leadership and organizational context (Aarons, 2004; Aarons \& Sommerfeld, 2012). Despite growing research, generalizability of most studies is limited due to sample size, approaches and measures (Allen et al., 2012; Perepletchikova et al., 2007). Additionally, most previous studies examining the impact of practitioner characteristics on implementation fidelity have historically focused on the use of treatment manuals and research-based information (Addis et al., 1999; Addis \& Krasnow, 2000; Allen et al., 2012; Morrow-Bradley \& Elliott, 1986; Prochaska \& Norcross, 1983). Lastly, relatively little is known about practitioner individual characteristics and their impact on implementation fidelity. Considering the literature support and ever-evolving need for evidence-based interventions, this dissertation study involves secondary data analysis from Centene Corporation, a national health care company that provides services to government-sponsored healthcare programs, which trained a volunteer practitioner group $(N=201)$ in a specific EBP, Trauma-Focused Cognitive Behavioral Therapy (TFCBT).

\section{Research Aims}

Overarching Aim. To better understand the relationship between individual and organizational characteristics on implementation fidelity of EBPs

Research Question 1: Document in a diverse group of practitioners' their demographic characteristics, along with their attitudes and beliefs towards EBPs.

Hypothesis 1: no hypothesis as this is for descriptive purposes

Research Question 2: Is there a relationship between individual practitioner characteristics and EBP implementation fidelity? 
Hypothesis 2A: Practitioner belief in the value of EBP will be positively associated with greater implementation fidelity.

Hypothesis 2B: Practitioner belief in their ability to perform skills necessary for EBP execution will be positively associated with greater implementation fidelity. Hypothesis 2C: Practitioner endorsement of supervisory requirements as a reason for EBP usage will be positively associated with greater implementation fidelity. Hypothesis 2D: Practitioner age will be negatively associated with EBP implementation fidelity.

Hypothesis 2E: A less professionally experienced Practitioner professional experience will be negatively associated with EBP implementation fidelity.

Research Question 3: Is there a possible moderating influence of practitioners' perception of organizational characteristics on the relationship between their individual practitioner characteristics and implementation fidelity?

Hypothesis 3A: The associations between practitioner individual characteristics and EBP implementation fidelity will be stronger for practitioners who perceive their organizational climate as supportive Hypothesis $3 B$ : The associations between practitioner individual characteristics and EBP implementation fidelity will be stronger for practitioners who perceive greater readiness for change in their organization. 


\section{CHAPTER II: LITERATURE REVIEW \\ Prevalence of Childhood Trauma Exposure}

According to the U.S. Department of Health and Human Services (2016), nearly 35 million U.S. children have experienced one or more types of serious childhood trauma. Even while considering this statistic, and the resulting elevated rates of posttraumatic stress disorder (PTSD) and other symptomatology, many trauma-exposed youth either do not receive treatment or receive treatment that has not been demonstrated to be effective (Burns et al., 2004; Cohen et al., 2011a; Ringeisen et al., 2009). Devoid of appropriate and adequate treatment, over time trauma symptoms may exacerbate or linger, and may develop into other mental health problems such as externalizing or internalizing disorders (Hamblen, 1999; Hoven et al., 2005; Siegel \& Williams, 2003). Additionally, this deficiency of treatment may potentially increase secondary adversities, especially for youth impacted by the child welfare system, including health problems, school difficulties, social maladjustment, home and foster home placement disruptions, and substance abuse (Felitti et al., 1998; Goodman et al., 2012; Kramer et al., 2013; National Institute for Mental Health, 2001).

Attempts at large scale dissemination of evidence-based practices (EBPs) to community setting practitioners have increasingly become an effective solution to address trauma-exposed youth (Fixsen et al., 2009). There remains, however, an observed gap between EBT identification, implementation and use of EBPs (Bhattacharyya et al., 2009; Greenhalgh et al., 2014). Many efforts to close these gaps have built upon federal and state legislation and policy evolutions that have served as foundations to support implementation efforts, yet disrupted outcomes continue (Berger et al., 2009). 
Additionally, research shows that disruptions in mental health service delivery, including services in child welfare systems, and can be categorized as falling in to one of three categories: organizational setting, practitioner and intervention challenges (Beidas \& Kendall, 2014; Fixsen et al., 2009). The following section examines the prevalence and characteristics of trauma exposed youth, and the challenges associated with addressing and treating the resulting short and long-term symptomology.

\section{Prevalence of Trauma Exposure: United States}

The American Psychiatric Association defines a traumatic experience as exposure to either actual or threatened severe injury, sexual violence or death via the direct experience of the event, witnessing the event, being made aware that a close family member or friend experienced such an event, or exposure to full details of a traumatic event (American Psychiatric Association [APA], 2013). Traumatic experiences may include: loss of a loved one, family and community violence, childhood physical, sexual and emotional abuse, natural disasters, serious motor vehicle collisions, serious medical incidents, residing with a family member who demonstrates impaired caregiving abilities, terrorism, refugee status and war (APA, 2013).

A considerable number of trauma-exposed youth have also experienced maltreatment, highlighting how child maltreatment, including physical and sexual abuse, has become a serious public health issue in the United States (U.S. Department of Health and Human Services, Administration of Children and Families, 2016). Within the Child Welfare system, the term child maltreatment is used to indicate a child has experienced a traumatic exposure (Jamora et al., 2009). Child maltreatment is a term referred to as acts of omission (neglect) or commission (abuse) by a parent or other caregiver, resulting in 
potential for harm, threat of harm or harm to a child (Leeb et al., 2008). In 2014, there were nationally estimated 702,000 victims of child abuse and neglect (U.S. Department of Health and Human Services, Administration of Children and Families, 2016). Further data shows that $37 \%$ of youth experienced a physical assault during a 1-year period, and $15 \%$ of children and youth experienced maltreatment by a caregiver (Finkelhor et al., 2015). Yet even more studies focusing on trauma exposure indicate that over $60 \%$ of children and/or adolescents report one or more traumatic experiences during their childhood (Copeland et al., 2017).

\section{Prevalence of Trauma Exposure: Florida}

According to the 2015 Census Bureau, Florida maintains a large child population, just over 4 million, (U.S. Census Bureau, 2017) along with an elevated rate of children exposed to trauma and/or maltreatment (U.S. Department of Health and Human Services, 2016). Further, 2016 statistics show:

- Florida had 217,895 total referrals to the Department of Children and Families for child neglect and abuse.

- Of those $217,895,160,733$ reports were referred for investigation.

- Specific percentages related to categories of maltreatment:

○ $54.3 \%$ were neglected

○ $9.7 \%$ were physically abused

$\circ \quad 5.7 \%$ were sexually abused

- 124 child deaths were deemed to have resulted from abuse or neglect (U.S. Department of Health and Human Services, 2016). 
Overall, both United States and Florida statistics confirm unacceptable rates of trauma-exposed and maltreated youth, that left unaddressed, create profound and devastating impacts.

\section{Childhood Trauma Characteristics}

Many trauma-exposed youth develop what is referred to as traumatic stress following exposure to a traumatic event and/or maltreatment. The National Child Traumatic Stress Network (NCTSN) refers to traumatic stress as what has become a common term for reactive depression and anxiety, although it is not a medical term nor is it included in the Diagnostic and Statistical Manual of Mental Disorders (DSM; NCTSN, 2005). The DSM-IV does address traumatic stress under Adjustment Disorders in the subtypes of depression, anxiety and disturbance of conduct and these symptom combinations, as it denotes that the resulting stress from these events are less threatening and distressing than those that lead to post-traumatic stress disorder (Saunders \& Adams, 2014).

Characteristics of childhood maltreatment manifest differently for many children, resulting in a range of behavioral, social and emotional responses following exposure to a traumatic event. These reactions can include symptoms of depression anxiety, attention and behavioral concerns and even post-traumatic stress disorder (Gilbert et al., 2009; Paolucci et al., 2001). Statistics show that trauma-exposed children experience near double the rates of psychiatric disorders compared to youth not exposed to traumatic events, in addition to displaying behavioral, neurocognitive and relational challenges, and that variables such as previous trauma exposure, the child's emotional and mental strengths and weaknesses, in addition to the level of support they experience impacts 
their individualized responses to traumatic events (Copeland et al., 2017; DeBellis et al., 2009, 2013; Paolucci et al., 2001; Scheeringa et al., 2011).

Characteristics of traumatic response may differ depending upon victim subgroups as well. For example, girls from certain ethnic or cultural groups that value virginity more than another group may be reticent or less likely to report the trauma of sexual abuse. Likewise, males may be more impacted by perceived stigmatization of reporting a sexual assault, particularly if the offender is male, and subsequently less likely to report. In geographic regions where physical punishment may be more of a norm, children may be less likely to report because they do not perceive the abuse to be out of the ordinary (Saunders \& Adams, 2014). When children are exposed to trauma and experience the stress associated with it, there is an unfortunate number of short and longterm potential physical, cognitive and emotional consequences.

\section{Impact of Childhood Trauma}

Research shows that children exposed to trauma early in life is linked to emotional, physical, and mental health challenges as they age. The Adverse Childhood Experiences (ACE) study evaluated adults in primary care settings, examining the association between their current health concerns and self-reported childhood family dysfunction or child abuse issues. That data indicated a robust connection between household dysfunction or childhood exposure to abuse and numerous risk factors for multiple primary causes of adult deaths, such as cancer and heart disease (Felitti et al., 1998). Additionally, most patients who affirmed their experience with trauma were typically exposed to more than one traumatic event (Felitti et al., 1998). Thus, trauma in early childhood has the potential to lead to severe long-term consequences. 
Some unfortunate long-term and lasting psychological effects that may result from exposure to trauma include mental health disorders (mood-related), physical health issues (heart disease risk factors); anxiety (panic, phobia and PTSD), social problems (including difficulty forming positive relationships and being bullied or bullying), substance abuse, emotional problems (emotional regulation challenges), low self-esteem, future susceptibility for victimization, and perpetuation of abuse cycle and violence and abuse (Bremner et al., 2003; Ekern, 2013; Kendler et al., 2000; Repetti et al., 2002). In addition to the aforementioned impacted areas, trauma exposure can cause lasting changes in regions of the brain causing impairment in cognitive functioning, such as the prefrontal cortex, part of the frontal lobe and the part of the human brain primarily responsible for executive functioning (Bremner et al., 2003; Márquez-Ruiz et al., 2012). These functions are classified as the "higher order" processes in the brain, composed of multiple and varied cognitive abilities, including reasoning, working memory, problemsolving, mental flexibility, inhibition, monitoring, planning, organization, and regulation (Chan et al., 2008). Moreover, there is a strong relationship between childhood neglect and abuse and the subsequent emergence of future depression in both women and men (Chan et al., 2008; Ekern, 2013). Additionally, childhood exposure to the trauma of physical abuse has been linked to a greater risk for long term depression (Widom et al., 2012).

The NCTSN (2005) outlines several common domains that trauma exposure impacts in children as they develop. These areas include: 


\section{Attachment and Relationships}

Many neglected or abused children have difficulty developing healthy and strong connections or relational attachments to a caregiver. When children do not experience these healthy attachments, vulnerability to stress in relationships is likely. Subsequently, a child may encounter challenges as they age in friendships, romantic partnerships and with persons in authority over them, such as teachers or law enforcement officers (Finkelhor et al., 2015).

\section{Physical Health: Body and Brain}

If a child grows up in an environment in which they are fearful or under extreme or constant stress, the body's stress response and immune systems (such as the brain and nervous system) may not develop normally. Later, as children grow and experience typical levels of stress, systems may respond automatically as if they are experiencing a more extreme level of stress, in addition to possibly developing complaints of recurrent or chronic physical ailments, such as stomachaches or headaches, lasting well into adulthood (Chan et al., 2008). Their risks of engaging in risky behaviors as they age increase as well (e.g., substance abuse, smoking, substance use, and diet and exercise habits that lead to obesity; Felitti et al., 1998).

\section{Emotional Responses}

Trauma exposed children often experience ongoing challenges as they age with identifying, expressing, and managing their emotions. Additionally, they may only be equipped with limited language for various states of expressing how they are feeling. Patterns of internalization and/or the externalization of reactions to stress can lead to ongoing experiences with anxiety, anger and significant depression as the child ages 
(NCTSN, 2005). Reminders of traumatic events can be met with sadness, anger, avoidance and fear, even a propensity toward feeling constantly fearful (Finkelhor et al., 2015).

\section{Dissociation}

Trauma exposed children may dissociate or separate themselves mentally from a terrifying or overwhelming experience. They may picture themselves as detached from their actual bodies, somewhere else in the room (e.g., on the ceiling) as an observer to what is happening to them. Even though they may be unable to dissociate purposefully, once they have intrinsically adopted this practice as a defense mechanism, it may become an automatic response to other stressful situations in which the growing child is reminded of their trauma (Schoedl et al., 2010). Dissociation can affect a person's ability to be fully present in the daily activities of life, interrupting a sense of continuity and time, resulting in long term adverse impacts on learning and social interactions (Chan et al., 2008).

\section{Behaviors}

Trauma exposed children may be easily "set off" or triggered and will tend to react with more intensity than the situation calls for. Self-regulation (i.e., knowing how to calm down) may be a continuous struggle as the child grows, in addition to impulse control challenges and consequential, or "if-then" thinking. This may manifest in behaviors that can appear oppositional, unpredictable, extreme and volatile (Condly, 2006). As they grow, the impact of this trauma exposure may lead to engagement in highrisk behaviors, including unsafe sexual practice, excessive risk-taking and self-harm. Research shows a propensity for participation in illegal activities, including stealing, 
running away, prostitution, assault, alcohol \& substance use resulting in entry into the justice system (Ekern, 2013; Finkelhor et al., 2015).

\section{Cognition: Thinking and Learning}

Cognitive exposure to traumatic events early in life has been linked to cognitive developmental problems and neuropsychological impairments. Research has suggested that during periods of increased brain plasticity, such as childhood, brain circuitry is highly vulnerable to the influence of stressful life events (DeBeilis et al., 2013). Trauma exposed children may experience challenges thinking clearly, reasoning capabilities and solving problems. Planning, anticipating future events and executing an organized plan may pose major difficulty. Internal resources are mobilized toward surviving when the child develops under conditions where danger is imminent, and they have adjusted to being in chronic stress mode. As these children age, it may become difficult to learn additional information and acquire new skills, as reactions to trauma reminders may disrupt their attention and cognitive processing. Deficits in language development and reasoning skills may be impacted, thus posing difficulties with learning throughout life (Jaffee \& Maikovic-Fong, 2011).

\section{Self-Concept and Future Orientation}

Trauma exposed children, especially those who have been abused or surrounded by violence, will often place blame on themselves as a safer alternative to recognizing a parent is not reliable or dangerous (Goodman et al., 2012). Lasting effects of feelings of guilt, shame, a poor self-image are typical and lingering challenges birthed by trauma. Further, those surrounded by family and community violence understand from a very young age that the world is unsafe, and they do not have the power to change their 
circumstances (Goodman et al., 2012). This serves as the unstable foundation in which they build their beliefs about themselves others and their world as they age. Negative expectations disrupt needed positive problem-solving activities, and thwart chances of creating change and plotting a different life course for themselves. A growing child may view themselves as damaged and powerless and feel hopeless about a successful and happy future (NCTSN, 2000).

\section{Economic Impact}

The economic burden of childhood trauma exposure is also tremendously high. Based upon data from the 2015 Child Welfare Outcomes Executive Summary, the estimated conservative annual cost of abuse and neglect and was $\$ 103.8$ billion (U.S. Department of Health and Human Services, 2016). This number includes about $\$ 70.7$ billion in direct costs of caring for the direct or immediate needs of trauma-exposed maltreated children (e.g., mental health care, hospitalization, law enforcement and child welfare systems) as well as $\$ 33.1$ billion in indirect, inclusive of long-term effects and impacts of child abuse and neglect (juvenile delinquency, adult criminal justice system, special education, mental health and health care and lost societal productivity; Fang et al., 2012).

The aforementioned areas define trauma, examine long and short-term impacts of trauma exposure and outline potential characteristics of trauma-exposed youth. Of paramount importance is not only understanding the origin of trauma but to have policies and programs, as well as people in general, evolve in their understanding and subsequent addressing of the signs and symptoms of childhood trauma exposure. Education and maintaining heightened awareness are crucial to recognizing when a child has 
experienced trauma. For many children, they are identified via their entry into the child welfare system a potential victim of child maltreatment. Considering this, the next section examines closely the process in this system for addressing the needs of trauma-exposed children, including mental health service delivery.

\section{Trauma Exposed Youth in the Child Welfare System}

Most children in the child welfare system have been exposed to chronic and multiple traumatic events (Aarons et al., 2011; Ko et al., 2008). Additional to the negative consequences of experiencing multiple traumas, children involved in the child welfare system may be particularly vulnerable to having impaired attachments to caregivers as well (Brookman-Frazee et al., 2009). Furthermore, in many ways the behavioral, emotional and interpersonal problems traumatized children exhibit mimic those displayed by wards of State, due to the common factor of disrupted attachment (Ko et al., 2008). As examined in the previous section on characteristics of trauma, common traumatic reactions, including problems with boundaries, emotional self-regulation, aggression, distrust and suspiciousness, problems, oppositional behaviors and reenactment of trauma pose threats to forming new attachments in relationships and placement stability within the child welfare system (Kira et al., 2012). The following section details how specific forms of abuse may impact the child who is additionally affected by participation in the child welfare system.

\section{Child Sexual Abuse}

Many victims of sexual abuse have additionally been subjected to multiple forms of abuse, most often a combination of emotional, physical and sexual abuse (Dallam, 2001). Ackerman et al. (1998) found that children endorsing both sexual and physical 
abuse were at the highest risk of experiencing psychiatric problems compared to children with either sexual or physical abuse (Ackerman et al., 1998). Child sexual abuse has been described uniquely as an extremely traumatic form of interpersonal victimization that can potentially intensify as the child grows, is inescapable and repetitive without supportive intervention (Dallam, 2001). Further, child sexual abuse is commonly linked with loss of memory, a higher probability of engaging in high-risk behaviors, a greater tendency to dissociate and experience mental disorganization, along with self-injurious behaviors and sexual suicide attempts (Finkelhor et al., 2015).

\section{Multiple Maltreatment}

Although statistics regarding abuse in child welfare are separated into distinct categories, most children in child welfare have experienced multiple types of abuse from various sources. The National Child Abuse and Neglect Data System (NCANDS) data reveals $14 \%$ of substantiated child abuse cases involved those who endured more than two types of abuse, classifying it as multiple maltreatment (U.S. Department of Health and Human Services Administration on Children Youth and Families, 2015).

\section{Complex Trauma}

Additional to multiple maltreatment, the trauma children in the child welfare system endure is largely chronic in nature and occurs within an overall traumatic and abusive context, meaning a setting that heightens the child's perceptions of danger (Cloitre et al., 2009). This situation typically denotes trauma that occurs across a sustained time span and developmental stages can cause an individual to suffer from various psychological problems separate from Post-Traumatic Stress Disorder (PTSD; (Cohen et al., 2011b). Several terms including multiple maltreatment, poly-victimization, 
Type 2, and chronic trauma are used in child trauma literature to describe this phenomenon (Finkelhor et al., 2005; Kaysen et al., 2008). The term "complex trauma," however, is generally used to define chronic and repeated exposure to multiple traumas, most often in childhood or adolescence, often perpetrated by adult caregivers or those who are expected to be protectors and trustworthy (Cloitre et al., 2009). Research shows that children with complex trauma histories maintain are at higher risk of experiencing more severe trauma symptoms (Ford et al., 2012)

As described, experiencing a traumatic event at any age can be a life-altering; however, studies show that the earlier the experience occurs, the greater the potential for damage to the psyche (Cloitre et al., 2009). Additionally, childhood trauma has been long recognized as a steady predictor of psychological stress, resulting from the premise that the emotional and cognitive coping capacities for traumatic events and the subsequent meanings attributed to such events are expected to be quite varied for victims of different ages (Schumacher et al., 2006). For children involved in the child welfare system, it is evident that assessing and addressing trauma early is as clear and vital a priority, as safety and permanency. National data drawn from the National Survey of Child and Adolescent Well-Being (NSCAW) shows that children known to the child welfare system display alarmingly high rates of trauma symptomatology associated with their maltreatment. Among this population, more than 1 in 10 children display trauma-related symptoms at a level requiring clinical or therapeutic intervention (Casanueva et al., 2012).

This unfortunate epidemic has birthed a public health issue as it serves as the foundation for myriad physical and behavioral health afflictions associated with trauma exposure and maltreatment experiences (Jamora et al., 2009). Studies of traumatic stress 
in children actively involved in the child welfare system, as anticipated, reveal significantly higher rates than those children observed in the general population. To address the ever-evolving needs of this epidemic, policies at both the federal and state levels continuously endeavor to rise to the challenge. This next section will highlight several components of this evolution in child welfare policy that continues seeking to realize gaps in meeting the needs of trauma-exposed youth.

\section{Child Welfare System: Mental Health and Trauma Exposed Youth}

\section{Policy Evolution}

Originally, child welfare services were managed in the private sector, due in large part to child welfare concerns not being a public-sector responsibility to the degree it is today, with philanthropic private organizations filling the gaps in an unsystematic needbased method, including the establishment of the first orphanages (Embry et al., 2000). Amidst growing concerns regarding children growing up in orphanages, almost 50 years later, private agencies initiated the practice of the placement of orphans into the foster family setting. The early 1900s realized the passage of the first state laws regarding child abuse prevention and neglect, along with the inaugural convening of the national conference on the needs of dependent children, and the establishment of the first federal children's bureau. The Social Security Act of 1935 sanctioned the first child welfare service federal grants for child welfare, under a provision which later became known as Subpart 1 of Title IV-B of the Social Security Act. Even though small, these initial federal grants served as a stimulus for many states to develop local programs and establish child welfare agencies. In the decades that followed, the umbrella of child welfare services grew to include a larger array of services. Another milestone occurred 
under the Social Security Act, creating the Aid to Dependent Children (ADC). This program provided additional funds to states to address the fiscal burn of assisting needy, dependent children.

In the years between 1962 and 1974, amendments to the Social Security Act prompted an expansion of the use of privately delivered services. Further, these amendments sanctioned the usage of federal funds for health and social services by charitable nongovernmental agencies. The seminal legislation, CAPTA or the Child Abuse Prevention and Treatment Act of 1974 brought new funding and a further paradigm shift to the child welfare system. Fueled by the "War on Poverty," additional government funds were invested into ensuring that health and social services became more widely accessible, principally via service arrangements contracts (Rosenthal, 2000). In 1980, a follow up expansion occurred as the Adoption Assistance and Child Welfare Act was enacted, and the subsequent increase in federal funding for child welfare services. In the 1990s, national research showed that between 50 percent to 80 percent of states had increased their use of contracted social services during this time (GAO, 1997).

The Adoption and Safe Families Act (ASFA) was passed in 1997, realigning further the goals of the United States child welfare system and its delivery systems of case associated interventions and case planning towards achieving safety, permanency and well-being for maltreated children (DePanfilis \& Salus, 2003). This prompted reform in expectations of child welfare workers to seek to facilitate environmental conditions that would encourage parent and overall family well-being while still maintaining clear emphasis on the child's needs and well-being as primary. Such plans were and are 
designed to be implemented at initial child welfare engagement, with expected revisions over time as child and family/caregiver needs change (DePanfilis \& Salus, 2003).

ASFA directed case plans to be developed guided by the child welfare workers assessment of the child's individual needs, exposure to maltreatment and needs for both intervention and stabilization specifics, spurred by the supposition that a child's current trauma-responsive behaviors are predictive of future behaviors (Rosenthal, 2000). Consequently, the challenge for child welfare workers as they create case plans is to accurately assess risks, identify outcomes, and set specific and measurable goals and identify service and tasks that will attend to those specific goals (DePanfilis \& Salus, 2003; Rittner, 2002). Research shows that vital services for children include relational, physical and mental health therapies (Fulcher \& McGladdery, 2011)

The connection between maltreatment and trauma exposure symptomatology continues to gain national and state attention. In 2011, concerns over trauma associated with child maltreatment were recorded in federal legislation. The Child and Family Services Improvement and Innovation Act (P.L. 112-34), authorizing Title IV-B of the Social Security Act, newly required states to develop plans to identify and address emotional trauma associated with the child's maltreatment and removal from the home. Since the time of that shift in federal policy, the field of child welfare has continued to work more systematically, efficiently and effectively to integrate the knowledge of trauma and trauma-informed approaches into the work of caring for maltreated children. Even with this shift in the approach of incorporating trauma knowledge and using trauma-informed approaches within the child welfare systems, barriers continue to be a drag on mental health service delivery. 


\section{Service Delivery Barriers}

Even as the child welfare system at large acknowledges the vital nature of addressing mental health needs of trauma-exposed youth as a vital component of supporting child well-being, a significant gap continues to exist in the operationalization of delivering appropriate mental health services and treatment to those whom it is indicated for (Levitt, 2009). One national study of children with completed maltreatment investigations found roughly 75 percent with documented mental health concerns were unlikely to receive treatment. Yet another study presented that only 23 to 38 percent of children in foster care were receiving any mental health services at all (Burns et al., 2004; Rosenbach et al., 1999). These findings highlight key areas of growth for case planning that focus directly on the needs of children, specifically mental health needs to address their trauma exposure. Numerous challenges plague this system, impeding service delivery and reception. Glisson and Green (2005) mention several barriers, including bureaucratic, organizational, culture and climate that thwart access to mental health services. Further challenges, such as proper assessment techniques, reunification pressures, worker burnout and subsequent turnover and limited collaboration with other child-serving systems which would support efficient and effective referral pathways for mental health services for the child block needed fluidity in delivering mental health services to trauma-exposed children (Glisson et al., 2008).

Considerable cross-system barriers exist that impede service delivery for youth in child welfare systems and to facilitating effective collaboration among youth and familyserving systems. Challenges to effective collaboration include "silo-ed" delivery services by different child-serving systems (Lyon et al., 2013), restricted funding mechanisms, 
difficulty presenting as a unified team during service delivery, and ultimately the practitioners and interventions themselves (Blakey, 2014). Existing divisions in the delivery of and responsibilities for relevant services and supports often lead to "fingerpointing" and lack of shared accountability (Lyons \& Rogers, 2004). Further, there is a propensity to take sides and increase divisiveness when services from mental health and child welfare systems are not sufficiently rendered (Blakey, 2014).

Obstacles to coordinated service delivery additionally include the mal-aligned goals between those working with youth and/or families in the mental health and child welfare systems, along with the fact that these systems each display a notable lack of uniform methods for monitoring the outcomes, fidelity and quality of services and supports provided (Blakey, 2014). Basic collaborative strategies are not consistently employed within and across child welfare service systems, in addition to limited information sharing and insufficient communication between those working in the child welfare and mental health systems, substantially hindering the coordination of care, especially for children who present with significant mental health challenges (Blakey, 2014; Kerns et al., 2014).

This lack of collaboration and communication is a salient issue, and several factors have been identified that serve as barriers to communication and knowledge sharing across child-serving systems working with child welfare agencies (Allen et al., 2012; Blakey, 2014; Kerns et al., 2014). For instance, there is clear variability between child welfare and early intervention or treatment systems in their values, priorities, and overall orientation to families; while intervention programs are frequently voluntary and family-driven, child welfare tends to be viewed as mandatory, investigation-oriented, and 
adversarial (Allen et al., 2012). Additionally, child welfare agencies face considerable time pressures related to legal requirements and the need to find suitable placements when a child enters custody. In turn, these agencies must often take immediate action to put into place interventions for the youth and/or family due to state and federal mandates, while other child-serving systems, including early intervention, specialized treatment, and mental health programs, are frequently slowed by service authorization and information sharing delays (Allen et al., 2012). The sometimes contradictory requirements, goals, and timelines for child welfare and other systems can strain working relationships between social workers and service providers and impede the development of inter-organizational partnerships. In addition, concerns over a youth and family's right to confidentiality can impede and delay the sharing of critical information that can inform service and treatment planning as well as impact service eligibility (Allen et al., 2012; Kerns et al., 2014).

\section{Intervention Fidelity and Trauma Exposed Youth}

Another challenging area is the actual quality and fidelity of the intervention that the trauma-exposed child receives, often referred to as implementation fidelity, which includes the key components of competence and treatment adherence (Tucker \& Blythe, 2008). According to Tucker and Blythe (2008), adherence is defined as the degree to which practitioners utilize prescribed approaches and techniques outlined in each intervention while competence refers to the skill level at which the intervention is delivered by the practitioner. When a child is assessed and deemed in need of support and intervention to address his or her trauma symptomology, variables such as the practitioner delivering the intervention, the organization the practitioner is employed by and the intervention itself all can act as both facilitators and barriers to a child receiving 
such services within the system (Gotham et al., 2010). Additionally, these variables have a significant impact on the level of fidelity an intervention is delivered to a traumaexposed child (Landsverk et al., 2011).

\section{Challenges to Intervention Fidelity}

Many factors have been identified as impacting implementation fidelity of interventions used to address trauma-exposed youth. These can be placed into three categories: characteristics of the intervention, characteristics of the practitioner, and characteristics of the organization. Below, each component of the problem is examined.

Characteristics of the intervention. Interventions regarded by practitioners as more complex (Carroll et al., 2014; Rogers, 2003) and challenging to adjust to the variable needs of the clients are less likely to be adopted (Rogers, 2003; Simpson, 2009). Further, if complex interventions are adopted, they are less likely to be sustained over time (Yeaton \& Sechrest, 1992). To support intervention uptake, a few strategies have proved beneficial in increasing the degree of implementation fidelity, including supervision, training, and the use of detailed program manuals, (Webster-Stratton, 2004), and checklists to determine immediate feedback from intervention implementing practitioners to address concerns in real-time (Eames et al., 2009). However, barriers noted earlier, place a heavy burden on the system, creating challenges to the time and resources needed for these activities to occur.

Another significant issue regarding the types of interventions used historically has been the utilization of EBPs developed to meet the needs of those diagnosed with Post Traumatic Stress Disorder (PTSD). While countless children in the child welfare system have experienced numerous trauma exposures, accompanying symptoms of traumatic 
stress and experience disrupted functioning, not all meet full criteria for PTSD, especially younger children (Kornor et al., 2008). Consequently, studies that relied on this measurement standard have likely reported underestimates of the actual numbers of children needing trauma-focused intervention. Present practice standards endorse that all youth with clinically impairing trauma symptoms be provided evidence-based interventions regardless of diagnosis to prevent the development of negative long term psychosocial consequences; however, this continues to be a tall challenge (Aarons \& Sommerfeld, 2012).

Another barrier specific to the intervention itself, is the need for maintaining close collaboration between key agency stakeholders and the research team responsible for training staff on the intervention, as it is imperative for successful implementation, especially complex EBPs (Fixsen et al., 2009). These relationships may garner needed practitioner buy-in of intervention adoption and result in implementing it as intended. Assessing and measuring implementation fidelity, as well as factors that impact its usage are vital to realizing the full benefits of an intervention.

Characteristics of the Practitioner. Participants' knowledge about, perception of, and ability to implement an intervention have shown to facilitate or challenge successful implementation of an intervention (Carroll et al., 2014; Edmunds et al., 2013). Additionally, practitioner perceptions and attitudes toward evidence-based practices are significant in implementation efforts as well (Aarons, 2004; Burgess et al., 2016; JensenDoss et al., 2009). Practitioner attitudes are associated with the adoption of EBPs (Nelson $\&$ Steele, 2007), better engagement in training and consultation activities (Nelson et al., 2012; Pemberton et al., 2015), and skill and adherence in EBP delivery (Beidas \& 
Kendall, 2014). Recent studies suggest that practitioner perceptions vary based on the specific EBP (Cook et al., 2015; Reding et al., 2014). As child welfare systems are likely to implement more than one EBP to meet the range of mental health needs children present with (Chorpita \& Daleiden, 2009; Chorpita et al., 2011), it is essential to anticipate challenges with the adoption of multiple EBP interventions with features associated with more positive end-user responses (Reding et al., 2014).

Multiple components provide foundational challenges for positive attitudes associated with EBP uptake, including practitioner interaction with the EBP structure (i.e., prescribed content and order), training and consultation activity requirements, practitioner emotional exhaustion and job burn out (Borntrager et al., 2009; Burgess et al., 2016; Jensen-Doss et al., 2009). Research shows that other practitioner variables, such as age, number of years in practice, whether a practitioner is licensed or not, influence the practitioner's attitude toward utilizing an EBP, therefore impacting the fidelity of that intervention (Christian et al., 2014; Lyon et al., 2013). For example, even when practitioners express need for consultation to support EBP delivery (Nelson et al., 2012), the time and format of the consultative activity requirements of can potentially be viewed as burdensome (Christian et al., 2014; Lyon et al., 2013).

Given the high rates of emotional exhaustion among practitioners in publiclyfunded mental health settings (Morse et al., 2012), practitioner burnout may be the most challenging and impactful practitioner characteristic in large-scale implementation efforts. Emotional exhaustion, or feelings of being emotionally exhausted and overextended in one's vocation, is a component of workplace burnout (Maslach \& Jackson, 1981) and is linked to poor job performance and turnover (Cropanzano et al., 
2003). As studies show, practitioner characteristics are influenced in large part by the organizational setting they work within. As outlined previously, child welfare systems are challenged to implement increasingly effective and efficient programs amidst existing barriers that thwart that work. The next section outlines organizational characteristics that impact mental health service delivery within the system.

Characteristics of the Organization. Several organizational dimensions and factors inherent in the organizational environment impact intervention implementation. These include organizational culture, organizational climate, organizational structure, and absorptive capacity. According to Glisson (2002), organizational culture is how things are done within an organization, organizational climate is how employees' perception of their work environment, organizational structure is referred to as role formularization and the centralization of power within an organization. Concepts such as role clarity, role conflict, role overload, and emotional exhaustion encompass organizational climate. Consensus, conformity, motivation and level of support are examples of organizational culture. Organizational structure is comprised of the involvement in decision-making, degree of formalization, division of labor compose and hierarchy of authority.

Specific to creating organizational climate within the child welfare system, the creation of trauma-informed systems has been deemed a vital condition to address maltreated children's recovery needs, prevent system-induced trauma and decrease risks for mental health problems in affected children (Kramer et al., 2013). Trauma-informed child-serving systems are described as systems able to integrate the trauma-perspective into practice, from screening children for trauma exposure and related stressors, referring them for trauma-focused interventions and actively facilitating a continuity of care (Ko et 
al., 2008). Numerous challenges are inherent with implementation of these practice parameters into child welfare systems. Namely, to be achieved, necessary and significant system-wide training efforts must be made mandatory. Implementation fidelity is impacted by the organizational setting and its facilitation of or barriers to supporting practitioners and other practitioners learning the new intervention, as quality comprehensive training programs are a critical component of the adoption of evidencebased practices in child welfare (Aarons \& Sommerfeld, 2012).

Overall, substantial improvement efforts are needed to facilitate better implementation fidelity in the delivery of well-targeted, high-quality mental services to trauma-exposed youth.

\section{Review of the Published Literature}

A preliminary search on the topic was completed to identify appropriate and related terms to obtain relevant research in this area of study. A literature search via ProQuest was conducted November 2019. A thorough search was conducted using databases from various disciplines including and Cochrane Library, EBSCOHost, PsychInfo, PubMed and SocINDEX. A combination of the following keywords, in addition to the insertion of Boolean operators "AND" and "OR" were used to identify relevant sources: fidelity, implementation, implementation fidelity, adherence, practitioner characteristics and organizational characteristics. Additional to the formal search strategy, a few studies were found using the reference lists of journal articles.

To refine findings of the search and to identify relevant research, further guidelines were put into place. Criteria for articles inclusion included: quantitative peerreviewed studies with satisfactory explanation of methods and results for interpretation 
purposes, and available in full-text through Florida International University and in English. As implementation science is a global field, studies from counties outside of the U.S. were included provided results were available in English. As Sampson's (2009) guidance on search strategies of peer-reviewed articles outlines, studies were included when fidelity was the dependent variable and individual or organizational factors were the independent or covariate variables.

The initial search generated 482 articles; however, a number were immediately excluded for review as they were solely descriptive in nature or theoretical. Some were excluded as the sole focused was measuring client outcome or simply EBP uptake as the primary dependent variable without giving attention to the impact implementation fidelity bore on the outcome. Additionally, several studies were qualitative. Additional to the formal search strategy, a few studies were found using the reference lists of journal articles. Overall, thirteen studies that explored practitioner and/or organizational characteristics and implementation fidelity were examined for this review.

Once deemed relevant, the full text of the article was read for consideration of inclusion. Reference lists of selected articles were also examined to further identify other published research. Each article was reviewed to identify relevant selections using the following inclusion criteria: (a) implementation fidelity was a dependent variable or outcome focus, (b) independent variables focused on practitioner and/or organizational characteristics, (c) article employed quantitative research methods, and (d) studies were published in the last 15 years. All studies were reviewed for study bias using the guidelines provided by the Cochrane Handbook for Systematic Reviews of Interventions (Higgins \& Thomas, 2019). 


\section{Practitioner Characteristics Measured}

Most of the studies reviewed (Allen et al., 2011; Bearman et al., 2013; Cronley \& Patterson, 2010; Gotham et al., 2010; Henggeler et al., 2010; Klimes-Dougan et al., 2009; Sanders et al., 2009; Stein et al., 2012; Zvoch, 2009) measured both organizational and practitioner characteristics by collecting various demographic characteristics. Examples of practitioner characteristics include gender, race/ethnicity practitioners' age, occupation, job and/or clinical experience, number of years employed and educational background. All but one of the studies measured practitioner characteristics (Cronley \& Patterson, 2010), who utilized a combination of these factors, examining the influence practitioner's gender has on implementation fidelity only.

Several measures were used to evaluate self-reported practitioner characteristics that prior literature has shown to enhance implementation fidelity. These included a modified Pre-Implementation Expectancies (PIE) scale and the NEO-Five Factor Inventory (Klimes-Dougan et al., 2009), the Evidence-Based Practice Attitude Scale (EBPAS; Bearman et al., 2013; Henggeler et al., 2012), Consultation Record (MATCH and Standard Versions; Bearman et al., 2013), and a modified practitioner attitude scale developed by Addis and Krasnow (2000). Additional scales include the Staff Attributes Index, which was constructed by averaging subscales from the Organizational Readiness for Change Scale (Gotham et al., 2010) and researcher-developed scales (Allen et al., 2012; Cooke, 2010; Klimes-Dougan et al., 2009; Stein et al., 2012; Zvoch, 2009). While these measures may differ in concepts measured, the central components include practitioners' beliefs and/or attitudes regarding the intervention (EBPAS, researcher developed questionnaires) and knowledge/skills that are intervention related (Staff 
Attributes Index, Consultation Record, researcher-developed questionnaires/Staff

Attributes Index). One study (Klimes-Dougan et al., 2009) measure assessed

practitioners' personality including openness, agreeableness, and conscientiousness

(NEO-Five Factor Inventory).

\section{Organizational Characteristics Measured}

Multiple studies used standardized scales to measure organizational

characteristics, including the Organizational Culture Survey (Cronley \& Patterson, 2010;

Klimes-Dougan et al., 2009), the Organizational Climate Survey (Klimes-Dougan et al., 2009), the Work Environment Scale (Cooke, 2010), Psychological Climate Questionnaire (Schoenwald et al., 2009), and the Organizational Readiness for Change Survey (Gotham et al., 2010; Henggeler et al., 2010). Some created new scales to measure organizational characteristics (Livet et al., 2008; Mihalic et al., 2008; Sanders et al., 2009; Stein et al., 2012). Objective methods were used by two studies to assess organizational characteristics, which included agency location, policy, size and presence of standardized procedures (Allen et al., 2011; Zvoch, 2009). None of the studies included in this review examined all three organizational constructs (culture, structure, climate). Two studies used culture and climate to assess organizational characteristics (Henggeler et al., 2010; Klimes-Dougan et al., 2009), two used structure and culture (Livet et al., 2008), two used structure and climate (Gotham et al., 2010; Schoenwald et al., 2009), two assessed structure (Cooke, 2010; Cronley \& Patterson, 2010), two examined culture (Mihalic et al., 2008; Stein et al., 2012), and one study measured solely climate (Sanders et al., 2009). Organization is a multi-dimensional concept which necessitates a thorough examination of each construct to assess the level to which an organization facilitates or 
hinders the process of implementation. In this review, however, most studies focused solely on one or two organizational components.

\section{Measuring Implementation Fidelity}

Implementation fidelity evaluation has historically been a challenge, related to the unique concepts associated with each intervention being implemented, thus increasing the difficulty in developing scales applicable across disciplines (Dusenbury et al., 2003; Fixsen et al., 2015). As a result, researcher-developed surveys were utilized extensively in the articles in this review, with practitioner adherence criterion used most often to assess implementation fidelity. While the definition of adherence varied slightly across studies, the intention was consistent; the evaluation of the level to which an intervention was implemented as intended. Additional to the concept of adherence, two studies measured exposure (Cooke, 2010; Henggeler et al., 2010), and two measured quality (Gotham et al., 2010; Stein et al., 2012) and one measured predictors of EBP use (Bearman et al., 2013). No study reviewed utilized all five ways to measure the multifaceted construct of implementation fidelity (dose, exposure, dose, quality, participant responsiveness). Klimes-Dougan et al. (2009) did, however, measure quality, adherence and exposure, while Mihalic et al. (2008) measured quality, adherence, exposure in addition to participant responsiveness. Two studies did not measure adherence and its impact on implementation, rather choosing the variable of exposure as the indicator for implementation fidelity (Cronley \& Patterson, 2010; Sanders et al., 2009). 


\section{Interventions}

Of the reviewed studies, eight executed a program or intervention novel to the organization. These included Triple P Parenting program (Sanders et al., 2009), the Early Risers prevention program (Klimes-Dougan et al., 2009), Fresh Start smoking cessation program (Cooke, 2010), Life Skills Training program (Mihalic et al., 2008), MultiSystemic Treatment (Schoenwald et al., 2009), K-PALS program (Stein et al., 2012) and childhood literacy programs (Zvoch, 2009), and CBT for Anxiety and Depression and BPT for Disruptive Conduct (Bearman et al., 2013). The studies remaining reviewed a new service delivery model for their intervention, for which the intention was for that to become a new operational practice for the organization. Some examples of the service delivery models included the Continuum of Care program (Cronley \& Patterson, 2010) and Co-Occurring Disorder Services (Gotham et al., 2010). Four studies examined the implementation of innovative programs which exclusively examined the effect of organizational characteristics on implementation fidelity, possibly supporting the belief that intricate interventions necessitate vital organizational supports (i.e., training, supervision, resources), explaining the justification for solely focusing on those organizational aspects shown to influence implementation fidelity.

\section{Research Design}

Many studies used a cross-sectional design to examine the relationship between organizational characteristics and fidelity in implementation (Livet et al., 2008; Mihalic et al., 2008) or organizational and practitioner characteristics and implementation fidelity (Allen et al., 2011; Bearman et al., 2013; Cooke, 2010; Cronley \& Patterson, 2010; Klimes-Dougan et al., 2009; Sanders et al., 2009). Three studies opted for longitudinal 
designs (Henggeler et al., 2010; Schoenwald et al., 2009; Zvoch, 2009) and one utilized follow-up (Gotham et al., 2010), presenting research of optimal rigor amongst all reviewed studies. One study depicts an experimental design (Stein et al., 2012).

\section{Samples}

The unit of analysis was organizations for most studies, apart from Bearman and fellow researchers (2013) and Sanders and colleagues (2009). They chose to use individuals to assess the degree to which a new employee program was implemented, as indicated by employees' self-endorsed program usage. Furthermore, the sample size of the other studies varied from 6 to 105 organizations. Additionally, the number of employees within each organization from which the data were collected varied. For example, the study (Mihalic et al., 2008) with the largest sample of 105 agencies was not the study with the largest number of employees sampled (Sanders et al., 2009).

Organizations assessed included hospitals, mental health agencies, schools and various not-for-profit agencies. The agencies were in both rural and urban and environments.

\section{Methods}

Multiple rigorous and appropriate methods were used to examine the impact of relationships between practitioner and organizational characteristics on implementation fidelity. Most utilized hierarchical linear modeling (HLM; Allen et al., 2011; Cronley \& Patterson, 2010; Henggeler et al., 2010; Schoenwald et al., 2009; Stein et al., 2012; Zvoch, 2009) due to the nature of "nested" data (individuals in organizations) assessed. Regression techniques were used in five studies (Bearman et al., 2013; Cooke, 2010; Gotham et al., 2010; Klimes-Dougan et al., 2009; Mihalic et al., 2008; Sanders et al., 2009) in addition to repeated measures (Gotham et al., 2010) or correlations (Klimes- 
Dougan et al., 2009), which additional consideration is given too as those methods most closely aligned with the study at hand. Livet and colleagues only used correlations. Where studies were longitudinal, three used HLM, while one study (Gotham et al., 2010) used multiple regression and repeated measures to examine hypotheses regarding practitioner and organizational characteristics and implementation fidelity. HLM was not utilized in some studies due to the lack of nested data.

Though all studies reviewed examined factors (practitioner and/or organizational) that could impact implementation fidelity, due to the varied way fidelity was defined (adherence, quality, use/exposure), comparing results proved challenging. Moreover, almost all studies explored direct effects between independent variables (organizational characteristics, practitioner characteristics) and the dependent variable (implementation fidelity) regardless of most implementation theoretical models highlighting interactive effects. Implementation literature purports implementation as being a process which occurs over time (Fixsen et al., 2015); yet, most studies reviewed did not employ a longitudinal research design. Therefore, the findings regarding changes over time are limited to a few studies. The review findings below are organized and summarized in the following categories: direct effects of practitioner and organizational characteristics, interactive effects of these two factors, and impact of time on implementation fidelity.

\section{Direct effect of practitioner and organizational characteristics}

Four studies examined assessed the direct effect of the independent variable on implementation fidelity, another four studies additionally explored organizational and practitioner and organizational factors (Allen et al., 2011; Bearman et al., 2013; Cooke, 2010; Sanders et al., 2009) and yet another three evaluated organizational characteristics 
(Livet et al., 2008; Mihalic et al., 2008; Schoenwald et al., 2009). Sanders et al. (2009) explored the relationship between practitioner and the organizational variable counterpart and the amount of use of the program (exposure), finding that gender, race, occupational status (education or health professional), supervisory support adequate training, and sufficient resources were factors positively associated with exposure and fidelity. Conversely, a knowledge/skills deficit and divergence of beliefs were identified as exposure and fidelity barriers.

These findings proved consistent with Allen and fellow researchers (2011) discovery that practitioners who held more positive beliefs regarding the program's value, their ability to perform the skills needed, and positive perception of support from their organization were more likely to implement/use the program. Livet et al. (2008) examined organizational factors and their impact on implementation fidelity alone; similarly, they as well-realized formalized organizational climate, increased leadership support and adequate training were associated with increase in program usage. Cooke (2010) assessed the impact organizational and practitioner factors have on the stages of the implementation process and discovered that organizational factors (i.e., openness to change and climate) forecast the early implementation stage, defined as exposure/use, while practitioner characteristics (i.e., ability, beliefs) predicted the subsequent or later stage of implementation, defined as adherence. Mihalic et al. (2008) and Schoenwald et al. (2009) additionally explored constructs that promoted implementation adherence. While not plainly defined, Schoenwald et al. explored whether practitioners adhered to the nine principles found in Multisystemic Therapy. Organizational factors only were examined in these two studies, which realized variables such as adequate resources, 
clarity of goals, positive management support, job satisfaction, decreased emotional exhaustion, collaboration, and opportunity for advancement/ growth were associated with or predictive of adherence (Schoenwald et al., 2009).

\section{Analyses of organizational and practitioner characteristics}

Three of the reviewed studies (Cronley \& Patterson, 2010; Klimes-Dougan et al., 2009; Stein et al., 2012) examined the interactive and direct effect of organizational and practitioner characteristics on implementation fidelity. Like Sanders et al. (2009), Cronley and Patterson (2010) studied the impact of gender on exposure/use, finding that women reported higher usage of interventions. Nevertheless, the more resistant to change or rigid an organization was perceived to be, the less gender impacted outcomes. KlimesDougan and colleagues (2009). Berman and fellow researchers (2013) discovered that while younger practitioners had higher rates of intervention usage overall, senior practitioners showed more usage when provided ongoing supervision that included modeling and role play.

Stein and colleagues (2012) found management support was associated with quality (how well the intervention was implemented) or/and implementation adherence (level the intervention was implemented as intended). After controlling for practitioner characteristics (age, race, gender, work location, employment status, length of employment in organization, years of education,), employee commitment to their organization was associated with the quality of implementation and perceived supervisory support was related directly to employee commitment, signifying the vital element of supervisory support. Similarly, observed leadership support proved to significantly impact implementation adherence and quality. 


\section{Change over time}

Gotham et al. (2010), Henggeler et al. (2010), and Zvoch (2009) explored change in implementation fidelity over time. All three reported increases over time in exposure and/or use (Henggeler et al., 2010), quality (Gotham et al., 2010), or adherence (Henggeler et al., 2010; Zvoch, 2009); however, predictors varied by study. Henggeler et al. found only practitioner characteristics (i.e., increased years employed in current position, increased education, increased positive attitude towards intervention) predicted exposure, while both practitioner (female, younger age and social work degree) and organizational (larger volume caseloads and organizational readiness to change) characteristics were related to increased adherence. Gotham et al. additionally reported not practitioner, but that certain organizational characteristics (urban organizations, smaller agencies, improved training) were associated with implementation quality. Yet, Gotham et al. found lower levels of management openness to change in 2007 led to increased quality of implementation in 2009. In comparing all three studies, it is important to remember that Henggeler et al. used adherence, or the degree a program is implemented as intended, as their implementation fidelity measure, in contrast to Gotham et al., use of quality, or how well an innovation was able to be implemented, as their outcome variable of implementation fidelity. Zvoch (2009), like Henggeler et al., measured implementation adherence over time, finding that classrooms/schools of greater size began with lower adherence levels initially, yet realized an increased over time.

\section{Findings Summary}

Overall, regarding the direct effect of practitioner and organizational characteristics, organizational factors that promoted implementation adherence were 
adequate resources, clarity of goals, positive supervisory support, job satisfaction, decreased emotional exhaustion, collaboration, openness to scientifically informed treatment options and opportunity for advancement/ growth. Organizational factors that supported increased program usage were formalized organizational climate, perceived leadership support and adequate training. Certain organizational factors (i.e., openness to change and climate) impacted the forecast of the early implementation stage, while practitioner characteristics (i.e., ability, beliefs) predicted the subsequent or later stage of implementation stage, defined as adherence. The organization factor of management support was associated with quality (how well the intervention was implemented) or/and implementation adherence (level the intervention was implemented as intended).

Certain practitioner provider factors (affinity for novel intervention techniques, perception of the overall value of the technique, endorsement of adequate preparation and training and supervisory requirements) predicted greater earlier adoption and higher implementation fidelity of EBPs. Further, after controlling for practitioner characteristics (age, race, gender, work location, experience, employment status), women reported higher usage of interventions. Nevertheless, the more resistant to change or rigid an organization was perceived to be, the less gender impacted outcomes. Finally, younger practitioners had higher rates of EBP usage overall, while senior practitioners showed more usage when provided ongoing supervision.

In this review, study findings varied, making overall generalizations concerning what is known and unknown about predictors of implementation fidelity difficult to report on, due to the dissimilarity in the studies' target populations, design, measures, innovations, and analyses. Most of the studies reviewed were cross-sectional, and with 
non-random samples that limited causal relationship establishment and generalization ability. While half of the studies utilized HLM due to data that was nested, most did not consider the "change over time" component. Furthermore, even as implementation is regarded as a multifaceted process impacted by both practitioner and organizational factors, all studies did not measure both characteristics. For those that did so, most measured solely the direct effects of practitioner and organizational characteristics on implementation fidelity. Self-reporting of data proved to be another limitation in the studies reviewed.

Ultimately, these findings highlight the impact of practitioner attitudes and beliefs, as well as the role perceived organizational support or lack thereof play in the adoption and quality implementation of EBPs. There is a vital need for greater understanding of how these factors interact and influence programs focused on improving provider attitudes and beliefs, implementation fidelity.

\section{Guiding Theoretical Frameworks}

\section{Diffusion of Innovations}

The literature suggests a few theoretical frameworks that explain the implementation process. One foundational theoretical framework which Everett Rogers is credited with developing is the Diffusion of Innovations (2003), characterized as the spreading of ideas among individuals, mainly via imitation. He developed this theory during the 1950s while analyzing the diffusion of multiple agricultural innovations in rural Iowa, based on the premise that uptake of an innovation is subsequent to the universal process of social change. With its genesis in communications, Rogers sought to describe how, over time, a product or idea gains momentum and diffuses via a specific 
social system or population. The theory further explains how, and ultimately whether, an intervention is implemented within an organization by assessing the organizational contextual climate. Diffusion is considered a process characterized as the (a) acceptance, (b) over time, (c) of some specific item (an idea or practice), (d) by individuals, groups or other adopting units, linked (e) to specific channels of communication, (f) to a social structure, and (g) to a given system of values, or culture (Katz et al., 1963). Rogers describes this process as an "S-shape" due to adopters' varying degree of readiness to take up an intervention, which may be influenced by motivation to change, personality characteristics, knowledge about the intervention, perceived needs, and meaning ascribed to the intervention (Greenhalgh et al., 2014). This results in early intervention adoption by some, then gradual spread or diffusion of the intervention over time, followed by later adoption of the intervention by other individuals within the organization. Additionally, in keeping with the theory, roughly $16 \%$ of potential adopters will lag behind others in uptake of the innovation (Rogers, 2003). Rogers refers to them as laggards; see Figure 1. 


\section{Figure 1}

Diffusions of Innovations

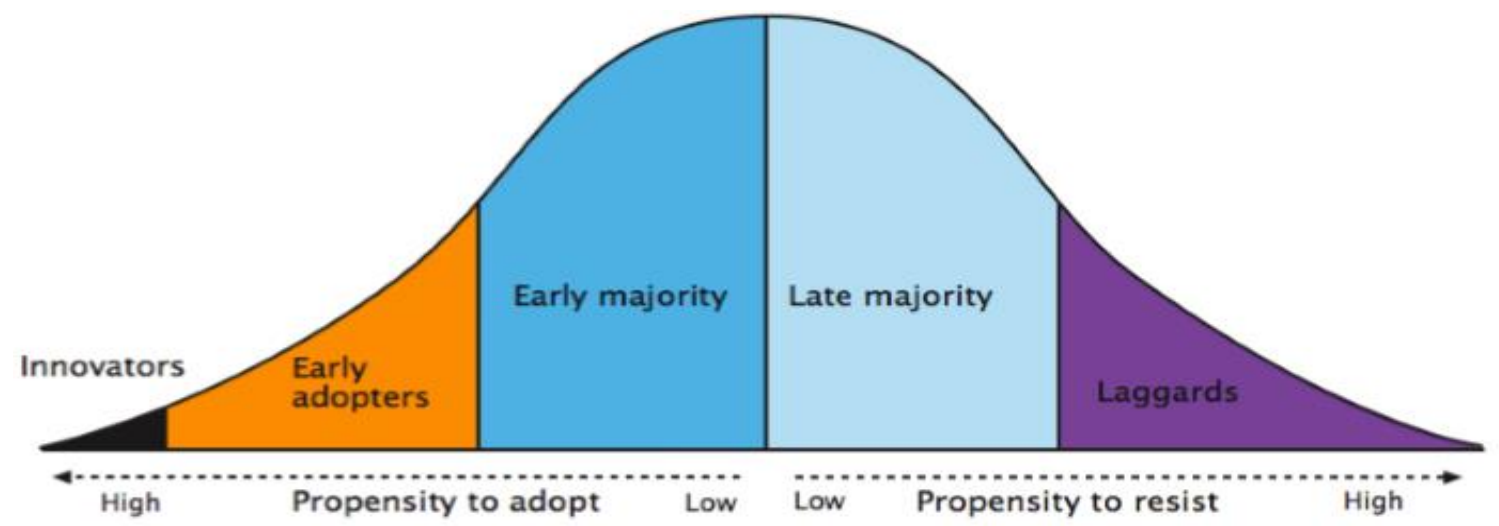

Note. Adapted from Diffusion of Interventions (5th ed.), by E. M. Rogers, 2003. Copyright 2003 Free Press.

Diffusion of Innovations theory has been applied to myriad disciplines including communications, anthropology, marketing, economics, geography, science, political science, sociology, and public health (Rogers, 2003). The diffusion process includes four main elements: (a) the innovation, (b) the communication channels, (c) time, and (d) the social system (Rogers, 2003); still, the diffusion process is a general one, not bound by the adopters, culture or innovation, therefore making it germane to varied disciplines. The final result of this process is the adoption, implementation, and institutionalization of the innovation (Rogers, 2003). The term adoption denotes an individual or group or organization's decision to utilize the innovation; while, implementation refers to putting the innovation into practice. Institutionalization describes wholly embracing the innovation and integrating it into routine practice (Dusenbury et al., 2003).

Diffusion research has historically focused on the characteristics of the innovation, specifically the qualities of relative advantage (clear advantage in either 
effectiveness, including cost-effectiveness), trialability (ability to experiment on partial basis with the innovation), simplicity (ease of usage), compatibility (innovation compatibility with practitioners' norms, values, and perceived needs), and observability (observable practitioner benefits; Greenhalgh et al., 2014). However, researchers increasingly are examining barriers to implementation of innovations by exploring the importance of studying key adopters' perceptions of the innovation rather than innovation attributes alone (Greenhalgh et al., 2014). Innovations perceived by key adopters as simple, effective, and consistent with their values, norms, and needs are more likely to be adopted (Rogers, 2003).

As the theory purports, organizational context is a vital component of adoption as well. Individuals within an organization are influenced by the organizational climate, and likewise influence the organization. This reciprocity governs whether, and to what extent innovation implementation is realized. This is referred to as the innovation-values fit, or the individual's perceptions of the fit of the innovation to their personal values (Klein \& Knight, 2005). The innovation-values fit can differ between an organization's members, explaining mixed degrees of acceptance and implementation of an innovation within an organization. Still, once an innovation is implemented by a few members, it is more probable that others within the organization will implemented as well, particularly if the attitude toward the innovation by those who adopted it is a positive one (Greenhalgh et al., 2014). Greenhalgh et al. (2014) additionally identified multiple organizational climate factors that could hinder the adoption of the innovation, including organization size, resource availability, organizational hierarchy, the organizational capacity for uptake of new knowledge, and the general organizational climate towards openness to change. 


\section{Active Implementation Frameworks}

The next guiding framework for this dissertation builds upon the work of Roger's Diffusion of Innovations Theory (Dearing \& Cox, 2018). The Active Implementation Frameworks, currently classified as a mid-range theory, is comprised of a set of individual frameworks used to assess implementation capacity in organizations and systems (Fixsen et al., 2015; St. Martin et al., 2015; Ward et al., 2015). A mid-range theory is more limited in scope, less abstract, addresses explicit phenomena, and mirrors practice. It incorporates a reduced number of concepts and a limited aspect of the real world. Mid-range theories are designed to guide empirical inquiry and are comprised of relatively concrete concepts that are operationally defined and relatively concrete propositions that can be empirically tested (Carpiano \& Daley, 2006). These areas assess leadership and executive management investment, system alignment, and commitment to Implementation Team development. This theory is a compilation of an analysis of more than three decades of empirical literature on implementation of varied endeavors in corporate business, farming, education, hospital administration, nursing, juvenile justice, mental health, and other social services, including Rogers Diffusion of Innovations theory discussed further on (Dearing \& Cox, 2018).

The Active Implementation Frameworks chief aim is to decrease confusion and improve focus on the areas that have proved most relevant when endeavoring to use innovations in practice (Fixsen et al., 2019). The theory is a product of the past few decades of doing the work of implementation, examining and synthesizing the literature related to implementation, and working with policy and system leaders. Figure 2 outlines the six frameworks that constitute this theory, explained in more detail below. 


\section{Figure 2}

Active Implementation Frameworks
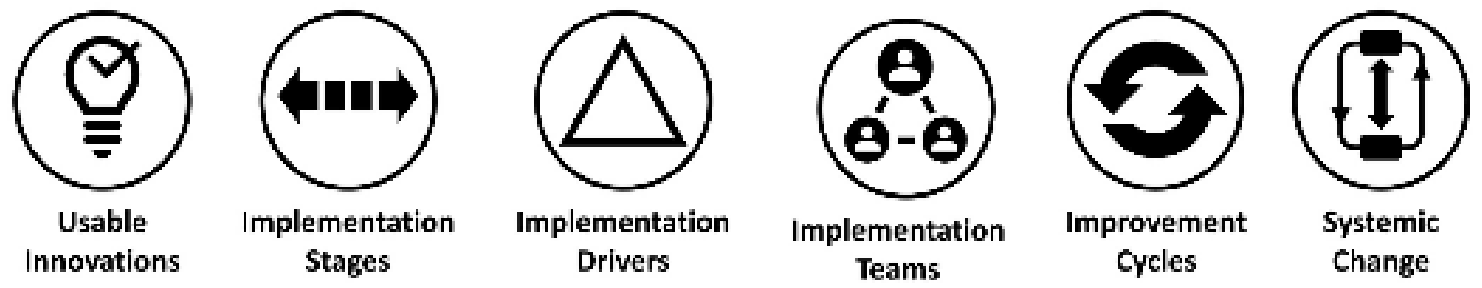

Note. Adapted from "Implementation Science," by D. L. Fixsen, K. A. Blase, A. Metz, and M. K. Van Dyke, 2019, in International Encyclopedia of the Social and Behavioral Sciences (Vol. 11), J. D. Wright (Ed.), pp. 695-702. Copyright 2015 by Elsevier.

\section{Usable Innovations}

An innovation is defined as something novel to an individual, organization, or human service system (Rogers, 2003). Innovations can include instructional methods, clinical guidelines, policy directives, therapeutic interventions, evaluation methods, management practice, improvement initiative, or other programs or activities. Such innovations may or may not have research evidence to support it. Additionally, Usable Innovations are operationalized, and maintain characteristics of being easily teachable, learnable, achievable, and assessable in practice. A hallmark of Usable Innovations is that they are effective when used as intended. They additionally have the ability to distinguish the presence and strength of the innovation used in daily practice (Fixsen et al., 2019).

\section{Implementation Stages}

Implementation is a process, not simply a one-time event (Dearing \& Cox, 2018).

This framework highlights integral stages identified in practice and used to direct organization and system investments in innovations. These stages are denoted as Exploration, Installation, Initial Implementation, and Full Implementation (Fixsen et al., 
2019). The theory highlights that these stages are not linear, but rather interactive, additive and dynamic as impacted by fluctuations in people, environments and implementation supports.

\section{Implementation Drivers}

The Implementation Drivers framework highlights the need for what is are required to produce, sustain, and improve the effectiveness and efficiency of innovations as they are used in practice (Fixsen et al., 2009). This focus consists of competency (selection, training, coaching), organization (systems intervention, facilitative administration, and decision support/data support) and drivers that are measured over time (Performance Assessment), allowing for adjustments in any of the "drivers" to ensure implementation fidelity. This concept supports the belief that training alone does not guarantee implementation, but rather that these implementation drivers work together to influence organizational culture and practitioners' behaviors and to support implementation fidelity. According to Fixsen et al. (2008), implementation components can be thought of as drivers placed on a circle with two-headed arrows going from one driver to every other driver, resulting in a situation where a weakness in one implementation driver can be compensated for by strengths in other drivers. The premise purports that an ineffective program can be implemented well and likewise an effective program can be implemented poorly. The outcome then rests upon the degree of core implementation driver's implementation and how they are integrated and adjusted as per key stakeholder feedback throughout the implementation process (Fixsen et al., 2009, 2019). 


\section{Implementation Teams}

This next framework describes how expertise is essential to purposefully and successfully use the Active Implementation Frameworks to support innovation use, ultimately producing planned outcomes repeatedly and reliably. Such expertise is developed within Implementation Teams, which are created within organizations and systems. An Implementation Team consists of three to five members working closely with an organization's executive leadership. Team members are experts in identifying and developing Usable Innovations, as well as skilled in their personal use of the Active Implementation Frameworks and the ability to instruct others on framework usage (Fixsen et al., 2019).

\section{Improvement Cycles}

Improvement cycles are critical to the continued use of effective innovations and are an essential part of using effective implementation methods. In this framework, the Improvement Cycle's mission is to detect and correct errors and strengthen facilitators that occur during the path to successful implementation (Fixsen et al., 2019).

\section{System Change}

Systemic Change, the final framework within this theory, describing the broader scope and vital impact of societal context essential for producing population benefits (Fixsen et al., 2019). Effective implementation supports and the use of effective innovations are useful tools in challenging traditional standard practice or status quo. In order to realize successful innovation implementation, systems must change, along with role and function restructuring to successfully sustain and improve future outcomes (Dearing \& Cox, 2018). 
Regardless of theory variations outlined above, each acknowledges implementation not as an event, but a process, influenced greatly by individual and organizational factors. To ascertain the degree to which an intervention is adopted, implemented, and eventually becomes a component of practice, it is vital to critically review such factors that may prevent or foster intervention implementation and the intervention becoming part of practice.

\section{Summary}

It is crucial that skillful solutions for bridging the gap between EBPs shown to address and treat childhood trauma exposure, and the youth who desperately need them to be sought after and implemented. This need is especially paramount for youth engaged with the child welfare system, as statistics evidence that the need for such services is sadly increasing. Federal and State legislative evolution and momentum promote the hope that policies, programs and procedures within the child welfare system, wraparound partners and stakeholders are aware of and endeavoring after such solutions to address gaps in mental health service delivery. However, continued effort is needed to expeditiously address child welfare system deficits at policy, programmatic, organizational, intervention and practitioner levels to improve mental health outcomes in maltreated children exposed to trauma. 


\section{CHAPTER III. RESEARCH DESIGN AND METHODOLOGY}

The literature review highlights the vital nature of studying both moderating and direct effects of organizational and practitioner characteristics on implementation fidelity. As outlined previously, more favorable attitudes toward change and scientific information distinguish early adopters from late adopters of interventions (Aarons, 2004; Rogers, 2003). Furthermore, practitioner attitudes toward EBPs are associated with provider characteristics, leadership and organizational context (Aarons, 2004; Aarons \& Sommerfeld, 2012). Considering the literature support and ever-evolving need for evidenced-based interventions, the study at hand examines implementation fidelity of an EBP (TF-CBT), with community setting practitioners by exploring specific organizational and practitioner characteristics that may impact implementation fidelity. Overarching aim, research questions and hypothesis are as follows:

\section{Research Questions}

Overarching Aim. To better understand the relationship between individual and organizational characteristics on implementation fidelity of EBPs

Research Question 1: Document in a diverse group of practitioners their demographic characteristics, along with their attitudes and beliefs towards EBPs.

Hypothesis 1: no hypothesis as this is for descriptive purposes

Research Question 2: Is there a relationship between individual practitioner characteristics and EBP implementation fidelity?

Hypothesis 2A: Practitioner belief in the value of EBP will be positively associated with greater implementation fidelity. 
Hypothesis 2B: Practitioner belief in their ability to perform skills necessary for EBP execution will be positively associated with greater implementation fidelity. Hypothesis 2C: Practitioner endorsement of supervisory requirements as a reason for EBP usage will be positively associated with greater implementation fidelity. Hypothesis 2D: Practitioner age will be negatively associated with EBP implementation fidelity.

Hypothesis 2E: A less professionally experienced Practitioner professional experience will be negatively associated with EBP implementation fidelity.

Research Question 3: Is there a possible moderating influence of practitioners' perception of organizational characteristics on the relationship between their individual practitioner characteristics and implementation fidelity?

Hypothesis 3A: The associations between practitioner individual characteristics and EBP implementation fidelity will be stronger for practitioners who perceive their organizational climate as supportive Hypothesis 3B: The associations between practitioner individual characteristics and EBP implementation fidelity will be stronger for practitioners who perceive greater readiness for change in their organization.

\section{Population and Setting}

This study involves secondary data analysis from Centene Corporation, a national health care company that provides services to government-sponsored healthcare programs, focusing on under-insured and uninsured individuals. In Florida, Centene provides such services to the Sunshine Health Child Welfare Specialty Plan (CWSP), which is available to Medicaid recipients under the age of 21 who have an open case for 
child welfare services in the Department of Children and Families' Florida Safe Families Network database. The plan works together with the Community Based Care agencies throughout the state to coordinate medical and behavioral health care for recipients in the state child welfare system.

Analysis from this study drew specifically from data derived from Centene Behavioral Health $(\mathrm{CBH})$, a department within Centene, that focuses on developing innovative solutions to meet provider and health care member needs through physical and behavioral health provider training. In an effort to enhance and raise the skill set of community-based practitioners that work with trauma-exposed youth, $\mathrm{CBH}$ facilitates several EBP trainings at no cost throughout Florida each year. The secondary data used in this analysis focused on once such 2017 training, comprised of a volunteer practitioner group $(N=201)$ from multiple provider agencies $(n=51)$ in the South Florida region who participated in a Trauma-Focused Cognitive Behavioral Therapy (TF-CBT) training.

\section{Recruitment and Inclusion Criteria for Participation in TF-CBT Training}

Participating practitioners were invited to participate in a 2-day TF-CBT educational workshop. Participants were recruited via email correspondence sent to practitioners who had previously voluntarily "opted in" to receive notification of open registration for upcoming TF-CBT training events, in addition to information posted on CBH's website regarding a call for participants. Additional inclusion criteria mandated all participants be contracted providers or in the process of becoming a provider with Health Plan. Further, participants had to have met criteria for TF-CBT certification (having a master's degree in a mental health discipline, being licensed or licensed eligible within 2 years of the training, currently working with trauma-exposed youth) and attested 
to their intent to participate in post-workshop training consultation calls. The participants represented a variety of self-reported job titles and agencies, but for the purposes of analyses, were grouped together as practitioners.

\section{The Intervention}

Trauma-Focused Cognitive-Behavioral Therapy (TF-CBT) is a components-based treatment model for youth ages 3 to 18 , that can include their caregivers, affected by trauma (Cohen et al., 2006). Effectiveness and efficacy trials have concluded that youth participating in TF-CBT show improvements in depression, anxiety, posttraumatic stress disorder (PTSD), externalizing behavior problems, relationship and attachment problems, as well as academic difficulties (Cohen et al., 2006), while caregiver outcomes reveal reduced parental distress and improvements in overall parenting skills (for reviews, see Cary \& McMillen, 2012). The model maintains a scientific rating of "1" on the California Evidenced Based Clearinghouse (CEBC) for Child Welfare, meaning that is "well supported by research evidence," rated "high" for its usage in meeting the needs of individuals receiving child welfare services (Walsh, et al., 2015). The TF-CBT model is comprised of eight essential elements summarized by the acronym PRACTICE: Psychoeducation and Parenting Skills (P), Relaxation (R), Affect Expression and Regulation (A), Cognitive Coping (C), Trauma Narrative Development and Processing (T), In Vivo Gradual Exposure (I), Conjoint Parent/Child Sessions (C), and Enhancing Safety/Future Development (E). A hallmark of TF-CBT is that its components allow for flexibility within this manualized treatment approach. The model consists of 12 to 25 weekly sessions, lasting approximately 60 to 90 minutes in length to be conducted on a 
weekly basis at a pace determined by the client's cognitive and affective readiness

(Cohen et al., 2006).

\section{TF-CBT Training Components}

In response to the evidence base surrounding best practices of effectiveness and efficacy of community setting dissemination needs, a three-track strategy was developed for the training of TF-CBT to therapists (Cohen \& Mannarino, 2008). These methods include:

1. web-based learning

2. live training workshop learning

3. ongoing consultation via learning collaboratives

The Web-based learning component was developed by investigators at the Medical University of South Carolina Crime Victims Center in collaboration with TFCBT developers (accessible at www.musc.edu/tfcbt). The participant must complete this web-based component which includes child and parent video examples of all treatment components, handouts for children and parents, includes component of the model with specific parent and child sections, printable scripts for the therapist's use, instructions on handling clinically challenging circumstances, cultural consideration guidelines, as well as links to resources.

The next two TF-CBT dissemination elements involve more intensive training and structured follow up. The live training, as well as the consultation calls involve inperson training followed by live phone or in-person consultation. The training and consultation are provided by approved trainers or treatment developers who provide supportive supervision to trainees in an effort to certify the treatment is being delivered 
and used with fidelity. The overarching advantage of these two components is the support therapists receive support as they begin treatment with new clients. The developers surmise that this may enhance sustainability along with fidelity following the completed training components (Cohen \& Mannarino, 2008).

\section{Overview of Design and Procedures}

\section{Procedures}

As stated previously, $\mathrm{CBH}$ promoted the TF-CBT training event via their website, allowing for preliminary registration once eligibility was established. Registration organization and management of participant survey information was conducted via the $\mathrm{CBH}$ training registrar. Practitioners participated in the live in-person training as per model protocol, facilitated via an approved master's level and licensed clinician, authorized by the developers to train others in this model. Participants attested to their agreement to additionally participate in twice-monthly TF-CBT expert consultation calls with behavioral rehearsal over the subsequent 6 months following the 2-day training. The demographic survey, as well as the practitioner and organizational attitudes and beliefcapturing surveys were disseminated by the $\mathrm{CBH}$ on-site training proctor and were completed by participants prior to the beginning of the training on day one. Once collected, surveys were manually scored by the $\mathrm{CBH}$ training proctor and registrar. Following the training event, the $\mathrm{CBH}$ registrar electronically sent participants the TFCBT Checklist for in-session skills tracking as per measure protocol. Practitioners used the checklist with one client engaged with TF-CBT treatment. Practitioners electronically returned the checklist five months following the training via email to the $\mathrm{CBH}$ training registrar. The TF-CBT checklist was recorded by the $\mathrm{CBH}$ registrar and scored for 
fidelity, earning a "yes" for delivering the EBP with fidelity or "no" if fidelity criteria were not met.

\section{Measures}

\section{Practitioner Demographic and Professional Background Survey}

A practitioner demographic survey was drafted by $\mathrm{CBH}$ and utilized to gather practitioner information prior to the training. Survey responses included participant age, gender, race/ethnicity as well as professional background questions including education level, licensure, and post-masters experience. (See Appendix A for a copy of the full assessment.)

The data on age were collected in a categorical fashion, asking practitioners to select one of three age ranges (Group A = 18-29 years old, Group B = 30-50 years old, Group $\mathrm{C}=51-70$ years old). After conducting a frequency distribution of the three levels, only four practitioners reported their age range as Group C (51-70 years old). Therefore, for the current study, age Groups, B and C age were combined to create a dichotomous variable as follows (Group A = 18-29 years old and Group B = 30 years and older). Data on professional experience was collected in a categorical fashion, asking practitioners to select one of three ranges of years of experience (Group A = 0-5 years, Group B = 5-10 years, Group $\mathrm{C}=10$ or more years).

\section{Evidence-Based Practice Attitude Scale}

EBPAS (Aarons, 2004) is a 15-item self-report measure that was utilized to capture practitioners' attitudes toward adopting new types of evidenced-based techniques and manualized treatments (See Appendix B for a copy of the full assessment.) 
Response options for the items are scored using a 5-point Likert scale, ranging from 0 ("Not at All") to 4 ("To a Very Great Extent"). Mean scores for the EBPAS can be combined to compute subscale scores as well as total scores; four items are reverse scored (i.e., divergence subscale). Therefore, total possible scores can range from 0 to 4 . These subscores consist of 1) Requirements (3 items, \#11, 12, 13), such as if the intervention or new program is required by their agency, state or supervisor, or, 2) Appeal (4 items, \# 9, 10, 14, 15), which highlight their belief regarding the sensibility of the intervention, if it is intuitively appealing, and their skillset adequacy for the intervention, 3) Openness (4 items, \# 1,2, 4, 8), refers to the respondents endorsement of liking new types of therapy, finding value in evidenced-based techniques and new types of therapy, and whether they will follow a treatment manual or therapy designed by researchers, and 4) Divergence (4 items, \#3, 5, 6, 7), which assesses a respondents attitudes that are challenges to EBP implementation, for example as believing researchbased treatments are not useful, that a practitioner's experience is of higher regard.

The EBPAS has consistently demonstrated psychometric strength, in regard to its reliability and validity and reliability. Measurement development consisted of interviewing 51 program managers and administering the scale to 322 mental health service providers (Aarons, 2004). Exploratory Factor Analysis was conducted with half the sample, followed by Confirmatory Factor Analysis (CFA) conducted with the other half, resulting in the four-factor solution. While two of the factor loadings for items on the Divergence subscale are less than .50 , all loadings proved significant $(\mathrm{p}<.01)$. Several years later, a CFA follow-up with 221 different mental health reconfirmed the four-factor structure (Aarons et al., 2007); with just one item on the Appeal subscale 
showing a factor loading of less than .50 , and maintaining all loadings were significant $(p$ $<.05)$. In 2010, another investigation of the EBPAS' psychometric properties was conducted, $\mathrm{N}=1,089$ mental health care providers in 26 states, with all factor loadings significant at the $\mathrm{p}<.05$ level (Aarons et al., 2010). Overall, this measure appears to have strong internal construct validity. Internal consistency reliability estimates are also strong. Initial alpha values reported as .77 for the overall scale, with subscales as follows: .59 for Divergence, .78 for Openness, .80 for Appeal, .90 for Requirements (Aarons, 2004). The recent methods resulted in Cronbach's alpha of .76 for the total score, with subscale alphas ranging from .67 to .91 (Aarons et al., 2010). Regarding external validity or generalizability, the EBPAS is utilized frequently as measurement tool for researchers intending to capture practitioner attitudes, external validity or generalizability (Rye et al., 2017). Additionally, the EBPAS is regarded as one of the first existing methods for reliable, standardized measurement of attitudes toward EBPs, filling a large gap in training literature (Beidas \& Kendall, 2014).

For the current study, practitioners' responses to three of the subscales were utilized to create separate composite scores. three scales demonstrated reliability with Cronbach's alpha coefficients. First, the Openness Subscale constituted the composite score labeled PBV with $(\alpha=.67)$, denoting practitioner belief in the value of evidencebased techniques. Next, the Appeal Subscale comprised the composite score labeled PBPS $(\alpha=.61)$, endorsing practitioner belief in their perceived skillset. Lastly, the Requirement Subscale composite score (labeled PBES $[\alpha=.81]$ ), measures practitioner endorsement of their supervisory structure or state mandate on potential EBP uptake. 
Possible ranges for all subscale items were 0-4, with higher scores indicating a greater endorsement of the construct.

\section{Readiness for Organizational Change}

The Readiness for Organizational Change scale measures an organization's readiness for change from the individual's perspective (Holt et al., 2007). This scale measures the relationship between content (i.e., what is being changed), process (i.e., how the change is being implemented), context (i.e., conditions under which the change is occurring), and the individuals (i.e., characteristics of those being asked to make a change) involved based on theory about the change process itself (Holt et al., 2007).

This 25-item scale consists of four subscales: Appropriateness $(\alpha=.94)$, Management Support $(\alpha=.87)$, Change Efficacy $(\alpha=.82)$, and Personal Valence $(\alpha=$ .66) (Holt et al., 2007). The Appropriateness subscale contains 10 items, while the Change Efficacy and Management Support scales include 6 items each, and Personal Valence subscale consists of only 3 items. The subscales (Change Efficacy) measure employees' belief in their organization's readiness for and capability of implementing a proposed change, (Appropriateness) if the proposed change is appropriate for the organization, (Management Support) the leaders are committed to the proposed change, and (Personal Valence) the proposed change is beneficial to organizational members (Holt et al., 2007).

A 7-point response format is used by all scale items, ranging from $1=$ strongly disagree to $7=$ strongly agree, maintain that the higher the score, the higher the level of agreement that their organization is ready for change. Participants respond to statements within each subscale, such as "I think that the organization will benefit from this change" 
(Change Efficacy), "This change matches the priorities of our organization" (Appropriateness), “Our organization's top decision makers have put all their support behind this change effort" (Management Support), and "My past experiences make me confident that I will be able to perform successfully after this change is made" (Personal Valence). Cronbach's alpha was used to calculate internal consistency reliability for The Readiness for Organizational Change scale, with subscales yielding the following Appropriateness $(\alpha=.94)$, Management Support $(\alpha=.87)$, Change Efficacy $(\alpha=.82)$, and Personal Valence $(\alpha=.70)$. There is no composite score for this scale, as the authors simply scored it by computing the mean for each of the scale scores. The developers surmised the utility of the instrument was with the subscale scores as this would give organizational leaders more guidance regarding actions that might facilitate readiness (Holt et al., 2007) (See Appendix C for a copy of the full assessment).

For the current study, practitioners' responses to two of the subscales were utilized to create separate composite scores. First, the Change Efficacy scale constituted the composite score, labeled Readiness, denoting practitioner belief that their organization was ready and capable of implementing a change. Initially, Cronbach's alpha coefficient for this scale was $(\alpha=.33)$. Further analysis and examination revealed that reverse coding one of the items was the prudent next step. This question varied from the other items, as it was posed in a negative frame, asking for respondents to consider the statement "there are some tasks that will be required when I change that I don't think I can do well." Once the scale item was reversed, Cronbach's alpha coefficient for this sub scale increased $(\alpha=.74)$. Next, the Management Support scale comprised the composite score labeled Support ( $\alpha=.73$ ) endorsing practitioner belief that leadership 
was committed to the proposed change. Possible range for both Readiness and Support scales is 1-7 with higher scores indicating a greater endorsement of the construct.

\section{TF-CBT Practice Fidelity Checklist}

Fidelity assessments typically are designed to assess essential features of an intervention (Fixsen et al., 2009). This checklist is an example of such an interventionspecific assessment. The TF-CBT PRACTICE Fidelity Checklist (Deblinger et al., 2001) is a 49-item self-report measure designed to assess fidelity to the components of TF-CBT (See Appendix D for a copy of the full assessment.)

A 5-point response format is used by all scale items, ranging from "never" to "almost always" to describe how often various treatment strategies are utilized during TF-CBT treatment. The checklist identifies TF-CBT components addressed during each session, and a total composite fidelity score is derived by computing the proportion of required treatment components as reported by the practitioner over the entire duration of treatment. Component categories prompt the practitioner to consider statements that assess one of 6 treatment components, such as (1) General Therapy Structure/Style of Session will be assessed by the practitioners scoring of example statement "Encouraged client collaboration"; (2) Psychoeducation via example statement "Provided or reviewed education regarding characteristics and prevalence of the identified trauma(s) and/or offered choice in determining therapy activity for the session"; (3) Coping Skills are assessed by example statement "Encouraged child/parent to expand his/her emotions/feelings vocabulary and enhance his/her emotional expression skills"; (4) Trauma-Focused Intervention with statement "Encouraged the use of coping skills when confronted with trauma reminders or trauma-related distress"; (5) Personal Safety Skills 
via example statement "Presented or reviewed names for private parts or had child practice the names for private parts"; (6) Behavior Management Skills Training with statement "Helped parent review what happened before, during, and after positive and negative parent-child interactions"; (7) Other/Miscellaneous via example statement "Felt successful in accomplishing the goals of the session." For this study, practitioners were asked to additionally answer (Q26) "How many practice components did you complete?" in the question 7 field. A score from 0-8 was derived for each practitioner with points allotted as follows $(0=0$ components completed, $1=1-2$ components completed, $2=3-4$ components completed, $3=5-6$ components completed, $4=7-8$ components completed).

The TF-CBT PRACTICE Fidelity Checklist is still in the early stages of development and its validity has yet to be fully established. The TF-CBT PRACTICE Fidelity Checklist was derived from the PRACTICE Checklist Self-Report developed by Deblinger et al. (2001). In studies conducted by Ebert et al. (2012) and Hanson et al. (2018), the Cronbach coefficient $\alpha$ s for the PRACTICE Checklist Self-Report were > .95. For the current study, practitioner responses to the checklist were evaluated via the $\mathrm{CBH}$ training registrar and scored either "yes" fidelity to the TF-CBT model was achieved or "no" fidelity to the TF-CBT model was not achieved, creating a binary variable.

Analysis. Given that the outcome variable of fidelity was a dichotomous variable, logistic regressions were employed to assess the factors associated with fidelity. Prior to conducting the primary analyses, analyses of descriptive information, frequency distributions, and correlations of all variables were conducted using SPSS version 20.0. The data were examined for missing data frequency and patterns. Binary and multivariate logistic regressions were conducted, with $p<.05$ as a threshold for statistical 
significance. Categorical predictor variables were dummy coded and were interpreted as compared to the reference group (K-1 categories were included in each model run). Lastly, to examine the possible moderating influence of practitioners' perception of organizational characteristics on the relationship between their individual practitioner characteristics and implementation fidelity (see Figure 3) interaction product terms were created with each focal independent variable ( $\mathrm{R} 1$ and $\mathrm{R} 2$ respectively) and the proposed moderator variables (R3). For each moderation analysis, the outcome variable (fidelity) was regressed onto the respective focal independent variable, the moderator variable and the newly created interaction product term. Results were evaluated for significance of the product term to see if there was a statistically significant $(\mathrm{p}<.05)$ interaction. 
Figure 3

\section{Conceptual Framework}

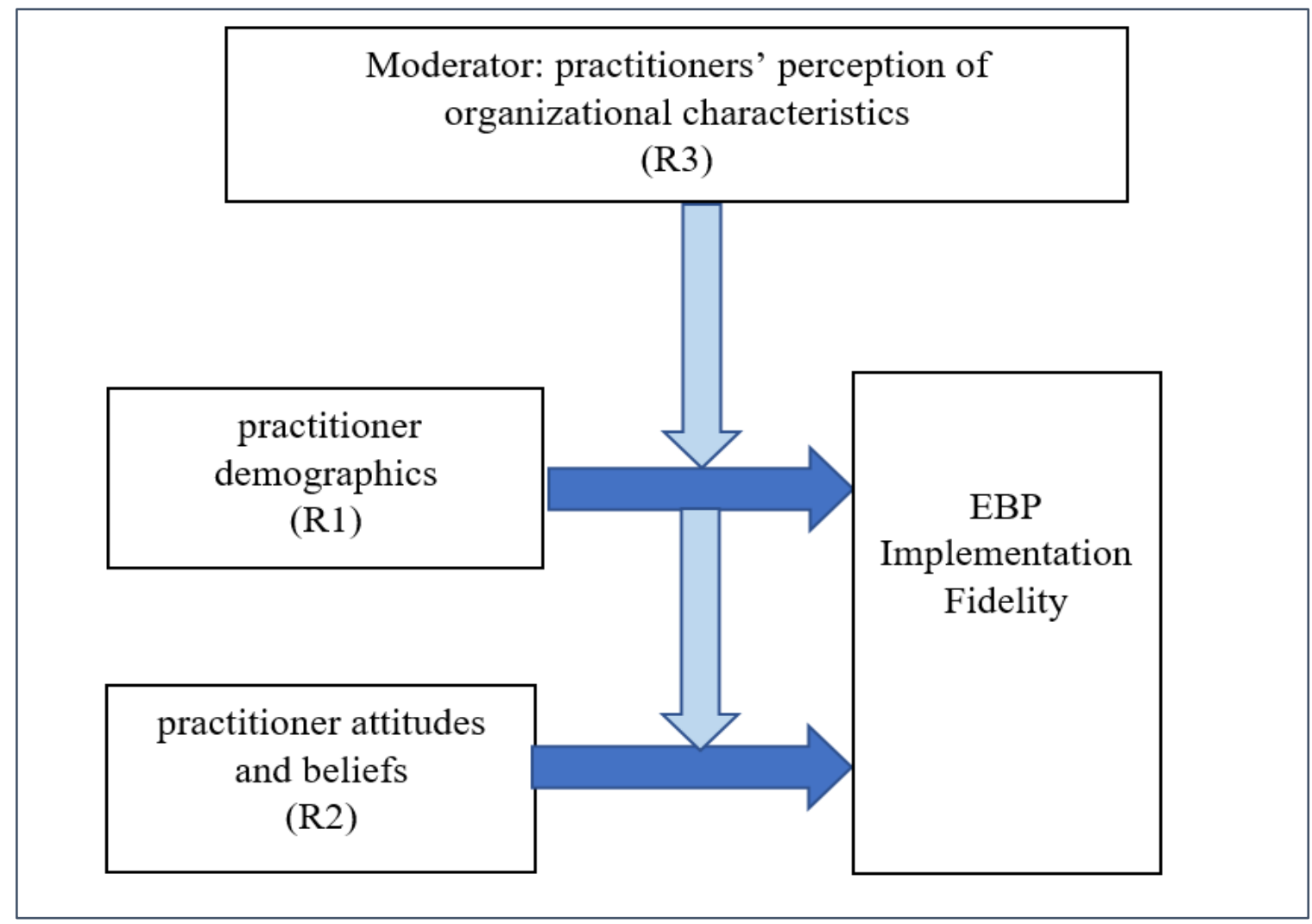




\section{CHAPTER IV. RESULTS}

This chapter presents the study's findings organized by Research Question and the corresponding hypotheses.

\section{Research Questions}

\section{Research Question 1}

R1 Document in a diverse group of practitioners, demographic characteristics, along with attitudes and beliefs towards EBPs.

H1 No hypothesis as this is for descriptive purposes

As shown in Table 1 , the sample $(N=201)$ self-identified their race/ethnicity in one of four categories, Black (15.90\%), Caucasian (61.20\%), Hispanic (19.90\%) and Other (3\%). The sample was mixed gender, with the majority identifying as female $(85.10 \%)$. Participants endorsed one of three categories of clinical experience, ranging from 0-5 years $(43.80 \%), 5-10$ years $(36.30 \%)$ or $10+$ years $(19.90)$. Ninety-six percent held a master's degree and five percent a Ph.D. Nearly half (46.30\%) indicated they had a post-masters clinical license. Means and standard deviations (SD) of participants' attitudes and beliefs towards adopting new types of evidence-based techniques and manualized treatments also were documented in Table 1. All demographic characteristics are presented in Table 1. 


\section{Table 1}

Demographic and Professional Background Characteristics

Characteristic

Total Sample

$\mathbf{N}=201$

\begin{tabular}{|l|c|}
\hline Age & \\
\hline $18-29$ years & $37.30 \%$ \\
\hline 30+ years & $62.70 \%$ \\
\hline Gender & \\
\hline Female & $85.10 \%$ \\
\hline Male & $14.90 \%$ \\
\hline Race/Ethnicity & \\
\hline Black & $15.90 \%$ \\
\hline Caucasian & $61.20 \%$ \\
\hline Hispanic/Latino & $19.90 \%$ \\
\hline Other/including Asian & $3 \%$ \\
\hline Education & $96 \%$ \\
\hline Master's Degree & $5 \%$ \\
\hline PhD Degree & $46.30 \%$ \\
\hline Clinical license & \\
\hline Years of clinical experience & $43.80 \%$ \\
\hline $0-5$ years & $36.30 \%$ \\
\hline 5-10 years & $19.90 \%$ \\
\hline $10+$ years & Mean (SD) \\
\hline Practitioner Attitudes \& Beliefs & $3.49(.37)$ \\
\hline PBV & $3.63(0.35)$ \\
\hline PBPS & $3.58(.48)$ \\
\hline PBES & $83.60 \%$ \\
\hline Practitioner Fidelity & \\
\hline yes & $16.40 \%$ \\
\hline no & \\
\hline
\end{tabular}

Note PBV=Practitioner Belief in the Value; $\mathrm{PBPS}=$ Practitioner Belief in their skillset; $\mathrm{PBES}=$ Practitioner endorsement of supervisory requirements

${ }^{a}$ represents a post-masters clinical license

${ }^{\mathrm{b}}$ practitioners adherence to TF-CBT model protocol 
Research Question 2: Is there a relationship between individual practitioner characteristics and EBP implementation fidelity?

H2a Practitioner belief in the value of EBP will be positively associated with greater implementation fidelity.

Tables 2 presents the results of a binary logistic regression performed in order to assess the effects of practitioner belief in the value of adopting new types of evidencebased techniques and manualized treatments (PBV) on implementation fidelity. Fidelity was considered the dependent variable, and PBV the independent variable. PBV was not a statistically significant $(p>.05)$ predictor of implementation fidelity in this univariate analysis.

\section{Table 2}

Binary Logistic Regression of Fidelity on Practitioner Belief in the Value (PBV) of EBP

\begin{tabular}{|l|c|c|c|c|c|c|c|}
\hline & B & S.E. & df & Sig. & $\operatorname{Exp(B)}$ & \multicolumn{2}{|c|}{ 95\% C.I.for $\operatorname{EXP(B)}$} \\
& & & & & & Lower & Upper \\
\hline PBV & 0.113 & 0.52 & 1 & 0.827 & 1.12 & 0.405 & 3.101 \\
\hline Constant & 1.226 & 1.818 & 1 & 0.5 & 3.408 & & \\
\hline
\end{tabular}

H2b Practitioner belief in their ability to perform skills necessary for EBP execution will be positively associated with greater implementation fidelity.

Table 3 displays the results of a binary logistic regression performed to assess the effects of practitioner belief that their skillset was adequate to adopt new types of evidenced based techniques and manualized treatments (PBPS) on implementation fidelity. Fidelity was considered the dependent variable, and PBPS the independent 
variable. PBPS was not a statistically significant $(p>.05)$ predictor of implementation fidelity in this univariate analysis.

\section{Table 3}

Binary Logistic Regression of Fidelity on Practitioner Belief in Their Skillsets (PBPS)

\begin{tabular}{|l|c|c|c|c|c|c|c|}
\hline & B & S.E. & df & Sig. & $\operatorname{Exp(B)}$ & \multicolumn{2}{|c|}{ 95\% C.I.for $\operatorname{EXP(B)}$} \\
& & & & & & Lower & Upper \\
\hline PBPS & 0.994 & 0.532 & 1 & 0.061 & 2.703 & 0.953 & 7.667 \\
\hline Constant & -1.949 & 1.897 & 1 & 0.304 & 0.142 & & \\
\hline
\end{tabular}

H2c Practitioner endorsement of supervisory requirements (PBES) as a reason for EBP usage will be positively associated with greater implementation fidelity.

Table 4 presents with the results of a binary logistic regression performed in order to assess the effects of practitioner belief in supervisory requirements of adopting new types of evidence-based techniques (PBES) on implementation fidelity. Fidelity was considered the dependent variable, and PBES the independent variable. PBES was not a statistically significant $(p>.05)$ predictor of implementation fidelity in this univariate analysis.

\section{Table 4}

Binary Logistic Regression of fidelity on Practitioner Endorsement of Supervisory Requirements (PBES)

\begin{tabular}{|l|c|c|c|c|c|c|c|}
\hline & B & S.E. & df & Sig. & $\operatorname{Exp(B)}$ & \multicolumn{2}{|c|}{ 95\% C.I.for EXP(B) } \\
& & & & & & Lower & Upper \\
\hline PBES & 0.301 & 0.386 & 1 & 0.435 & 1.352 & 0.634 & 2.879 \\
\hline Constant & 0.551 & 1.375 & 1 & 0.688 & 1.735 & & \\
\hline
\end{tabular}


An additional analysis was conducted using multivariate logistic regression in order to examine the impact of all practitioner attitudes and beliefs (PBV, PBPS and PBES) on fidelity. Table 5 presents results from this multivariate logistic regression. After controlling for expectations of supervisory requirements (PBES) and practitioner belief in the value of an EBP (PBV), the association between practitioner belief in their skillset (PBPS) and implementation fidelity was statistically significant ( $p=.041)$. On average, for every one-unit increase in practitioner confidence or belief in their skillset, the odds of implementation fidelity increase by a factor of 4 .

\section{Table 5}

Multivariate Logistic Regression of fidelity on all practitioner beliefs (PBV, PBPS and PBES)

\begin{tabular}{l|r|r|r|r|r|r|r|}
\hline & B & S.E. & df & \multicolumn{1}{l}{ Sig. } & $\operatorname{Exp}(B)$ & \multicolumn{2}{|c|}{$\begin{array}{l}\text { 95\% C.I.for EXP(B) } \\
\text { Lower }\end{array}$} \\
\hline & & & & & & & Upper \\
\hline PBV & -0.783 & 0.677 & 1 & 0.248 & 0.457 & 0.121 & 1.723 \\
\hline PBPS & 1.408 & 0.689 & 1 & 0.041 & 4.088 & 1.06 & 15.773 \\
\hline PBES & 0.12 & 0.42 & 1 & 0.775 & 1.127 & 0.495 & 2.569 \\
\hline Constant & -1.132 & 2.198 & 1 & 0.607 & 0.323 & & \\
\hline
\end{tabular}

Note. $\mathrm{PBV}=$ Practitioner belief in the value of EBP; PBPS=Practitioner belief in their skillset; PBES=Practitioner endorsement of supervisory requirements

H2d Practitioner age will be negatively associated with EBP implementation fidelity.

Table 6 presents the results of a binary logistic regression performed in order to assess the effects of practitioner age on fidelity. Fidelity was considered the dependent variable, and age the independent variable. There was a statistically significant $(p=.017)$ relationship between practitioner age and implementation fidelity in this univariate model. The analysis indicated that practitioner age was inversely associated with EBP 
implementation fidelity. In other words, the odds of implementing the EBP with fidelity were greater for practitioner age Group A (18-29 years old) than practitioner age Group B (ages 30 and older; $\operatorname{Exp}(\mathrm{B})=3.136 p=.017)$.

\section{Table 6}

Binary Logistic Regression of fidelity on practitioner age

\begin{tabular}{|l|c|c|c|c|c|c|c|}
\hline & B & S.E. & df & Sig. & \multicolumn{2}{|c|}{$\operatorname{Exp}(B)$} & \multicolumn{2}{c|}{ 95\% C.I.for $\operatorname{Exp}(B)$} \\
& & & & & & Lower & Upper \\
\hline Age & 1.143 & 0.478 & 1 & 0.017 & 3.136 & 1.229 & 8.001 \\
\hline Constant & 1.299 & 0.217 & 1 & 0 & 3.667 & & \\
\hline
\end{tabular}

Note. Age: practitioner age group A (ages18-29 years old) $=1$ and practitioner age group $\mathrm{B}($ ages 30 and older $)=0$

Table 7 presents the results of a multivariate logistic regression performed in order to assess the effects of all three subscales of practitioner attitudes and beliefs (PBV, PBPS and PBES) and practitioner age ${ }^{1}$ on fidelity. After controlling for PBV, PBPS and PBES, a statistically significant $(p=.012)$ relationship between practitioner age and EBP implementation fidelity was found. Consistent with the univariate finding reported in the previous section, the odds of implementing the EBP with fidelity were greater for the younger practitioner group (18-29 years old) than the older practitioner group (ages 30 and older $(\operatorname{Exp}(\mathrm{B})=3.474 p=.012)$, even after accounting for variability in practitioner beliefs (PBV, PBPS and PBES). Additionally, after controlling for practitioner age, expectations of supervisory requirements (PBES) and practitioner belief in the value of

\footnotetext{
${ }^{1}$ A Pearson Chi-Square test was computed to assess the relationship between practitioner age and years of experience. The relationship between these variables was significant, $X^{2}(2, N=201)=21.97, p>.001$. Therefore, to avoid problems of collinearity, practitioner age and years of experience were not included in the same regression models.
} 
an EBP (PBV), a statistically significant relation between practitioner belief in their skillset (PBPS) and implementation fidelity remained ( $p=.023)$. On average, for every one-unit increase in practitioner confidence or belief in their skillset (PBPS), the odds of implementation fidelity increase by a factor of 4.853 .

Table 7

Multivariate Logistic Regression of Fidelity on PBV, PBPS and PBES and Practitioner Age

\begin{tabular}{|l|c|c|c|c|c|c|c|}
\hline & B & S.E. & df & Sig. & \multicolumn{2}{|c|}{$\operatorname{Exp}(\mathbf{B})$} & \multicolumn{2}{|c|}{ 95\% C.I.for EXP(B) } \\
\hline & & & & & & Lower & Upper \\
\hline PBV & -0.87 & 0.687 & 1 & 0.205 & 0.419 & 0.109 & 1.61 \\
\hline PBPS & 1.58 & 0.696 & 1 & 0.023 & 4.853 & 1.241 & 18.969 \\
\hline PBPS & -0.182 & 0.45 & 1 & 0.686 & 0.834 & 0.345 & 2.014 \\
\hline Age & 1.245 & 0.496 & 1 & 0.012 & 3.474 & 1.315 & 9.176 \\
\hline Constant & -0.738 & 2.238 & 1 & 0.742 & 0.478 & & \\
\hline
\end{tabular}

Note. $\mathrm{PBV}=$ Practitioner Belief in the value of EBP; PBPS=Practitioner belief in their skillset; PBES=Practitioner endorsement of supervisory requirements; Age: practitioner age group A (ages 18-29 years old) = 1 and practitioner age group B (ages 30 and older) $=0$

H2e A less professionally experienced practitioner will be negatively associated with EBP implementation fidelity.

Table 8 displays results of a binary logistic regression performed in order to assess the effects of practitioner years of experience on EBP implementation fidelity. Fidelity was considered the dependent variable while experience the independent variable. There was a statistically significant $(p=.05)$ relationship between practitioner years of experience and implementation fidelity in this univariate model. The analysis indicated that practitioner years of experience was inversely associated with EBP implementation fidelity. Specifically, the odds of implementing the EBP with fidelity were lower for the more experienced (5-10 years of experience) than for the less 
experienced $(0-5$ years' experience $)(\operatorname{Exp}(B)=.356, p=.027)$. Similarly, the odds of implementing the EBP with fidelity were lower for the more experienced $(10+$ years of experience) than for the less experienced (0-5 years' experience) $(\operatorname{Exp}(\mathrm{B})=.344 p=$ .044). Practitioner experience Group B was not significantly different on implementation fidelity than practitioner experience Group C.

\section{Table 8}

Binary Logistic Regression of Fidelity on Clinical Experience

\begin{tabular}{|c|c|c|c|c|c|c|c|}
\hline & B & S.E. & df & Sig. & $\operatorname{Exp}(B)$ & \multicolumn{2}{|c|}{ 95\% C.I.for EXP(B) } \\
\hline & & & & & & Lower & Upper \\
\hline Group B: 5-10 years exp. & - -1.03 & 0.466 & 1 & 0.027 & 0.356 & 0.143 & 0.889 \\
\hline Group C: $10+$ years exp. & -1.07 & 0.53 & 1 & 0.044 & 0.344 & 0.122 & 0.973 \\
\hline Constant & 2.303 & 0.371 & 1 & 0 & 10 & & \\
\hline \multicolumn{8}{|c|}{ Note. The reference group for this analysis was Group A ( $0-5$ years of experience) } \\
\hline & B & S.E. & df & Sig. & $\operatorname{Exp}(B)$ & \multicolumn{2}{|c|}{ 95\% C.I.for EXP(B) } \\
\hline & & & & & & Lower & Upper \\
\hline Group B: 5-10 years exp. & 0.034 & 0.473 & 1 & 0.943 & 1.034 & 0.41 & 2.612 \\
\hline Group A: 0-5 years exp. & 1.066 & 0.53 & 1 & 0.044 & 2.903 & 1.027 & 8.203 \\
\hline Constant & 1.237 & 0.379 & 1 & 0.001 & 3.444 & & \\
\hline
\end{tabular}

Table 9 highlights the results of a multivariate logistic regression performed in order to assess the effects of practitioner years of experience, and practitioner attitudes and beliefs (PBV, PBPS and PBES), on EBP implementation fidelity. There were two significant relationships. First, after controlling for PBV, PBPS and PBES, there was statistically significant $(p=.05)$ relationship between practitioner years of experience and implementation fidelity. Even after controlling for the variability in practitioner beliefs (PBV, PBPS and PBES), the odds of implementing the EBP with fidelity were lower for 
Group B (5-10 years of experience) than for practitioner Group A (0-5 years' experience) $(\operatorname{Exp}(B)=.334, p=.022)$. Similarly, the odds of implementing the EBP with fidelity were lower for practitioner Group C (10+ years of experience) than practitioner Group A $(0-5$ years' experience $)(\operatorname{Exp}(B)=.293, p=.026)$. Practitioner experience Group B was not significantly different on implementation fidelity than practitioner experience Group C.

Second, after controlling for variability in practitioner years of experience, expectations of supervisory requirements (PBES) and belief in the value of an EBP (PBV), the relation between practitioner belief in their skillset (PBPS) and implementation fidelity remained statistically significant $(\mathrm{p}=.022)$. On average, for every one-unit increase in practitioner confidence or belief in their skillset (PBPS), the odds of implementation fidelity increase by a factor of 4.932 . 


\section{Table 9}

Multivariate Logistic Regression of Fidelity on PBV, PBPS and PBES and Experience

\begin{tabular}{|l|c|c|c|c|c|c|c|}
\hline & B & S.E. & df & Sig. & \multicolumn{2}{|c|}{$\operatorname{Exp(B)}$} & \multicolumn{2}{|c|}{ 95\% C.I.for EXP(B) } \\
& & & & & & Lower & Upper \\
\hline Group B: 5-10 years exp. & -1.098 & 0.478 & 1 & 0.022 & 0.334 & 0.131 & 0.851 \\
\hline Group C: 10+ years exp. & -1.229 & 0.552 & 1 & 0.026 & 0.293 & 0.099 & 0.862 \\
\hline PBV & -0.7 & 0.68 & 1 & 0.303 & 0.496 & 0.131 & 1.882 \\
\hline PBPS & 1.596 & 0.698 & 1 & 0.022 & 4.932 & 1.255 & 19.377 \\
\hline PBES & -0.097 & 0.44 & 1 & 0.825 & 0.907 & 0.383 & 2.148 \\
\hline Constant & -0.587 & 2.269 & 1 & 0.796 & 0.556 & & \\
\hline
\end{tabular}

Note. $\mathrm{PBV}=$ Practitioner belief in the value of EBP; PBPS=Practitioner belief in their skillset; PBES=Practitioner endorsement of supervisory requirements. The reference group for this analysis was Group A (0-5 years of experience)

\begin{tabular}{|l|c|c|c|c|c|c|c|}
\hline & B & S.E. & df & Sig. & \multicolumn{2}{|c|}{$\operatorname{Exp}(\mathbf{B})$} & \multicolumn{2}{|c|}{ 95\% C.I.for EXP(B) } \\
\hline & & & & & & Lower & Upper \\
\hline Group A & 1.229 & 0.552 & 1 & 0.026 & 3.419 & 1.16 & 10.076 \\
\hline Group B: & 0.131 & 0.486 & 1 & 0.787 & 1.14 & 0.44 & 2.954 \\
\hline PBV & -0.7 & 0.68 & 1 & 0.303 & 0.496 & 0.131 & 1.882 \\
\hline PBPS & 1.596 & 0.698 & 1 & 0.022 & 4.932 & 1.255 & 19.377 \\
\hline PBES & -0.097 & 0.44 & 1 & 0.825 & 0.907 & 0.383 & 2.148 \\
\hline Constant & -1.816 & 2.293 & 1 & 0.428 & 0.163 & & \\
\hline
\end{tabular}

Note. $\mathrm{PBV}=$ Practitioner belief in the value of EBP; PBPS=Practitioner belief in their skillset; PBES=Practitioner endorsement of supervisory requirements. The reference group for this analysis was Group C (10+ years of experience)

\section{Research Question 3}

R3 Is there a possible moderating influence of practitioners' perception of organizational characteristics on the relationship between their individual practitioner characteristics and implementation fidelity?

H3a The associations between practitioner individual characteristics and EBP implementation fidelity will be stronger for practitioners who perceive their organizational climate as supportive. 
A multivariate logistic regression was conducted in order to assess the interaction effects of organizational support on the association between practitioner age and fidelity using a product term approach (as noted in the Methods section). The interaction effect was not significant $(p=.779)$. This indicates that practitioner perception of organizational readiness for change did not moderate the relationship between practitioner age and implementation fidelity.

H3b The associations between practitioner individual characteristics and EBP implementation fidelity will be stronger for practitioners who perceive greater readiness for change in their organization.

A multivariate logistic regression was conducted in order to assess the interaction effects of organizational greater readiness for change on the relationship between practitioner age and fidelity using a product term approach (as noted in the Methods section). The interaction effect was not significant $(p=.391)$. This indicates that practitioner perception of organizational readiness for change did not moderate the relationship between practitioner age and implementation fidelity. 


\section{CHAPTER V. DISCUSSION}

The primary focus of this dissertation was to gain a better understanding of the relationship between individual and organizational characteristics on EBP implementation fidelity. To explore implementation fidelity, this dissertation used secondary data from surveys and checklists completed by community setting TF-CBT practitioners working with trauma-exposed youth impacted by the child welfare system in South Florida. This chapter considers the findings of the present study, the strengths and limitations of the study, and the study's finding's implications for social work practice and future research.

\section{Research Question 1 Discussion}

Intended for descriptive and purposes only, Research Question 1 documented practitioner demographics and professional background characteristics as well as their attitudes and beliefs about EBPs (see Table 1 in Chapter 4). It is interesting to note that prior to the TF-CBT training, more practitioners on average endorsed supervisory or state-mandated usage of an EBP as a reason for using such an intervention. However, in inferential analyses, mandated usage did not ultimately prove a significant predictor of fidelity in this study. Since this assessment was taken before the intensive EBP training occurred, most participants had yet to be trained in the reason for and components necessary to deliver TF-CBT with fidelity.

\section{Research Question 2 Discussion}

Findings from Research Question 2 support the likelihood of practitioner characteristics influencing implementation fidelity. The analysis revealed that a particular set of practitioner beliefs, the belief in their ability to skillfully execute an EBP labeled 
PBPS, had a significant and positive association with EBP implementation fidelity. Specifically, EBP implementation fidelity was more likely to occur for practitioners who endorsed a higher degree of PBPS.

In some cases, as with Sanders and colleagues (2009), practitioners have been less likely to use a program if they had lower confidence in their skill set, and more likely if that had robust training in the program. Additionally, practitioners who reported receiving robust training reported fewer implementation barriers (Allen et al., 2011). In regard to the current study, it is important to note that practitioner belief in their skillset was a greater predictor of fidelity than the other beliefs, including belief in the value of an EBP and in a supervisory mandate of EBP usage. One could speculate that the true motivating factor appears to be related to a practitioner's confidence in their actual functional readiness to execute an EBP or manualized treatment, such as TF-CBT. These findings further elucidate the impact that provider attitudes and beliefs have on implementation fidelity.

Consistent with earlier studies (i.e., Allen et al., 2011; Bearman et al., 2013; Cooke, 2010; Cronley \& Patterson, 2010; Gotham et al., 2010; Sanders et al., 2009), robust training appears to be an essential predictor of EBP usage and implementation quality. Particular components of training should focus on improving provider attitudes and beliefs, with a specific goal of increasing providers' confidence in EBP usage via additional training that includes supervisory and peer support during the early adoption stage (Aarons, 2004; Addis, 2002; Rogers, 2003; Proctor et al., 2011). Such components could have a significant impact on practitioner EBP uptake, resulting in more practice and program usage with fidelity. Additionally, measuring practitioners PBPS after EBP 
training would provide an opportunity to follow up with practitioners who PBPS did not improve.

Another finding from Research Question 2 pertained to the practitioner characteristics of age and professional clinical experience influencing implementation fidelity. The analysis revealed practitioner age and experience were inversely associated with EBP implementation fidelity. Research shows that these practitioner variables influence the practitioner's attitude toward utilizing an EBP, therefore impacting the fidelity of that intervention (Christian et al., 2014; Lyon et al., 2013). Interestingly, one study has found senior practitioners improve in EBP use when provided ongoing supervision that included modeling, rehearsal, and role play (Bearman et al., 2013). It could be that younger, less experienced practitioners have received more recent "state-ofthe-science" education emphasizing the application of EBPs such as TF-CBT, laying the groundwork for greater fidelity. That said, results have been mixed regarding the relations of characteristics related to years of experience to implementation fidelity (Allen et al., 2011; Bearman et al., 2013; Cooke, 2010; Sanders et al., 2009), highlighting the need for continued research in this area.

Policy changes affecting the child welfare field, such as the Families First Prevention Act (FFPSA) in 2018, have expedited the need for EBP implementation into mental health services provided to trauma-exposed youth. Many collegiate social work programs have begun offering courses and workshops in implementation science and evidence-based interventions in order to meet the rising need. While results from this study indicated less fidelity with older practitioners, research does maintain that more senior practitioners did show increased practice use of EBPs when provided ongoing 
supervision that included modeling, rehearsal, and role play (Bearman et al, 2013).

Lastly, a more experienced practitioner may have developed a confident and customized eclectic approach over time in their clinical practice; therefore, the need for a templated or manualized treatment option, such as an EBP may not be as strong.

Findings for Research Question 2 suggest a vital need for understanding the characteristics of practitioners learning a new EBP prior to innovation dissemination. This is especially true due to the predictive nature of practitioner perception of their skill set, along with age and experience. Findings align with previous research suggestions of incorporating adult learning best practices into dissemination activities, such as prelearnings, role-play, model rehearsal, peer-support, and ongoing supervision, as a positive solution for all practitioners, regardless of age and experience (Saunders \& Adams, 2013).

\section{Research Question 3 Discussion}

Findings from Research Question 3 did not reveal any significant moderating influence of practitioners' perception of organizational characteristics on the relationship between their individual practitioner characteristics and implementation fidelity. Results

showed that the relations between fidelity and practitioner beliefs, age and experience did not vary by organizational readiness or organizational support. This is somewhat congruent with mixed results of organizational culture and climate's effect on fidelity (Cronley \& Patterson, 2010; Klimes-Dougan et al., 2009; Stein et al., 2012). Although there were no significant moderating influences, evaluation of practitioner perception 
towards organizational characteristics independent from their own beliefs and attitudes towards EBP as a direct influence may be a fertile area for future research.

\section{Overall Research Discussion}

In keeping with the Diffusion of Innovations theory (Rogers, 2003), it is not uncommon for practitioners to hesitate to immediately adopt an innovation. While diffusion research has historically focused on the characteristics of innovation, researchers increasingly are examining barriers to implementation of innovations by exploring key adopters' perceptions of the innovation rather than innovation attributes alone (Greenhalgh et al., 2014). Innovations perceived by key adopters as simple, effective, and consistent with their values, norms, and needs are more likely to be adopted successfully (Rogers, 2003). Over time adherence to the innovation may increase as staff members see the benefits of the innovation with clients (Katz et al., 1963) and/or begin to positively perceive the innovation (Greenhalgh et al., 2014). This can be enhanced through regular monitoring of the implementation process, supplemented with feedback and training as needed (Carroll et al., 2014; Fixsen et al., 2015).

Another consideration is the field in which the EBP (TF-CBT) was implemented. The child welfare field is fraught with clinical challenges to practitioners, who must accurately assess risks, identify outcomes, set specific and measurable goals, and identify service and tasks that will attend to those specific goals (DePanfilis \& Salus, 2003; Rittner, 2002). As per Rogers' theory (2003), it is wise to guard against the assumption that the diffusion and adoption of all innovations is desirable. Some potential adoptees may see innovation in treatment as undesirable due to the perceived burden of extra work, or delay adoption because the treatment model feels different, new or changed 
(Fixsen et al., 2015; Rogers, 2003). Understanding the setting in which potential adoptees are asked to use an EBP is vital to implementation fidelity assessment, as it may point to organizational barriers that must be addressed.

\section{Limitations of method and sample}

A few limitations of the research warrant mention. A notable limitation was the use of secondary data, as it constrains the ability to control and/or modify variables since the data have already been collected. Moreover, the data were not collected specifically to meet the aims of this study.

Another limitation was the exclusive use of self-report surveys, which might bias results due to social desirability (Shadish et al., 2002). There are also concerns with the definition and measurement of the dependent variable, as the fidelity assessment measure was scored with results in a yes/no format, limiting the ability to run more nuanced analyses on the dependent variable. Additionally, implementation fidelity was limited to measuring the degree to which practitioners adhered to the practice model; however, fidelity is considered a more complex construct that includes dose/exposure, adherence, and quality of implementation (Dane \& Schneider, 2008).

Another limitation is participants volunteered to participate in the TF-CBT training and were not randomly selected. Lastly, implementation fidelity research is commonly limited by poorly validated and insufficient assessment tools (Klimes-Dougan et al., 2009). This study utilized the TF-CBT Practice Fidelity Checklist, which is still in development; despite considerable face validity, its psychometric validity is yet to be wholly established. While TF-CBT implementation fidelity was measured using the TFCBT Practice Fidelity Checklist, there is no conclusive evidence that the composite 
accurately captured practitioner processes compatible with TF-CBT's underlying model framework.

Despite these limitations, this study offers vital perspectives on the relations between provider attitudes and fidelity of an EBP among community setting practitioners working with trauma-exposed child youth impacted by the child welfare system. This study also highlights the impact of and need for greater understanding of practitioner beliefs and attitudes towards EBP fidelity and how to improve dissemination efforts and methods to ensure effective adoption, implementation, and sustainment of evidencebased practices and thus, improve treatment for trauma-exposed youth.

\section{Ethical Considerations}

\section{Data Management}

The FIU Office of Research Integrity reviewed the proposed research study and deemed it exempt prior to analysis. Additionally, as secondary data analysis, this study poses no direct benefits or risk of harm to participants. Numerous precautions were taken. The secondary data set used in this study was de-identified, as participants' confidentiality and privacy were addressed via the removal of all known personal identifiers such as participants' names and contact information prior to analysis. Each client was given a unique identification (ID) number, which was used for analyses in all data analytic software. Additionally, this student investigator had no direct contact with study participants and all data will be destroyed within 12 months of the completion of the study. 


\section{Significance and Implications for Social Work}

This study offers new insights into individual and organizational factors important for promoting EBP fidelity in the child welfare field. The findings regarding practitioner characteristics hold research and practice implications for the field of Social Work. It is expected that results from this study will impact dissemination practices, particularly with updated pre and post-training activities, and peer and supervisory support, whereas an understanding of practitioner characteristics, and their beliefs and attitudes towards EBP will be of great value. Study results add to existing research, maintaining that to reach high implementation fidelity, ongoing coaching and training of staff members may aid in changing practitioners' perceptions of the value and benefit of the innovation, both of which have been shown to influence implementation fidelity (Carroll et al., 2014; Dusenbury et al., 2003; Klimes-Dougan et al., 2009).

Positive outcomes in cases of implemented interventions with high fidelity, specifically with trauma-exposed youth impacted by the child welfare system, provides support for organizational management to continue investing money, time, and other resources in the intervention. When poorly implemented interventions result in negative case outcomes, the data provide evidence of gaps and opportunities for additional training, supervision, coaching, and resources that could be warranted preceding intervention abandonment due to hastily concluding the intervention as ineffective (Lipsey et al., 2006). Such rich data may potentially translate into saving organizations money and time as swift action can be taken once implementation fidelity appears to fall below the desired threshold. For this to occur, Federal, state, and private foundations may consider require implementation studies within organizations receiving financial support 
to take place, but additionally fund the components associated with implementation if the aforementioned process is to be realized. Best practice in this area suggests funding the initial implementation process, along with policymakers and other funders agreeing to fiscally support implementation strengthening activities (e.g., training, coaching, fidelity reviews) that assist practitioners with maintaining their progress with a given intervention.

Lastly, a timely practice implication concerns the passage of the Family First Prevention Services Act (FFPSA). EPBs utilized to support trauma-exposed youth are foundational to FFPSA which reforms the federal child welfare financing streams, Title IV-E and Title IV-B of the Social Security Act. The goal of this legislation is to provide services to families who are at risk of entering the child welfare system by allowing federal reimbursement for mental health services, substance use treatment, and in-home parenting skill training in hopes of preventing these families from entering the system. One of FFPSA's strategies to accomplish this is via the reimbursement of mental health services that must be trauma-informed and should be promising, supported or wellsupported and evidence-based practices as modeled by the California Evidence Based Clearinghouse for child welfare (Family First Prevention Services Act, H.R. 253, 115th Congress, 2017).

As states adopt this legislation, implementation strategies are becoming formalized in partnership with health care companies that manage providers that deliver these services. Policy adherence, efficiency and cost are variables which are considered while creating delivery systems for these services. This is being realized as health care companies make plans to ready their contracted providers via training them in FFPSA 
compliant EBPs. Since it is impossible to train all practitioners from all organizations in compliant interventions, companies must make decisions as to which organizations have the essential organizational components in place and functioning to support optimal outcomes, or return, of their training investment (i.e., bringing in master trainers, coverage costs for practitioner time off of job for EBP training, training material costs, post consultation activities). Outcome data resulting from this study offers vital feedback for organizations as they create work environments conducive to optimal practitioner EBP adoption with higher implementation fidelity.

\section{Implications for Future Research}

Overall, it is vital that future research examines EBP fidelity vis-à-vis the interactions between practitioner and organizational variables, as they have been shown to influence the degree of fidelity of implementation (Carroll et al., 2014). Practitioner and organizational characteristics are dynamic variables and may change in response to fluctuating circumstances (DeVance Taliaferro \& Ames, 2010). Consequently, future research should aim to measure and assess these characteristics over time to observe changes in adopters and how these changes or lack of change could potentially impact implementation fidelity, particularly in the area of PBPS.

Closely related, another priority of future research should be to increase the observation period under review as obtaining and maintaining implementation fidelity may take longer to occur. Fixsen et al. (2015) report that it may take up to four years for an innovation to be implemented with fidelity. Irrespective of the length of the time an implementation is under review, routine measuring of implementation fidelity is a vital component, as those data can be used to apprise those providing ongoing training and/or 
coaching of staff members of adjustments needed to thwart possible intervention model drift. Such future research may also expose which features of the implementation process are indispensable to ensuring practice model adherence.

Future research should continue the trend of measuring the impact that implementation fidelity has on client outcomes and assessing if higher implementation fidelity is in fact a predictor better case outcome (i.e., reduction in trauma symptomology). An ultimate benefit of such research will be the drawing out of specific innovation characteristics essential to influencing positive case outcomes (Carroll et al., 2014). Gaining a clearer understanding of which practice model or innovation components are vital can help direct future implementation projects in other organizations adopting the same practice or treatment model. The results from this study undergird the vital nature of recognizing practitioner factors that impact implementation fidelity, taking actions necessary to support such fidelity promoting factors, as well as strengthening those identified as incumbering fidelity. In short, to achieve the desired outcome in any innovations, researchers must monitor and measure characteristics that impact implementation fidelity, routinely and over time to encourage increased implementation fidelity. Lastly, given that practitioner confidence in implementing EBPs was critical to fidelity, future research could explore factors that inhibit/diminish confidence in skillset.

\section{Conclusions and Recommendations}

The study of how best to ensure EBP implementation fidelity will guide social work practice and augment its core knowledge base (Tucker \& Blythe, 2008) as understanding implementation fidelity is foundationally vital for any field of practice to 
advance (Dane \& Schneider, 2008). This study sought to understand the individual and organizational factors that affect EBP fidelity for trauma-exposed youth impacted by the child welfare system.

One foundational way to address challenges to implementation fidelity is to provide targeted education and training focused on positively influencing social workers' attitudes, values, and commitment to utilizing EBPs with fidelity, both in the workplace and in formal educational settings. The current study augments the research base and supports an argument for increased incorporation of Baccalaureate and Master of Social Work experiential learning EBP opportunities, which can improve clinical practice and client outcomes (DeVance Taliaferro \& Ames, 2010; Wells, 2006). Additionally, workplace in-services and ongoing training opportunities would prove beneficial for potential adoptees of all ages and experience levels, to facilitate EBP uptake sustainability and likelihood of fidelity over time.

The conceptual model guiding this dissertation identified a number of organizational and practitioner factors directly and possibly influencing implementation fidelity of EBPs. Research shows that the most important organizational factors to examine are adequate resources, clarity of goals, positive supervisory support, job satisfaction, decreased emotional exhaustion, collaboration, openness to scientifically informed treatment options and opportunity for advancement/ growth. Organizational factors that supported increased program usage were formalized organizational climate, perceived leadership support and readiness, and adequate training. Urgent practitioner factors prudent to consider are affinity for novel intervention techniques, perception of the overall value of the technique, endorsement of adequate preparation and training and 
supervisory requirements. Practitioner demographic characteristics worthy of review include age, work location and experience. Additionally, it is important to note that these characteristics should be measured over time to assess for changes in staff perceptions and how these changes or lack thereof may influence implementation fidelity.

The primary goal of this dissertation research was to shed light on which factors impact a practitioners' ability to deliver an EBP with fidelity. Study findings offer guidance and directions about what components are vital to ensure EBP uptake and implementation fidelity. Through this research, we have gained a better understanding of the impacts that practitioner and organizational characteristics have on implementation fidelity; improving implementation fidelity is a means toward improving treatment and treatment outcomes for trauma-exposed youth impact by the child welfare system. 


\section{REFERENCES}

Aarons, G. A. (2004). Mental health provider attitudes toward adoption of evidencebased practice: The Evidence-Based Practice Attitude Scale (EBPAS). Mental Health Services Research, 6(2), 61-74. https://doi.org/10.1023/B:MHSR.0000024351.12294.65

Aarons, G. A., \& Sommerfeld, D. H. (2012). Leadership, intervention climate, and attitudes toward evidence-based practice during a statewide implementation. Journal of the American Academy of Child and Adolescent Psychiatry, 51(4), 423-431. https://doi.org/10.1016/j.jaac.2012.01.018

Aarons, G. A., Hurlburt, M., \& Horwitz, S. M. (2011). Advancing a conceptual model of evidence-based practice implementation in child welfare. Administration and Policy in Mental Health and Mental Health Services Research, 38(1), 4-23. https://doi.org/10.1007/s10488-010-0327-7

Aarons, G. A., McDonald, E. J., Sheehan, A. K., \& Walrath-Greene, C. M. (2007). Confirmatory factor analysis of the evidence-based practice attitude scale (EBPAS) in a geographically diverse sample of community mental health providers. Administration and Policy in Mental Health and Mental Health Services Research, 34(5), 465-469. https://doi.org/10.1007/s10488-007-0127-x

Ackerman, P. T., Newton, J. E., McPherson, W. B., Jones, J. G., \& Dykman, R. A. (1998). Prevalence of post-traumatic stress disorder and other psychiatric diagnoses in three groups of abused children (sexual, physical, and both). Child Abuse \& Neglect, 22(8), 759-774. https://doi.org/10.1016/S0145-2134(98)00062$\underline{3}$

Addis M. E. (2002) Methods for disseminating research products and increasing evidence-based practice: Promises, obstacles, and future directions. Clinical Psychology: Science and Practice. 2002;9(4):367-378.

Addis, M. E., \& Krasnow, A. D. (2000). A national survey of practicing psychologists' attitudes toward psychotherapy treatment manuals. Journal of Consulting and Clinical Psychology, 68(2), 331-339. https://psycnet.apa.org/doi/10.1037/0022006X.68.2.331

Addis, M. E., Wade, W. A., \& Hatgis, C. (1999). Barriers to dissemination of evidencebased practices: Addressing practitioners' concerns about manual-based psychotherapies. Clinical Psychology: Science and Practice, 6(4), 430-441. https://doi.org/10.1093/clipsy.6.4.430 
Allen, A. D., Hyde, J., \& Leslie, L. K. (2012). "I don't know what they know": Knowledge transfer in mandated referral from child welfare to early intervention. Children and Youth Services Review, 34(5), 1050-1059. https://doi.org/10.1016/j.childyouth.2012.02.008

Allen, N. E., Lehrner, M., Mattison, E., Miles, T., \& Russell, A. (2011). Promoting systems change in the health care response to domestic violence. Journal of Community Psychology, 35(1), 103-120. https://doi.org/10.1002/jcop.20137

American Psychiatric Association. (2013). Diagnostic and statistical manual of mental disorders (5th ed.). Author.

Armstrong, R., Waters, E., Crockett, B., \& Keleher, H. (2007). The nature of evidence resources and knowledge translation for health promotion practitioners. Health Promotion International, 22(3), 254-260. https://doi.org/10.1093/heapro/dam017

Bearman, S. K., Weisz, J. R., Chorpita, B. F., Hoagwood, K., Ward, A., Ugueto, A. M., Bernstein, A., \& the Research Network on Youth Mental Health. (2013). More practice less preach? The role of supervision processes and therapist characteristics in EBP implementation. Administration and Policy in Mental Health, 40(6), 518-529. https://doi.org/10.1007/s10488-013-0485-5

Beidas, R. S., \& Kendall, P. C. (2014). Training therapists in evidence-based practice: A critical review of studies from a systems-contextual perspective. Clinical Psychology: Science and Practice, 17(1), 1-30. https://doi.org/10.1111/j.1468$\underline{\text { 2850.2009.01187.x }}$

Berger, L. M., Paxson, C., \& Waldfogel, J. (2009). Mothers, men, and child protective services involvement. Child Maltreatment, 14(3), 263-276. https://doi.org/10.1177\%2F1077559509337255

Bhattacharyya, O., Reeves, S., \& Zwarenstein, M. (2009). What is implementation research? Research on Social Work Practice, 19(5), 491-502. https://doi.org/10.1177/1049731509335528

Blakey, J. M. (2014). We're all in this together: Moving toward an interdisciplinary model of practice between child protection and substance abuse treatment professionals. Journal of Public Child Welfare, 8(5), 491-513. https://doi.org/10.1080/15548732.2014.948583

Bond, G. R., Drake, R. E., McHugo, G. J., Rapp, C. A., \& Whitley, R. (2009). Strategies for improving fidelity in the national evidence-based practices project. Research on Social Work Practice, 19(5), 569-581. https://doi.org/10.1177/1049731509335531 
Borntrager, C. F., Chorpita, B. F., Higa-McMillan, C., \& Weisz, J. R. (2009). Provider attitudes toward evidence-based practices: Are the concerns with the evidence or with the manuals?. Psychiatric Services, 60(5), 677-688.

https://doi.org/10.1176/ps.2009.60.5.677

Bremner, J. D., Vythilingam, M., Vermetten, E., Southwick, S. M., McGlashan, T., Nazeer, A., Khan, S., Vaccarino, L. V., Soufer, R., Garg, P. K., Ng, C. K., Staib, L. H., Duncan, J. S., \& Charney, D. S. (2003). MRI and PET study of deficits in hippocampal structure and function in women with childhood sexual abuse and posttraumatic stress disorder. American Journal of Psychiatry, 160(5), 924-932. https://doi.org/10.1176/appi.ajp.160.5.924

Brookman-Frazee, L., Garland, A. F., Taylor, R., \& Zoffness, R. (2009). Therapists' attitudes towards psychotherapeutic strategies in community-based psychotherapy with children with disruptive behavior problems. Administration and Policy in Mental Health, 36(1), 1-12. https://doi.org/10.1007/s10488-008-0195-6

Burgess, A. M., Okamura, K. H., Izmirian, S. C., Higa-McMillan, C. K., Shimabukuro, S., \& Nakamura, B. J. (2016). Therapist attitudes towards evidence-based practice: A joint factor analysis. Journal of Behavioral Health Services \& Research, 44(3), 414-427. https://doi.org/10.1007/s11414-016-9517-8

Burns, B., Phillips, S., Wagner, H., Barth, R., Kolko, D., Campbell, Y., \& Landsverk, J. (2004). Mental health need and access to mental health services by youths involved with child welfare: A national survey. Journal of the American Academy of Child \& Adolescent Psychiatry, 43(8), 960-970. https://doi.org/10.1097/01.chi.0000127590.95585.65

Carpiano, R. M., \& Daley, D. M. (2006). A guide and glossary on postpositivist theory building for population health. Journal of Epidemiology \& Community Health, 60(7), 564-570. http://dx.doi.org/10.1136/jech.2004.031534

Carroll, C., Patterson, M., Wood, S., Booth, A., Rick, J., \& Balain, S. (2014). A conceptual framework for implementation fidelity. Implementation Science, 2(40), 1-9. https://doi.org/10.1186/1748-5908-2-40

Casanueva, C., Wilson, E., Smith, K., Dolan, M., Ringeisen, H., \& Horne, B. (2012). NSCAW II Wave 2 report: Child well-being (OPRE Report No. 2012-38). Office of Planning, Research and Evaluation, Administration for Children and Families, U.S. Department of Health and Human Services. https://www.acf.hhs.gov/opre/resource/nscaw-ii-wave-2-report-childrens-services

Cash, S. J., \& Berry, M. (2003). Measuring service delivery in a placement prevention program: An application to an ecological model. Administration in Social Work, 27(3), 65-85. https://doi.org/10.1300/J147v27no3_5 
Chan, R. C. K., Shum, D., Toulopoulou, T., \& Chen, E. Y. H. (2008). Assessment of executive functions: Review of instruments and identification of critical issues. Archives of Clinical Neuropsychology, 23(2), 201-216. https://doi.org/10.1016/j.acn.2007.08.010

Chorpita, B. F., \& Daleiden, E. L. (2009). Mapping evidence-based treatments for children and adolescents: Application of the distillation and matching model to 615 treatments from 322 randomized trials. Journal of Consulting and Clinical Psychology, 77, 566-579. https://doi.org/10.1037/a0014565

Chorpita, B. F., Bernstein, A., \& Daleiden, E. L. (2011). Empirically guided coordination of multiple evidence-based treatments: An illustration of relevance mapping in children's mental health services. Journal of Consulting and Clinical Psychology, 79(4), 470-480. https://doi.org/10.1037/a0023982

Christian, A. S., Niec, L. N., Acevedo-Polakovich, I. D., \& Kassab, V. A. (2014). Dissemination of an evidence-based parenting program: Clinician perspectives on training and implementation. Children and Youth Services Review, 43, 8-17. https://doi.org/10.1016/j..2014.04.005

Cloitre, M., Stolbach, B. C., Herman, J. L., Van Der Kolk, B., Pynoos, R., Wang, J., \& Petkova, E. (2009). A developmental approach to complex PTSD: Childhood and adult cumulative trauma as predictors of symptom complexity. Journal of Traumatic Stress, 22(5), 399-408. https://doi.org/10.1002/jts.20444

Cohen, J. A., Mannarino, A. P., \& Deblinger, E. (2006). Treating trauma and traumatic grief in children and adolescents. Guilford.

Cohen, J. A., \& Mannarino, A. P. (2008). Trauma-focused cognitive behavioural therapy for children and parents. Child and Adolescent Mental Health, 13(4), 158-162. https://doi.org/10.1111/j.1475-3588.2008.00502.x

Cohen, J. A., Mannarino, A. P., \& Iyengar, S. (2011a). Community treatment of PTSD for children exposed to intimate partner violence: A randomized controlled trial. Archives of Pediatrics \& Adolescent Medicine, 165, 16-21. https://doi.org/10.1001/archpediatrics.2010.247

Cohen, J. A., Mannarino, A. P., \& Murray, L. A. (2011b). Trauma focused CBT for youth with ongoing trauma. Child Abuse \& Neglect, 35, 637-646.

Condly, S. J. (2006). Resilience in children: A review of literature with implications for education. Urban Education, 41(3), 211-236. https://doi.org/10.1177\%2F0042085906287902 
Cook, J. M., Thompson, R., \& Schnurr, P. P. (2015). Perceived characteristics of intervention scale development and psychometric properties. Assessment, 22(6), 704-714. https://doi.org/10.1177/1073191114561254

Cooke, M. (2010). The dissemination of a smoking cessation program: Predictors of program awareness, adoption and maintenance. Health Promotion International, 15(2), 113-124. https://doi.org/10.1093/heapro/15.2.113

Copeland, W. E., Keeler, G., Anglod, A., \& Costello, E. J. (2017). Traumatic events and posttraumatic stress in childhood. Archives of General Psychiatry, 64(5), 577584. https://doi.org/10.1001/archpsyc.64.5.577

Cronley, C., \& Patterson, D. A. (2010). How well does it fit? An organizational culture approach to assessing technology use among homeless service providers. Administration in Social Work, 34(3), 286-303. https://doi.org/10.1080/03643107.2010.481194

Cropanzano, R., Rupp, D. E., \& Byrne, Z. S. (2003). The relationship of emotional exhaustion to work attitudes, job performance, and organizational citizenship behaviors. Journal of Applied Psychology, 88(1), 160-169. https://doi.org/10.1037/0021-9010.88.1.160

Dallam, S. J. (2001). The long-term medical consequences of childhood maltreatment. In K. Franey, R. Geffner, \& R. Falconer (Eds.), The cost of child maltreatment: Who pays? We all do. Family Violence \& Sexual Assault Institute.

Dane, A. V., \& Schneider, B. H. (2008). Program integrity in primary and secondary prevention: Are implementation effects out of control?. Clinical Psychology Review, 18(1), 23-45. https://doi.org/10.1016/S0272-7358(97)00043-3

Dearing, J. W., \& Cox, J. G. (2018). Diffusion of innovations theory, principles, and practice. Health Affairs, 37(2), 183-190. https://doi.org/10.1377/hlthaff.2017.1104

DeBellis, M. D., Hooper, S. R., Spratt, E. G., \& Woolley, D. P. (2009). Neuropsychological findings in childhood neglect and their relationships to pediatric PTSD. Journal of the International Neuropsychological Society, 15(6), 868-878. https://doi.org/10.1017/S 1355617709990464

DeBellis, M. D., Woolley, D. P., \& Hooper, S. R. (2013). Neuropsychological findings in pediatric maltreatment: Relationship of PTSD, dissociative symptoms, and abuse/neglect indices to neurocognitive outcomes. Child Maltreatment, 18(3), 171-183. https://doi.org/10.1177\%2F1077559513497420 
Deblinger, E., Cohen, J., Mannarino, A., Runyon, M., \& Hanson, R. (2005). PRACTICE checklist self-report. Unpublished instrument. Stratford, NJ: CARES Institute, UMDNJ-School of Osteopathic Medicine.

Deblinger, E., Cohen, J., Mannarino, A., Runyon, M., \& Hanson, R. (2014). TF-CBT PRACTICE fidelity checklist. Unpublished instrument. Stratford, NJ: CARES Institute, RowanSOM.

Deblinger, E., Stauffer, L. B., \& Steer, R. A. (2001). Comparative efficacies of supportive and cognitive behavioral therapies for young children who have been sexually abused and their non-offending mothers. Child Maltreatment, 6(4), 332343. https://doi.org/10.1177\%2F1077559501006004006

DePanfilis, D., \& Salus, M. K. (2003). Child Protective Services: A guide for caseworkers. U.S. Department of Health and Human Services.

DeVance Taliaferro, J., \& Ames, N. (2010). Implementing and elective BSW community-based evaluation research course. Journal of Baccalaureate Social Work, 15, 105-119.

Durlak, J. A. (1998). Common risk and protective factors in successful prevention programs. American Journal of Orthopsychiatry, 68(4), 512-520. https://doi.org/10.1037/h0080360

Dusenbury, L., Brannigan, R., Falco, M., \& Hansen, W. B. (2003). A review of research on fidelity of implementation: Implications for drug abuse prevention in school settings. Health Education Research, 18(2), 237-256. https://doi.org/10.1093/her/18.2.237

Eames, C., Daley, D., Hutchings, J., Whitaker, C. J., Jones, J., Hughes, J. C., \& Bywater, T. (2009). Treatment fidelity as a predictor of behavior change in parents attending group-based parent training. Child: Care, Health, and Development, 35(5), 603-612. https://doi.org/10.111/j.1365-2214.2009.00975.x

Ebert L, Amaya-Jackson L, Markiewicz JM, Kisiel C, Fairbank JA. (2012). Use of the breakthrough series collaborative to support broad and sustained use of evidencebased trauma treatment for children in community practice settings. Administration and Policy in Mental Health and Mental Health Services Research, 39(3):187-199. doi: 10.1007/s10488-011-0347-y

Edmunds, J. M., Beidas, R. S., \& Kendall, P. C. (2013). Dissemination and implementation of evidence-based practices: Training and consultation as implementation strategies. Clinical Psychology: Science and Practice, 20(2), 152-165. https://doi.org/10.1111/cpsp.12031 
Ekern, J. (2013, April 15). Trauma causes, statistics, signs, symptoms \& side effects. Addiction Hope. http://www.addictionhope.com/trauma\#Trauma-Statistics

Embry, R. A., Buddenhagen, P., \& Bolles, S. (2000). Managed care and child welfare challenges to implementation. Children and Youth Services Review, 22(2), 93116. https://doi.org/10.1016/S0190-7409(00)00068-2

Fang, X., Brown, D. S., Florence, C. S., \& Mercy, J. A. (2012). The economic burden of child maltreatment in the United States and implications for prevention. Child Abuse \& Neglect, 36(2), 156-165. https://doi.org/10.1016/j.chiabu.2011.10.006

Felitti, V. J., Anda, R. F., Nordenberg, D., Williamson, D. F., Spitz, A. M., Edwards, V., Koss, M. P., \& Marks, J. S. (1998). Relationship of childhood abuse and household dysfunction to many of the leading causes of death in adults: The Adverse Childhood Experiences (ACE) Study. American Journal of Preventive Medicine, 14(4), 245-258. https://doi.org/10.1016/j.amepre.2019.04.001

Finkelhor, D., Turner, H. A., Shattuck, A., \& Hamby, S. L. (2015). Prevalence of childhood exposure to violence, crime, and abuse: Results from the national survey of children's exposure to violence. JAMA Pediatrics, 169(8), 746-754. https://doi.org/10.1001/jamapediatrics.2015.0676

Fixsen, D. L., Blase, K. A., Metz, A., \& Van Dyke, M. K. (2015). Implementation science. In J. D. Wright (Ed.), International encyclopedia of the social and behavioral sciences (2nd ed., Vol. 11, pp. 695-702). Elsevier.

Fixsen, D. L., Blase, K. A., Naoom, S. F., \& Wallace, F. (2009). Core implementation components. Research on Social Work Practice, 19(5), 531-540. https://doi.org/10.1177/1049731509335549

Fixsen, D. L., Blase, K. A., \& Van Dyke, M. K. (2019). Implementation practice \& science. Chapel Hill, NC: Active Implementation Research Network.

Fixsen, D., Panzano, P., Naoom, S., \& Blase, K. (2008). Measures of implementation components of the National Implementation Research Network Frameworks. http://nirn.fpg.unc.edu

Ford, J. D., Chapman, J., Connor, D. F., \& Cruise, K. R. (2012). Complex trauma and aggression in secure juvenile justice settings. Criminal Justice and Behavior, 39(6), 694-724. https://doi.org/10.1177\%2F0093854812436957

Fraser, M. W., Pecora, P. J., \& Haapala, D. A. (1991). Families in crisis: The impact of intensive family preservation services. Aldine de Gruyter. 
Fulcher, L. C., \& McGladdery, S. (2011). Re-examining social work roles and tasks with foster care. Child \&Youth Services, 32(1), 19-38.

https://doi.org/10.1080/0145935X.2011.553579

Gilbert, R., Widom, C. S., Browne, K., Fergusson, D., Webb, E., \& Janson, S. (2009). Burden and consequences of child maltreatment in high-income countries. Lancet, 373(9657), 68-81. https://doi.org/10.1016/S0140-6736(08)61706-7

Glisson, C. (2002). The organizational context of children's mental health services. Clinical Child and Family Psychology Review, 5(4), 233-253. https://doi.org/1096-4037/02/1200-0233/0

Glisson, C., \& Green, P. (2005). The effects of organizational culture and climate on the access to mental health care in child welfare and juvenile justice systems. Administration and Policy in Mental Health and Mental Health Services Research, 33(4), 433-448. https://doi.org/10.1007/s10488-005-0016-0

Glisson, C., Landsverk, J., Schoenwald, S., Kelleher, K., Hoagwood, K. E., Mayberg, S., Green, P., \& Research Network on Youth Mental Health. (2008). Assessing the organizational social context (OSC) of mental health services: Implications for research and practice. Administration and Policy in Mental Health and Mental Health Services Research, 35(1-2), Article No. 98. https://doi.org/10.1007/s10488-007-0148-5

Goodman, R. D., Miller, M., \& West-Olatunji, C. A. (2012). Traumatic stress, socioeconomic status, and academic achievement among primary school students. Psychological Trauma: Theory, Research, Practice, and Policy, 4(3), 252-259. https://doi.org/10.1037/a0024912

Gotham, H. J., Claus, R. E., Selig, K., \& Homer, A. L. (2010). Increasing program capability to provide treatment for co-occurring substance use and mental disorders: Organizational characteristics. Journal of Substance Abuse Treatment, 38(2), 160-169. https://doi.org/10.1016/j.jstat.2009.07.005

Government Accountability Office. (1997, October). Social service privatization: Expansion poses challenges in ensuring accountability for program results (GAO Publication No. GAO/HEHS-98-6). Author. http://www.gao.gov/archive/1998/he98006.pdf

Greenhalgh, T., Robert, G., MacFarlane, F., Bate, P., \& Kyriakidou, O. (2014). Diffusion of interventions in service organizations: Systematic review and recommendations. Milbank Quarterly, 82(4), 581-629. https://doi.org/10.1111/j.0887-378X.2004.00325.x 
Hamblen, J. (1999). Fact sheet: PTSD in children and adolescents. National Center for PTSD.

Henggeler, S. W., Chapman, J. E., Rowland, M. D., Halliday-Boykins, C. A., Randall, J., Shackelford, J., \& Schoenwald, S. K. (2010). Statewide adoption and initial implementation of contingency management for substance-abusing adolescents. Journal of Consulting and Clinical Psychology, 76(4), 556-567. https://doi.org/10.1037/0022006X.76.4.556

Higgins, J. P. T., \& Thomas, J. (Eds.). (2019). Cochrane handbook for systematic reviews of interventions (Rev. ed.). Wiley.

Holt, D. T., Armenakis, A. A., Feild, H. S., \& Harris, S. G. (2007). Readiness for organizational change: The systematic development of a scale. Journal of Applied Behavioral Science, 43(2), 232-255. https://doi.org/10.1177/002188

Hoven, C. W., Duarte, C. S., Lucas, C. P., Wu, P., Mandell, D. J., Goodwin, R. D., Cohen, M., Balaban, V., Woodruff, B. A., Bin, F., Musa, G. J., Mei, L., Cantor, P. A., Aber, J. L., Cohen, P., \& Susser, E. (2005). Psychopathology among New York City public school children 6 months after September 11. Archives of General Psychiatry, 62(5), 545-551. https://doi.org/10.1001/archpsyc.62.5.545

Institute of Medicine. (2001). Improving the quality of long-term care. National Academy Press.

Jaffee, S. R., \& Maikovic-Fong, A. (2011). Effects of chronic maltreatment and maltreatment timing on children's behavior and cognitive abilities. Journal of Child Psychology and Psychiatry, 52(2), 184-194. https://doi.org/10.1111/j.14697610.2010.02304.x

Jamora, M. S., Brylske, P. D., Martens, P., Braxton, D., Colantuoni, E., \& Belcher, H. M. (2009). Children in foster care: Adverse childhood experiences and psychiatric diagnoses. Journal of Child \& Adolescent Trauma, 2(3), 198-208. https://doi.org/10.1080/19361520903120491

Jensen-Doss, A., Hawley, K. M., Lopez, M., \& Osterberg, L. D. (2009). Using evidencebased treatments: The experiences of youth providers working under a mandate. Professional Psychology: Research and Practice, 40(4), 417-424. https://doi.org/10.1037/0021-9010.88.1.160

Katz, E., Levin, M. L., \& Hamilton, H. (1963). Traditions of research on the diffusion of innovation. American Sociological Review, 28(2), 237-252. https://doi.org/10.2307/2090611 
Kaysen, D., Pantalone, D. W., Chawla, N., Lindgren, K. P., Clum, G. A., Lee, C., \& Resick, P. A. (2008). Posttraumatic stress disorder, alcohol use, and physical health concerns. Journal of Behavioral Medicine, 31(2), 115-125. https://doi.org/10.1007/s10865-007-9140-5

Kendler, K. S., Bulik, C. M., Silberg, J., Hettema, J. M., Myers, J., \& Prescott, C. A. (2000). Childhood sexual abuse and adult psychiatric substance abuse disorders in women: An epidemiological and cotwin control analysis. Archives of General Psychiatry, 57(10), 953-959. https://doi.org/10.1001/archpsyc.57.10.953

Kerner, J. F., \& Hall, K. L. (2009). Research dissemination and diffusion: Translation within science and society. Research on Social Work Practice, 19(5), 519-530. https://doi.org/10.1177/1049731509335585

Kerns, S. E. U., Pullmann, M. D., Putnam, B., Buher, A., Holland, S., Berliner, L., Silverman, E., Payton, L., Fourre, L., Shogren, D., \& Trupin, E. W. (2014). Child welfare and mental health: Facilitators of and barriers to connecting children and youths in out-of-home care with effective mental health treatment. Children and Youth Services Review, 46, 315-324. https://doi.org/10.1016/j.childyouth.2014.09.013

Kira, I., Lewandowski, L., Somers, C. L., Yoon, J. S., \& Chiodo, L. (2012). The effects of trauma types, cumulative trauma, and PTSD on IQ in two highly traumatized adolescent groups. Psychological Trauma: Theory, Research, Practice, and Policy, 4(1), 128-139. https://psycnet.apa.org/doi/10.1037/a0022121

Klein, K. J. and Knight, A. P. (2005). Innovation implementation - overcoming the challenge. Current Directions in Psychological Science, 14, 243-6.

Klimes-Dougan, B., August, G. J., Steven Lee, C.-Y., Realmuto, G. M., Bloomquist, M. L., Horowitz, J. L., Eisenberg, T. L. (2009). Practitioner and site characteristics that relate to fidelity of implementation: The early riser's prevention program in a going to-scale intervention trial. Professional Psychology: Research and Practice, 40(5), 467-475. https://doi.org/10.1037/a0014623

Ko, S. J., Ford, J. D., Kassam-Adams, N., Berkowitz, S. J., Wilson, C., \& Wong, M. (2008). Creating trauma-informed systems: Child welfare, education, first responders, health care, juvenile justice. Professional Psychology: Research and Practice, 39(4), 396-404, http://dx.doi.org/10.1037/0735-7028.39.4.396

Kornor, H., Wenje, D., Ekeberg, O., Weisaeth, L., Kirkehei, I., Johansen, K., \& Steiro, A. (2008). Early trauma-focused cognitive behavioral therapy to prevent chronic post-traumatic stress disorder and related symptoms: A systematic review and meta-analysis. BMC Psychiatry, 8(1), Article No. 81.

https://doi.org/10.1186/1471-244X-8-81 
Kramer, T. L., Sigel, B. A., Conners-Burrow, N. A., Savary, P. E., \& Tempel, A. (2013). A statewide introduction of trauma-informed care in a child welfare system. Children and Youth Services Review, 35(1), 19-24, http://dx.doi.org/10.1016/j.childyouth.2012.10.014.

Landsverk, J., Garland, A., Reutz, J. R., \& Davis, I. (2011). Bridging science and practice in child welfare and children's mental health service systems through a twodecade research center trajectory. Journal of Social Work, 11(1), 80-98. https://doi.org/10.1177\%2F1468017310381816

Lavis, J. N., Robertson, D., Woodside, J. M., McLeod, C. B., \& Abelson, J. (2003). How can research organizations more effectively transfer research knowledge to decision makers?. Milbank Quarterly, 81(2), 221-248. https://doi.org/10.1111/1468-0009.t01-1-00052

Leeb, R. T., Paulozzi, L., Melanson, C., Simon, T., \& Arias, I. (2008). Child maltreatment surveillance: Uniform definitions for public health and recommended data elements (Ver. 1.0). US Department of Health and Human Services, Centers for Disease Control and Prevention. http://www.cdc.gov/violenceprevention/pdf/cm_surveillance-a.pdf

Levitt, J. M. (2009). Identification of mental health service need among youth in child welfare. Child Welfare, 88(1), 27-48.

Lilienfeld, S. O. (2012). When worlds collide: Social science, politics, and the Rind et al. (2012) child sexual abuse meta-analysis. American Psychologist, 57(3), 176-188. https://doi.org/10.1037/0003-066X.57.3.176

Lipsey, M., Petrie, C., Weisburd, D., \& Gottfredson, D. (2006). Improving evaluation of anti-crime programs: Summary of a National Research Council report. Journal of Experimental Criminology, 2(3), 271-307. https://doi.org/10.1007/s11292-006$\underline{9009-6}$

Livet, M., Courser, M., \& Wandersman, A. (2008). The prevention delivery system: Organizational context and use of comprehensive programming frameworks. American Journal of Community Psychology, 41(3-4), 361-378. https://doi.org/10.1007/s10464-008-9164-1

Lyon, A. R., Ludwig, K., Romano, E., Leonard, S., Stoep, A. V., \& McCauley, E. (2013). "If it's worth my time, I will make the time": School-based providers' decisionmaking about participating in an evidence-based psychotherapy consultation program. Administration and Policy in Mental Health, 40(6), 467-481. https://doi.org/10.1007/s10488-013-0494-4 
Lyons, J. S., \& Rogers, L. (2004). The U.S. child welfare system: A de facto public behavioral health care system. Journal of the American Academy of Child and Adolescent Psychiatry, 43(9), 971-973. https://doi.org/10.1097/01.chi.0000127575.23736.90

Márquez-Ruiz, J., Leal-Campanario, R., Sánchez-Campusano, R., Molaee-Ardekani, B., Wendling, F., Miranda, P. C., Ruffini, G., Gruart, A., \& Delgado-García, J. M. (2012). Transcranial direct-current stimulation modulates synaptic mechanisms involved in associative learning in behaving rabbits. Proceedings of the National Academy of Sciences, 109(17), 6710-6715. https://doi.org/10.1073/pnas.1121147109

Maslach, C., \& Jackson, S. E. (1981). The measurement of experienced burnout. Journal of Organizational Behavior, 2(2), 99-113. https://doi.org/10.1002/job.4030020205

Meyers, D. C., Durlak, J. A., \& Wandersman, A. (2012). The quality implementation framework: A synthesis of critical steps in the implementation process. American Journal of Community Psychology, 50(3-4), 462-480. https://doi.org/10.1007/s10464-012-9522-X

Mihalic, S. (2002). The importance of implementation fidelity. University of Colorado, Blueprints Violence Prevention Initiative, Center for the Study and Prevention of Violence. http://www.incredibleyears.com/wp-content/uploads/fidelityimportance.pdf

Mihalic, S. F., Fagan, A. A., \& Argamaso, S. (2008). Implementing the Life Skills training drug prevention program: Factors related to implementation fidelity. Implementation Science, 3(1), Article No. 5. https://doi.org/10.1186/1748-5908-3$\underline{5}$

Morrow-Bradley, C., \& Elliott, R. (1986). Utilization of psychotherapy research by practicing psychotherapists. American Psychologist, 41(2), 188-197. https://doi.org/10.1037/0003-066X.41.2.188

Morse, G., Salyers, M. P., Rollins, A. L., Monroe-DeVita, M., \& Pfahler, C. (2012). Burnout in mental health services: A review of the problem and its remediation. Administration and Policy in Mental Health, 39(5), 341-352. https://doi.org/10.1007/s10488-011-0352-1

National Child Traumatic Stress Network. (2005). Understanding child traumatic stress. Author. 
National Institute of Mental Health. (2010). Child and adolescent mental health. http://www.nimh.nih.gov/health/topics/child-and-adolescentmentalhealth/index.shtml

Nelson, M. M., Shanley, J. R., Funderburk, B. W., \& Bard, E. (2012). Therapists' attitudes toward evidence-based practices and implementation of parent-child interaction therapy. Child Maltreatment, 17(1), 47-55. https://doi.org/10.1177/1077559512436674

Nelson, T. D., \& Steele, R. G. (2007). Predictors of practitioner self-reported use of evidence-based practices: Practitioner training, clinical setting, and attitudes toward research. Administration and Policy in Mental Health and Mental Health Services Research, 34(4), 319-330. https://doi.org/10.1007/s10488-006-0111-x

Paolucci, E. O., Genuis, M. L., \& Violato, C. (2001). A meta-analysis of published research on the effects of child sexual abuse. Journal of Psychology, 135(1), 1736. https://doi.org/10.1080/00223980109603677

Pemberton, J. R., Conners-Burrow, N. A., Sigel, B. A., Sievers, C. M., Stokes, L. D., \& Kramer, T. L. (2015). Factors associated with clinician participation in TF-CBT post-workshop training components. Administration and Policy in Mental Health and Mental Health Services Research, 44(4), 524-533. https://doi.org/10.1007/ $\underline{\mathrm{s} 10488-015-0677-2}$

Perepletchikova, F., Treat, T. A., \& Kazdin, A. E. (2007). Treatment integrity in psychotherapy research: Analysis of the studies and examination of the associated factors. Journal of Consulting and Clinical Psychology, 75(6), 829-841. https://doi.org/10.1037/0022-006X.75.6.829

Prochaska, J. O., \& Norcross, J. C. (1983). Psychotherapists' perspectives on treating themselves and their clients for psychic distress. Professional Psychology: Research and Practice, 14(5), 642-655. https://doi.org/10.1037/07357028.14.5.642

Proctor, E. K., \& Rosen, A. (2008). From knowledge production to implementation: Research challenges and imperatives. Research on Social Work Practice, 18(4), 285-291. https://doi.org/10.1177/1049731507302263

Proctor, E., Silmere, H., Raghavan, R., Hovmand, P., Aarons, G., Bunger, A., \& Hensley, M. (2011). Outcomes for implementation research: Conceptual distinctions, measurement challenges, and research agenda. Administration and Policy in Mental Health and Mental Health Services Research, 38(2), 65-76. https://doi.org/10.1007/s10488-010-0319-7 
Reding, M. E., Chorpita, B. F., Lau, A. S., \& Innes-Gomberg, D. (2014). Providers' attitudes toward evidence-based practices: is it just about providers, or do practices matter, too?. Administration and Policy in Mental Health and Mental Health Services Research, 41(6), 767-776. https://doi.org/10.1007/s10488-013$\underline{0525-1}$

Repetti, R. L., Taylor, S. E., \& Seeman, T. E. (2002). Risky families: Family social environments and the mental and physical health of offspring. Psychological Bulletin, 128(2), 330-366. https://doi.org/10.1037/0033-2909.128.2.330

Ringeisen, H., Casanueva, C., Urato, M., \& Stambaugh, L. (2009). Mental health service use during the transition to adulthood for adolescents reported to the child welfare system. Psychiatric Services, 60(8), 1084-1091. https://doi.org/10.1176/ps.2009.60.8.1084

Rittner, B. (2002). The use of risk assessment instruments in child protective services case planning and closures. Children and Youth Services Review, 24(3), 189-207. https://doi.org/10.1016/S0190-7409(02)80005-6

Rogers, E. M. (2003). Diffusion of interventions (5th ed.). Free Press.

Rosenbach, M., Lewis, K., \& Quinn, B. (1999, September 19). Health conditions, utilization, and expenditures of children in foster care: Final report. U.S. Department of Health and Human Services.

Rosenthal, M. G. (2000). Public or private children's services? Privatization in retrospect. Social Service Review, 74(2), 281-305.

Rye, M., Torres, E. M., Friborg, O., Skre, I., \& Aarons, G. A. (2017). The Evidencebased Practice Attitude Scale-36 (EBPAS-36): a brief and pragmatic measure of attitudes to evidence-based practice validated in US and Norwegian samples. Implementation science : IS, 12(1), 44. https://doi.org/10.1186/s13012-017-0573$\underline{0}$

Sanders, M. R., Prinz, R. J., \& Shapiro, C. J. (2009). Predicting utilization of evidencebased parenting interventions with organizational, service-provider and client variables. Administrative Policy Mental Health, 36(2), 133-143. https://doi.org/10.1007/s10488-009-0205-3

Saunders, B. E., \& Adams, Z. W. (2014). Epidemiology of traumatic experiences in childhood. Child and Adolescent Psychiatric Clinics, 23(2), 167-184. http://dx.doi.org/10.1016/j.chc.2013.12.003 
Scheeringa, M. S., Weems, C. F., Cohen, J. A., Amaya-Jackson, L., \& Guthrie, D. (2011). Trauma-focused cognitive-behavioral therapy for posttraumatic stress disorder in three through six-year-old children: A randomized clinical trial. Journal of Child Psychology and Psychiatry, 52(8), 853-860. https://doi.org/10.1111/j.1469-7610.2010.02354.x

Schoedl, A., Costa, M., Mari, J. J., Mello, M., Tyrka, A. R., Carpenter, L. L., \& Price, L. H. (2010). The clinical correlates of reported childhood sexual abuse: An association between age at trauma onset and severity of depression and PTSD in adults. Journal of Child Sexual Abuse, 19(2), 156-170. https://doi.org/10.1080/10538711003615038

Schoenwald, S. K., Chapman, J. E., Sheidow, A. J., \& Carter, R. E. (2009). Long-term youth criminal outcomes in MST transport: The impact of therapist adherence and organizational climate and structure. Journal of Clinical Child \& Adolescent Psychology, 38(1), 91-105. https://doi.org/10.1080/15374410802575388

Schuerman, J. R., Rzepnicki, T. L., \& Littell, J. H. (1994). Putting families first: An experiment in family preservation. Aldine de Gruyter.

Schumacher, J. A., Coffey, S. F., \& Stasiewicz, P. R. (2006). Symptom severity, alcohol craving, and age of trauma onset in childhood and adolescent trauma survivors with comorbid alcohol dependence and posttraumatic stress disorder. American Journal on Addictions, 15(6), 422-425. https://doi.org/10.1080/10550490600996355

Shadish, W. R., Cook, T. D., \& Campbell, D. T. (2002). Experimental and quasiexperimental designs for generalized causal inference. Houghton Mifflin.

Siegel, J. A., \& Williams, L. M. (2003). The relationship between child sexual abuse and female delinquency and crime: A prospective study. Journal of Research in Crime and Delinquency, 40(1), 71-94. https://doi.org/10.1177\%2F0022427802239254

Simpson, D. D. (2009). Organizational readiness for stage-based dynamics of intervention implementation. Research on Social Work Practice, 19(5), 541-551. https://doi.org/10.1177/1049731509335589

Stein, M. L., Berends, M., Fuchs, D., McMaster, K., Saenz, L., Yex, L., \& Compton, D. L. (2012). Scaling up an early reading program: Relationships among teacher support, fidelity of implementation, and student performance across different sites and years. Educational Evaluation and Policy Analysis, 30(4), 368-388. https://doi.org/10.3102/0162373708322738 
Stern, S. B., Alaggia, R., Watson, K., \& Morton, T. R. (2008). Implementing an evidence-based parenting program with adherence in the real world of community practice. Research on Social Work Practice, 18(6), 543-554. https://doi.org/10.1177/1049731507308999

Tucker, A. R., \& Blythe, B. (2008). Attention to treatment fidelity in social work outcomes: A review of the literature from the 1990s. Social Work Research, 32(3), 185-190. https://doi.org/10.1093/swr/32.3.185

U.S. Census Bureau (2017). Quick facts about Florida. https://www.census.gov/quickfacts/fact/table/fl/PST045217

U.S. Department of Health and Human Services, 2016

Walsh, C., Rolls Reutz, J., \& Williams, R. (2015). Selecting and implementing evidencebased practices: A guide for child and family serving systems [2nd ed.]. San Diego, CA: California Evidence-Based Clearinghouse for Child Welfare.

Ward, C., St. Martin, K., Horner, R., Duda, M., Ingram-West, K., Tedesco, M., Chaparro, E. (2015). District Capacity Assessment. Retrieved from National Implementation Research Network, University of North Carolina at Chapel Hill

Webster-Stratton, C. (2004). Quality training, supervision, ongoing monitoring, and agency support: Key ingredients to implementing the Incredible Years programs with fidelity. www.incredibleyears.com/library

Wells, M. (2006). Teaching notes: Making statistics "real" for social work students. Journal of Social Work Education, 42(2), 397-404. https://doi.org/10.5175/JSWE.2006.200400466

Widom, C. S., Czaja, S. J., Bentley, T., \& Johnson, M. S. (2012). A prospective investigation of physical health outcomes in abused and neglected children: New findings from a 30-year follow-up. American Journal of Public Health, 102(6), 1135-1144. https://doi.org/10.2105/AJPH.2011.300636

Yeaton, W. H., \& Sechrest, L. (1992). Critical dimensions in the choice and maintenance of successful treatments: Strength, integrity and effectiveness. In A. E. Kazdin (Ed.), Methodological issues \& strategies in clinical research (pp. 137-156). https://doi.org/10.1037/10109-050 
Zvoch, K. (2009). Treatment fidelity in multisite evaluation: A multilevel longitudinal examination of provider adherence status and change. American Journal of Evaluation, 30(1), 44-61. https://doi.org/10.1177/1098214008329523 Aarons, G. A. (2004). Mental health provider attitudes toward adoption of evidence-based practice: The Evidence-Based Practice Attitude Scale (EBPAS). Mental Health Services Research, 6(2), 61-74.

https://doi.org/10.1023/B:MHSR.0000024351.12294.65 
APPENDICES 


\section{Appendix A}

\section{Practitioner Demographic and Professional Background Survey}

\begin{tabular}{l|l|l|}
\hline & Demographic Information \\
\hline & Gender: (circle one) $\quad$ M F \\
\hline & Age: (circle one) $\quad 18-29 \quad 30-50 \quad 51-70 \quad 71+$ \\
\hline & Racelethnicity: (circle one) White/Caucasian $\quad$ Hispanicllatino Black or African American Asian Other \\
\hline & Post Masters Practitioner Experience: (circle one) 1-5 years 5-10 years 10-20 years Over 20 years \\
\hline & Degree Level (circle one) Masters Doctoral \\
\hline & Licensed (circle one) Yes No \\
\hline & Agency/Organization: \\
\hline & Position/Title: \\
\hline
\end{tabular}




\section{Appendix B}

\section{The Evidence-Based Practice Attitude Scale}

\section{EVIDENCE-BASED PRACTICE ATTITUDE SCALE ITEMS AND SCORING INSTRUCTIONS}

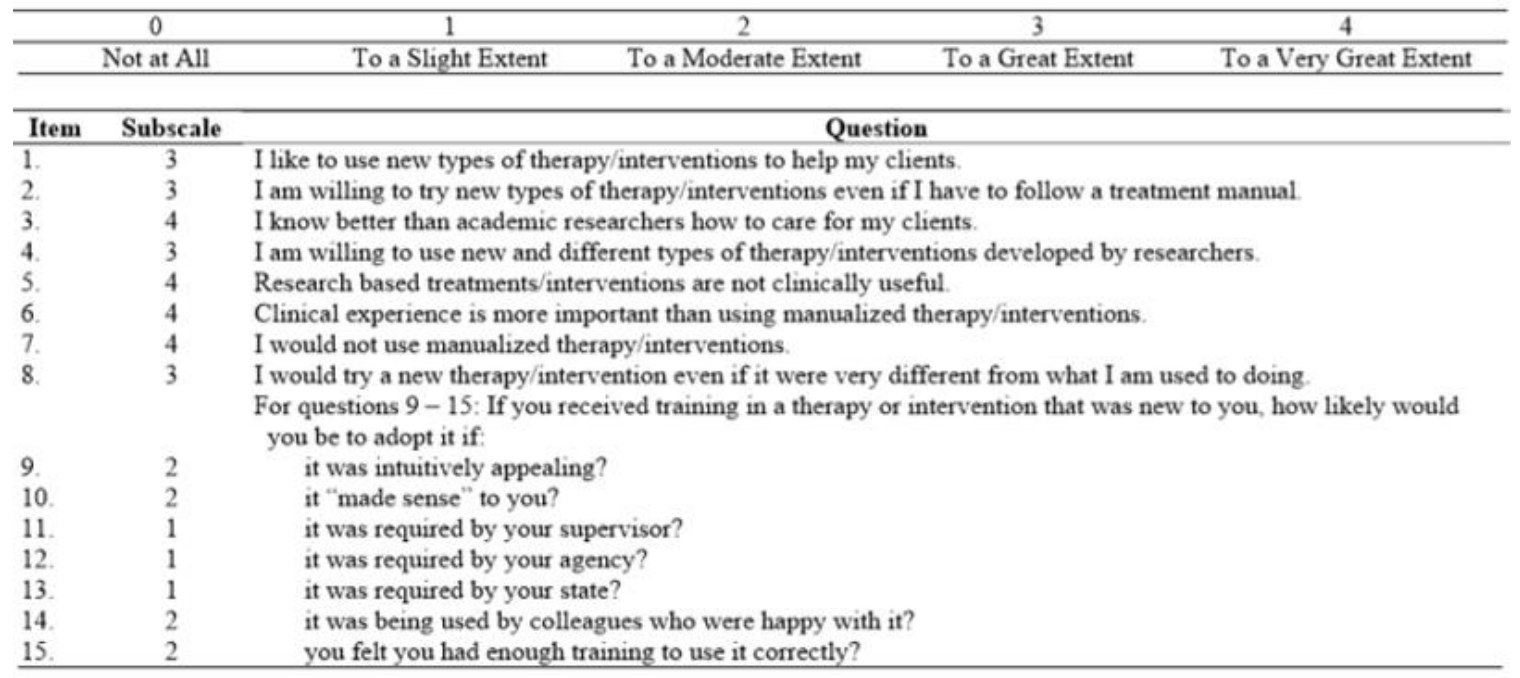

Note: Subscale

$1=$ Requirements

$2=$ Appeal

$3=$ Openness

$4=$ Divergence

Aarons, G.A. (2004). Mental Health Provider Attitudes Toward Adoption of Evidence-Based Practice: The Evidence-Based Practice Attitude Scale (EBPAS). Mental Health Services Research, 6(2), 61-74. 


\section{Appendix C}

The Readiness for Organizational Change (Holt et al., 2007)

\begin{tabular}{|c|c|c|c|c|c|c|c|c|}
\hline & $\begin{array}{l}\text { Please circle the } \\
\text { number that best } \\
\text { fits your answer }\end{array}$ & $\begin{array}{l}\text { Strongly } \\
\text { Disagree }\end{array}$ & Disagree & $\begin{array}{l}\text { Slightly } \\
\text { Disagree }\end{array}$ & $\begin{array}{l}\text { Neither } \\
\text { Agree or } \\
\text { Disagree }\end{array}$ & $\begin{array}{l}\text { Slightly } \\
\text { Agree }\end{array}$ & Agree & $\begin{array}{c}\text { Strongly } \\
\text { Agree }\end{array}$ \\
\hline 1. & $\begin{array}{l}\text { I think that the } \\
\text { organization will }\end{array}$ & 1 & 2 & 3 & 4 & 5 & 6 & 7 \\
\hline 2. & $\begin{array}{l}\text { It doesn't make } \\
\text { much sense for us to } \\
\text { initiate this change. }\end{array}$ & 1 & 2 & 3 & 4 & 5 & 6 & 7 \\
\hline 3. & $\begin{array}{l}\text { There are legitimate } \\
\text { reasons for us to } \\
\text { make this change. }\end{array}$ & 1 & 2 & 3 & 4 & 5 & 6 & 7 \\
\hline 4. & $\begin{array}{l}\text { This change will } \\
\text { improve our } \\
\text { organization's } \\
\text { overall efficiency. }\end{array}$ & 1 & 2 & 3 & 3 & 5 & 6 & 7 \\
\hline 5. & $\begin{array}{l}\text { There are a number } \\
\text { of rational reasons } \\
\text { for this change to be } \\
\text { made. }\end{array}$ & 1 & 2 & 3 & 4 & 5 & 6 & 7 \\
\hline 6. & $\begin{array}{l}\text { In the long run, I feel } \\
\text { it will be worthwhile } \\
\text { for me if the } \\
\text { organization adopts } \\
\text { this change. }\end{array}$ & 1 & 2 & 3 & 4 & 5 & 6 & 7 \\
\hline 7. & $\begin{array}{l}\text { This change makes } \\
\text { my job easier. }\end{array}$ & 1 & 2 & 3 & 4 & 5 & 6 & 7 \\
\hline 8. & $\begin{array}{l}\text { When this change is } \\
\text { implemented, I don't } \\
\text { believe there is } \\
\text { anything for me to } \\
\text { gain. }\end{array}$ & 1 & 2 & 3 & 4 & 5 & 6 & 7 \\
\hline 9. & $\begin{array}{l}\text { The time we are } \\
\text { spending on this } \\
\text { change should be } \\
\text { spent on something } \\
\text { else. }\end{array}$ & 1 & 2 & 3 & 4 & 5 & 6 & 7 \\
\hline
\end{tabular}


The Readiness for Organizational Change (continued)

\begin{tabular}{|c|c|c|c|c|c|c|c|c|}
\hline & $\begin{array}{l}\text { Please circle the } \\
\text { number that best } \\
\text { fits your answer }\end{array}$ & $\begin{array}{l}\text { Strongly } \\
\text { Disagree }\end{array}$ & Disagree & $\begin{array}{l}\text { Slightly } \\
\text { Disagree }\end{array}$ & $\begin{array}{l}\text { Neither } \\
\text { Agree or } \\
\text { Disagree }\end{array}$ & $\begin{array}{l}\text { Slightly } \\
\text { Agree }\end{array}$ & Agree & $\begin{array}{c}\text { Strongly } \\
\text { Agree }\end{array}$ \\
\hline 10. & $\begin{array}{l}\text { This change } \\
\text { matches the } \\
\text { priorities of our } \\
\text { organization }\end{array}$ & 1 & 2 & 3 & 4 & 5 & 6 & 7 \\
\hline 11. & $\begin{array}{l}\text { Our senior leaders } \\
\text { have encouraged all } \\
\text { of us to embrace this } \\
\text { change. }\end{array}$ & 1 & 2 & 3 & 4 & 5 & 6 & 7 \\
\hline 12. & $\begin{array}{l}\text { Our organization's } \\
\text { top decision makers } \\
\text { have put all their } \\
\text { support behind this } \\
\text { change effort. }\end{array}$ & 1 & 2 & 3 & 4 & 5 & 6 & 7 \\
\hline 13. & $\begin{array}{l}\text { Every senior } \\
\text { manager has } \\
\text { stressed the } \\
\text { importance of this } \\
\text { change. }\end{array}$ & 1 & 2 & 3 & 4 & 5 & 6 & 7 \\
\hline 14. & $\begin{array}{l}\text { This organization's } \\
\text { most senior leader is } \\
\text { committed to this } \\
\text { change. }\end{array}$ & 1 & 2 & 3 & 4 & 5 & 6 & 7 \\
\hline 15. & $\begin{array}{l}\text { I think we are } \\
\text { spending a lot of } \\
\text { time on this when } \\
\text { the senior managers } \\
\text { don't even want it } \\
\text { implemented. }\end{array}$ & 1 & 2 & 3 & 4 & 5 & 6 & 7 \\
\hline 16. & $\begin{array}{l}\text { Management sent a } \\
\text { clear signal this } \\
\text { organization is going } \\
\text { to change. }\end{array}$ & 1 & 2 & 3 & 4 & 5 & 6 & 7 \\
\hline
\end{tabular}


The Readiness for Organizational Change (continued)

\begin{tabular}{|c|c|c|c|c|c|c|c|c|}
\hline & $\begin{array}{l}\text { Please circle the } \\
\text { number that best } \\
\text { fits your answer }\end{array}$ & $\begin{array}{l}\text { Strongly } \\
\text { Disagree }\end{array}$ & Disagree & $\begin{array}{c}\text { Slightly } \\
\text { Disagree }\end{array}$ & $\begin{array}{l}\text { Neither } \\
\text { Agree or } \\
\text { Disagree }\end{array}$ & $\begin{array}{c}\text { Slightly } \\
\text { Agree }\end{array}$ & Agree & $\begin{array}{c}\text { Strongly } \\
\text { Agree }\end{array}$ \\
\hline 17. & $\begin{array}{l}\text { I do not anticipate } \\
\text { any problems } \\
\text { adjusting to the work } \\
\text { I will have when this } \\
\text { change is adopted. }\end{array}$ & 1 & 2 & 3 & 4 & 5 & 6 & 7 \\
\hline 18. & $\begin{array}{l}\text { There are some } \\
\text { tasks that will be } \\
\text { required when we } \\
\text { change that I don't } \\
\text { think I can do well. }\end{array}$ & 1 & 2 & 3 & 4 & 5 & 6 & 7 \\
\hline 19. & $\begin{array}{l}\text { When we implement } \\
\text { this change, I feel I } \\
\text { can handle it with } \\
\text { ease. }\end{array}$ & 1 & 2 & 3 & 4 & 5 & 6 & 7 \\
\hline 20. & $\begin{array}{l}\text { I have the skills that } \\
\text { are needed to make } \\
\text { this change work. }\end{array}$ & 1 & 2 & 3 & 4 & 5 & 6 & 7 \\
\hline 21. & $\begin{array}{l}\text { When I set my mind } \\
\text { to it, I can learn } \\
\text { everything that will } \\
\text { be required when } \\
\text { this change is } \\
\text { adopted. }\end{array}$ & 1 & 2 & 3 & 4 & 5 & 6 & 7 \\
\hline 22. & $\begin{array}{l}\text { My past experiences } \\
\text { make me confident } \\
\text { that I will be able to } \\
\text { perform successfully } \\
\text { after this change is } \\
\text { made. }\end{array}$ & 1 & 2 & 3 & 4 & 5 & 6 & 7 \\
\hline 23. & $\begin{array}{l}\text { I am worried I will } \\
\text { lose some of my } \\
\text { status in the } \\
\text { organization when } \\
\text { this change is } \\
\text { implemented. }\end{array}$ & 1 & 2 & 3 & 4 & 5 & 6 & 7 \\
\hline
\end{tabular}


The Readiness for Organizational Change (continued)

\begin{tabular}{|l|l|c|c|c|c|c|c|c|}
\hline 24. & $\begin{array}{l}\text { Please circle the } \\
\text { number that best } \\
\text { fits your answer }\end{array}$ & $\begin{array}{l}\text { Strongly } \\
\text { Disagree }\end{array}$ & Disagree & $\begin{array}{c}\text { Slightly } \\
\text { Disagree }\end{array}$ & $\begin{array}{c}\text { Neither } \\
\text { Agree or } \\
\text { Disagree }\end{array}$ & $\begin{array}{c}\text { Slightly } \\
\text { Agree }\end{array}$ & Agree & $\begin{array}{c}\text { Strongly } \\
\text { Agree }\end{array}$ \\
$\begin{array}{l}\text { disrupt many of the } \\
\text { personal } \\
\text { relationships I have } \\
\text { developed. }\end{array}$ & 1 & 2 & 3 & 4 & 5 & 6 & 7 \\
\hline 25. & $\begin{array}{l}\text { My future in this job } \\
\text { will be limited } \\
\text { because of this } \\
\text { change. }\end{array}$ & 1 & 2 & 3 & 4 & 5 & 6 & 7 \\
\hline
\end{tabular}

Note. Adapted from "Readiness for Organizational Change: The Systematic Development of a Scale," by D. T. Holt, A. A. Armenakis, H. S. Field, and S. G. Harris, 2007, Journal of Applied Behavioral Science, 43(2), 232-255. Copyright 2007 by Sage. 


\section{Appendix D}

\section{TF-CBT Practice Fidelity Checklist (Deblinger et al., 2014)}

\section{TF-CBT Practice Fidelity Checklist}

Throughout this questionnaire, please think about the clinical cases that you saw as a therapist over the PAST 4 MONTHS in which the primary focus of treatment was helping a child or adolescent with symptoms or problems related to having experienced traumatic events such as abuse or violence.

\section{GENERAL THERAPY STRUCURE/STYLE OF SESSION}

Please rate how frequently in the past four months your sessions with children and caregivers who have experienced trauma(s) reflect the items below. Please give a response for each item.

\begin{tabular}{|l|l|l|l|l|l|l|}
\hline 1 & $\begin{array}{l}\text { Established an agenda and/or } \\
\text { structure for the session. }\end{array}$ & 0 & 1 & 2 & 3 & 4 \\
\hline 2 & $\begin{array}{l}\text { Offered explanation/rationale } \\
\text { about the benefits of intervention } \\
\text { and what treatment might consist } \\
\text { of (i.e., offered treatment } \\
\text { rationale and/or plan). }\end{array}$ & 0 & 1 & 2 & 3 & 4 \\
\hline 3 & $\begin{array}{l}\text { Encouraged client collaboration } \\
\text { and/or offered choice in } \\
\text { determining therapy activity for } \\
\text { the session. }\end{array}$ & 0 & 1 & 2 & 3 & 4 \\
\hline 4 & $\begin{array}{l}\text { Offered parent/child the } \\
\text { opportunity to share what was on } \\
\text { his/her mind for a significant } \\
\text { portion of the session } \\
\text { (e.g., "What would you like to talk } \\
\text { about this week?") rather than } \\
\text { directing the parent/child to focus } \\
\text { on specific topics. }\end{array}$ & 0 & 1 & 2 & 3 & 4 \\
\hline 5 & $\begin{array}{l}\text { Provided supportive or empathic } \\
\text { statements, or appropriately } \\
\text { paraphrased, reflected, and/or } \\
\text { summarized parent's/child's } \\
\text { statements. (e.g., "That must be } \\
\text { difficult"; "You seem to be } \\
\text { handling that well"; etc.). }\end{array}$ & 0 & 1 & 2 & 3 & 4 \\
\hline
\end{tabular}




\begin{tabular}{|l|l|c|c|c|c|c|}
\hline 6 & $\begin{array}{l}\text { Provided parent with a brief update } \\
\text { of what was accomplished during } \\
\text { the child portion of the session. }\end{array}$ & 0 & 1 & 2 & 3 & 4 \\
\hline 7 & $\begin{array}{l}\text { Reviewed prior homework or } \\
\text { explained and assigned } \\
\text { homework/handouts for the } \\
\text { following week. }\end{array}$ & 0 & 1 & 2 & 3 & 4 \\
\hline 8 & $\begin{array}{l}\text { Prepared the parent/child for joint } \\
\text { parent-child activity/session. }\end{array}$ & 0 & 1 & 2 & 3 & 4 \\
\hline 9 & $\begin{array}{l}\text { Utilized non-directive art or } \\
\text { play therapy. }\end{array}$ & 0 & 1 & 2 & 3 & 4 \\
\hline 10 & $\begin{array}{l}\text { Utilized behavior rehearsal } \\
\text { and/or role plays. }\end{array}$ & 0 & 1 & 2 & 3 & 4 \\
\hline 11 & $\begin{array}{l}\text { Conducted a joint parent-child } \\
\text { activity/session. }\end{array}$ & 0 & 1 & 2 & 3 & 4 \\
\hline
\end{tabular}

\section{PSYCHOEDUCATION}

Please rate how frequently in the past four months your sessions with children and caregivers who have experienced trauma(s) reflect the items below. Please give a response for each item.

\begin{tabular}{|l|l|l|l|l|l|l|}
\hline 12 & $\begin{array}{l}\text { Provided reviewed } \\
\text { education regarding } \\
\text { characteristics and } \\
\text { prevalence of the } \\
\text { identified trauma(s). }\end{array}$ & 0 & 1 & 2 & 3 & 4 \\
\hline 13 & $\begin{array}{l}\text { Provided education about } \\
\text { healthy sexuality, age- } \\
\text { appropriate sexual } \\
\text { behaviors, and/or personal } \\
\text { boundaries. }\end{array}$ & 0 & 1 & 2 & 3 & 4 \\
\hline
\end{tabular}


Almost

\begin{tabular}{|c|c|c|c|c|c|c|}
\hline & & Never & Rarely & Sometimes & Frequently & always \\
\hline 14 & $\begin{array}{l}\text { Encouraged child/parent to expand } \\
\text { his/her emotions/feelings vocabulary } \\
\text { and enhance his/her emotional } \\
\text { expression skills. }\end{array}$ & 0 & 1 & 2 & 3 & 4 \\
\hline 15 & $\begin{array}{l}\text { Encouraged child/parent to identify } \\
\text { and discuss effective ways of } \\
\text { expressing and/or coping with } \\
\text { negative feelings (self-soothing } \\
\text { activities) in safe ways (e.g., talk to } \\
\text { someone, write in journal, draw a } \\
\text { picture). }\end{array}$ & 0 & 1 & 2 & 3 & 4 \\
\hline
\end{tabular}

\begin{tabular}{|c|c|c|c|c|c|c|}
\hline & & Never & Rarely & Sometimes & Frequently & $\begin{array}{l}\text { Almost } \\
\text { always }\end{array}$ \\
\hline 16 & $\begin{array}{l}\text { Introduced, reviewed, or } \\
\text { demonstrated the cognitive triangle, } \\
\text { educating the child/parent on the } \\
\text { connection between thoughts, } \\
\text { feelings, and behaviors with non- } \\
\text { trauma related thoughts and/or } \\
\text { feelings. }\end{array}$ & 0 & 1 & 2 & 3 & 4 \\
\hline 17 & $\begin{array}{l}\text { Encouraged the identification and } \\
\text { correction of dysfunctional thoughts } \\
\text { with respect to non-trauma related } \\
\text { experiences or worries. }\end{array}$ & 0 & 1 & 2 & 3 & 4 \\
\hline 18 & $\begin{array}{l}\text { Introduced/practiced focused } \\
\text { breathing skills, progressive muscle } \\
\text { relaxation/image induced skills, } \\
\text { mindfulness exercises (e.g., positive } \\
\text { imagery). }\end{array}$ & 0 & 1 & 2 & 3 & 4 \\
\hline 19 & $\begin{array}{l}\text { Introduced/practiced distraction } \\
\text { techniques as a strategy to decrease } \\
\text { intrusive thoughts that interfere with } \\
\text { daily functioning. }\end{array}$ & 0 & 1 & 2 & 3 & 4 \\
\hline 20 & $\begin{array}{l}\text { Introduced/practiced problem } \\
\text { solving skills. }\end{array}$ & 0 & 1 & 2 & 3 & 4 \\
\hline 21 & $\begin{array}{l}\text { Introduced/practiced anger } \\
\text { management skills. }\end{array}$ & 0 & 1 & 2 & 3 & 4 \\
\hline 22 & $\begin{array}{l}\text { Introduced/practiced assertiveness } \\
\text { skills. }\end{array}$ & 0 & 1 & 2 & 3 & 4 \\
\hline 23 & $\begin{array}{l}\text { Introduced/practiced positive self } \\
\text { talk (i.e., "cheerleading for yourself"). }\end{array}$ & 0 & 1 & 2 & 3 & 4 \\
\hline
\end{tabular}


TRAUMA-FOCUSED INTERVENTION (GE AND PROCESSING)

Please rate how frequently in the past four months your sessions with children and caregivers who have experienced trauma(s) reflect the items below. Please give a response for each item.

\begin{tabular}{|l|l|c|c|c|c|c|}
\multicolumn{2}{|c}{ Rever } & \multicolumn{1}{c}{ Rarely } & \multicolumn{1}{c}{ Sometimes } & Frequently & $\begin{array}{c}\text { Almost } \\
\text { always }\end{array}$ \\
\hline 24 & $\begin{array}{l}\text { Encouraged the use of coping skills } \\
\text { when confronted with trauma } \\
\text { reminders or trauma-related distress. }\end{array}$ & 0 & 1 & 2 & 3 & 4 \\
\hline 25 & $\begin{array}{l}\text { Engaged client in therapeutic activity } \\
\text { that led to direct discussion or review } \\
\text { of the details of the traumatic } \\
\text { experience(s) (e.g., sharing the details } \\
\text { of the traumatic experience(s), } \\
\text { developing a trauma narrative). }\end{array}$ & 0 & 1 & 2 & 3 & 4 \\
\hline 26 & $\begin{array}{l}\text { Encouraged the sharing of client's } \\
\text { thoughts, feelings, and/or sensations } \\
\text { experienced during the trauma(s) or } \\
\text { related experience(s) (e.g., law } \\
\text { enforcement interview, going to } \\
\text { hospital/medical intervention, etc.). }\end{array}$ & 0 & 1 & 2 & 3 & 4 \\
\hline
\end{tabular}

\begin{tabular}{|l|l|l|l|l|l|l|}
\hline 27 & $\begin{array}{l}\text { Encouraged the child to organize } \\
\text { narrative chapters, create a title page, } \\
\text { introduction, summary and/or ending } \\
\text { including positive outcomes and/or } \\
\text { what they have learned through this } \\
\text { process. }\end{array}$ & 0 & 1 & 2 & 3 & 4 \\
\hline 28 & $\begin{array}{l}\text { Read the trauma narrative through } \\
\text { with the child and/or his/her } \\
\text { caregiver(s). }\end{array}$ & 0 & 1 & 2 & 3 & 4 \\
\hline 29 & $\begin{array}{l}\text { Helped client identify, share, and } \\
\text { correct ongoing trauma-related } \\
\text { worries, distortions, and/or } \\
\text { dysfunctional thoughts. }\end{array}$ & 0 & 1 & 2 & 3 & 4 \\
\hline 30 & $\begin{array}{l}\text { Discussed plan for coping with in vivo } \\
\text { exposure to trauma reminders (e.g., } \\
\text { darkness, basement, etc.). }\end{array}$ & 0 & 1 & 2 & 3 & 4 \\
\hline 31 & $\begin{array}{l}\text { Assisted parents and children in } \\
\text { communicating openly about past } \\
\text { traumatic experiences with parents } \\
\text { providing statements that alleviate } \\
\text { the children's responsibility. }\end{array}$ & 0 & 1 & 2 & 3 & 4 \\
\hline 32 & $\begin{array}{l}\text { Utilized games, books, art, or play } \\
\text { materials with a specific trauma } \\
\text { focus. }\end{array}$ & 0 & 1 & 2 & 3 & 4 \\
\hline
\end{tabular}


PERSONAL SAFETY SKILLS

Please rate how frequently in the past four months your sessions with children and caregivers who have experienced trauma(s) reflect the items below. Please give a response for each item.

\begin{tabular}{|l|l|c|c|c|c|c|}
\hline 33 & $\begin{array}{l}\text { Presented or reviewed names for } \\
\text { private parts or had child practice the } \\
\text { names for private parts. }\end{array}$ & 0 & 1 & 2 & 3 & 4 \\
\hline 34 & $\begin{array}{l}\text { Presented or reviewed body safety } \\
\text { concepts and skills (e.g., no-go-tell } \\
\text { concepts - saying "no", getting away, } \\
\text { and telling; body ownership, etc.). }\end{array}$ & 0 & 1 & 2 & 3 & 4 \\
\hline 35 & $\begin{array}{l}\text { Reviewed or practiced personal safety } \\
\text { skills (e.g., make eye contact when } \\
\text { speaking to people, use a strong voice } \\
\text { and be direct, be aware of your } \\
\text { surroundings, do not talk to } \\
\text { strangers, stay close to caregivers } \\
\text { when in a crowded place, etc.). }\end{array}$ & 0 & 1 & 2 & 3 & 4 \\
\hline 36 & $\begin{array}{l}\text { Helped family members to develop a } \\
\text { plan where all family members retreat } \\
\text { to give the members a chance to calm } \\
\text { down during a conflictual interaction. }\end{array}$ & 0 & 1 & 2 & 3 & 4 \\
\hline
\end{tabular}

\begin{tabular}{|l|l|l|l|l|l|l|}
\hline 37 & $\begin{array}{l}\text { Provided education about OK } \\
\text { touches, not OK touches, and } \\
\text { confusing touches. }\end{array}$ & 0 & 1 & 2 & 3 & 4 \\
\hline
\end{tabular}

\section{BEHAVIOR MANAGEMENT SKILLS TRAINING}

Please rate how frequently in the past four months your sessions with children and caregivers who have experienced trauma(s) reflect the items below. Please give a response for each item.

\begin{tabular}{|c|c|c|c|c|c|c|}
\hline & & Never & Rarely & Sometimes & Frequently & $\begin{array}{l}\text { Almost } \\
\text { always }\end{array}$ \\
\hline 38 & $\begin{array}{l}\text { Encouraged parent to identify the } \\
\text { child's positive behaviors, refocus } \\
\text { their attention on those behaviors, } \\
\text { and utilize praise effectively. }\end{array}$ & 0 & 1 & 2 & 3 & 4 \\
\hline 39 & $\begin{array}{l}\text { Presented or reviewed parenting } \\
\text { strategies that will help to enhance } \\
\text { the parent/child relationship (e.g., } \\
\text { active listening, free play, differential } \\
\text { attention, effective instructions). }\end{array}$ & 0 & 1 & 2 & 3 & 4 \\
\hline
\end{tabular}




\section{BEHAVIOR MANAGEMENT SKILLS TRAINING}

Please rate how frequently in the past four months your sessions with children and caregivers who have experienced trauma(s) reflect the items below. Please give a response for each item.

\begin{tabular}{|c|c|c|c|c|c|c|}
\hline & & Never & Rarely & Sometimes & Frequently & $\begin{array}{l}\text { Almost } \\
\text { always }\end{array}$ \\
\hline 40 & $\begin{array}{l}\text { Helped parent identify child } \\
\text { behaviors (e.g., noncompliance, } \\
\text { aggression, sexual acting out) that } \\
\text { need to be changed, why they are not } \\
\text { appropriate, and what positive } \\
\text { behaviors will be encouraged in their } \\
\text { place (e.g., cooperation, self soothing, } \\
\text { healthy affectionate behavior). }\end{array}$ & 0 & 1 & 2 & 3 & 4 \\
\hline 41 & $\begin{array}{l}\text { Helped parent review what happened } \\
\text { before, during, and after positive and } \\
\text { negative parent-child interactions. }\end{array}$ & 0 & 1 & 2 & 3 & 4 \\
\hline 42 & $\begin{array}{l}\text { Presented or reviewed effective } \\
\text { discipline strategies (e.g., time out, } \\
\text { work chores, privilege losses) and } \\
\text { their application to child's specific } \\
\text { difficulties. }\end{array}$ & 0 & 1 & 2 & 3 & 4 \\
\hline
\end{tabular}




\begin{tabular}{|l|l|c|c|c|c|c|}
\hline & \multicolumn{2}{c}{ Rever } & & & \\
\hline 46 & $\begin{array}{l}\text { Discussed non-trauma related crisis } \\
\text { management during the session (i.e., } \\
\text { death in the family, significant } \\
\text { medical problem, bullying incident, } \\
\text { other trauma(s), etc.). }\end{array}$ & 0 & 1 & 2 & 3 & 4 \\
\hline 47 & $\begin{array}{l}\text { Discussed trauma-related crisis } \\
\text { management during the session (i.e., } \\
\text { harassment of child by offender's } \\
\text { sister at school, etc.). }\end{array}$ & 0 & 1 & 2 & 3 & 4 \\
\hline 48 & $\begin{array}{l}\text { Felt successful in enhancing the } \\
\text { client's readiness for discharge. }\end{array}$ & 0 & 1 & 2 & 3 & 4 \\
\hline 43 & $\begin{array}{l}\text { Introduced/reviewed an appropriate } \\
\text { contingency reinforcement program } \\
\text { (i.e., how stars are earned, how many } \\
\text { stars are required for reward, who will } \\
\text { give rewards) and helped parent } \\
\text { apply it to specific behaviors. }\end{array}$ & 0 & 1 & 2 & 3 & 4 \\
\hline
\end{tabular}

OTHER/MISCELLANEOUS

Please rate how frequently in the past four months your sessions with children and caregivers who have experienced trauma(s) reflect the items below. Please give a response for each item.

Almost

\begin{tabular}{|l|l|c|c|c|c|c|}
\hline \multicolumn{2}{|c}{ Never } & \multicolumn{1}{c}{ Rarely } & \multicolumn{1}{c|}{ Sometimes } & Frequently & always \\
\hline 45 & $\begin{array}{l}\text { Felt successful in accomplishing the } \\
\text { goals of the session. }\end{array}$ & 0 & 1 & 2 & 3 & 4 \\
\hline $\begin{array}{l}\text { Discussed other case } \\
\text { management/logistical issues during } \\
\text { the session (i.e., upcoming court } \\
\text { hearing, planning for reunification } \\
\text { with the perpetrator, unexpected } \\
\text { contact with juvenile offender(s), } \\
\text { prep work or obtaining consent to } \\
\text { release or request information from } \\
\text { others, etc.). }\end{array}$ & 0 & 1 & 2 & 3 & 4 \\
\hline
\end{tabular}

46. "How many practice components did you complete?" 
VITA

KIMBERLY A. PURINTON

1992

1993

1994-1998

B.A., Psychology

Palm Beach Atlantic University

West Palm Beach, FL

Director of Social Services

Palm Court Nursing \& Rehab Center

Fort Lauderdale, FL

Social Worker

Children's Diagnostic \& Treatment Center

Fort Lauderdale, FL

1997

M.S.W., Social Work

Florida International University

Miami, FL

1997- Present

Psychotherapist

Private Practice

Fort Lauderdale, FL

1998-2015

Social Worker

Broward County Schools

Fort Lauderdale, FL

2015-present

Clinical Training Manager

Sunshine Health

Sunrise, FL

2019-2020

Doctoral Candidate

Florida International University

Miami, FL

\section{LICENSES}

2000

LCSW

2012

Qualified LCSW Supervisor

\section{PUBLICATIONS AND PRESENTATIONS}


Purinton, K. (2016, December). Culturally Competent Care for the Older Adult. Annual Aging in America Conference, Washington D.C.

Purinton, K. (2018, November) Mental Health Concerns following Community Violence. Perspectives on Florida's Healthcare. Greater Fort Lauderdale Chamber of Commerce panel expert, Fort Lauderdale, FL.

Purinton, K. (2018, June). Working with Older Youth in Care. Annual National Foster and Adoptive Parent Association (FAPA) Conference, Orlando, Florida.

Purinton, K., Waddell, S. (2019, March) Successfully Working with Birth Parents. Annual Child Welfare League of America (CWLA) Conference, Washington D.C.

Mass Violence in America: Causes, Impacts and Solutions. National Council for Behavioral Health. (2019, Aug 06). Page 78-79.

Percovich, G., Purinton, K. (2019, October). Beneath the Surface: Human Trafficking and its Impact on Attachment. Broward Human Trafficking Coalition, Coconut Creek, Florida.

Anderson, L., Ford, H., Purinton K. (2019, December). Internet Safety Concerns for Youth Impacted by the Child Welfare System. Department of Children and Families Annual Summit, Orlando, Florida. 